Cristiane Follmann Jurinitz

Ecologia das populações de duas espécies arbóreas em fragmentos florestais no Planalto Atlântico Paulista

Population ecology of two tree species in forest fragments in Southeast Atlantic Plateau

São Paulo

2010 
Cristiane Follmann Jurinitz

Ecologia das populações de duas espécies arbóreas em fragmentos florestais no Planalto Atlântico Paulista

Population ecology of two tree species in forest fragments in Southeast Atlantic Plateau

Tese apresentada ao Instituto de Biociências da Universidade de São Paulo, para a obtenção de Título de Doutor em Ecologia, na Área de Ecossistemas Terrestres.

Orientador: Alexandre Adalardo de Oliveira

Co-orientador: Emilio Miguel Bruna

São Paulo

2010 
Jurinitz, Cristiane Follmann

Ecologia das populações de duas espécies arbóreas em fragmentos florestais no Planalto Atlântico Paulista

82 páginas

Tese (Doutorado) - Instituto de Biociências da Universidade de São Paulo. Departamento de Ecologia.

1. Dinâmica de populações 2. Estrutura de populações 3. Modelos matriciais I. Universidade de São Paulo. Instituto de Biociências. Departamento de Ecologia.

\section{Comissão Julgadora:}

Prof(a). Dr(a).

Prof(a). Dr(a).
Prof(a). Dr(a).

Prof(a). Dr(a).

Prof(a). Dr(a).

Orientador(a) 
Sinto-me realizada ao concluir esta etapa, pois ao comparar as expectativas que tinha quando decidi fazer o doutorado a hoje, posso afirmar, sem dúvida, que todas foram superadas. Foi um período de muitos desafios e intenso aprendizado, em que fiz muitos amigos e do qual sentirei saudades. Obviamente, isso jamais teria sido possível sem a participação de tantas pessoas e instituições, às quais tentarei fazer justiça em breves palavras.

Ao meu orientador, o Prof. Dr. Alexandre Adalardo de Oliveira (Alê), pela oportunidade e confiança. Obrigada por me apoiar nos momentos difíceis, sempre deixando clara a preocupação com a minha formação.

Ao meu co-orientador, o Prof. Dr. Emilio Miguel Bruna da Universidade da Flórida (Gainesville - EUA), por ter aceitado nosso convite e dado suporte em todas as fases do trabalho, além de me receber muito bem em seu laboratório.

Ao Programa de Pós-Graduação em Ecologia da Universidade de São Paulo (USP), pela oportunidade.

À Fundação de Amparo à Pesquisa do Estado de São Paulo (FAPESP), pela concessão da Bolsa de Doutorado (Processo $n^{0}$ 2005/54782-3) e do financiamento ao projeto (Auxílio à Pesquisa, Processo $n^{0}$ 2006/56054-8) e pelo exemplo de profissionalismo e eficiência.

Ao BMBF (German Federal Ministry of Education and Research, project ID 01 LB 0202), pelo apoio logístico coordenado pelo Dr. Cristoph Knogge, que foi fundamental à execução do projeto.

Aos pesquisadores e técnicos do Laboratório de Ecologia da Paisagem e Conservação (LEPaC) da USP, sob a coordenção do Prof. Dr. Jean Paul Metzger, pela seleção e facilitação do acesso às áreas de estudo.

A Cristina Banks-Leite, por apresentar os fragmentos selecionados pela primeira vez.

A Paula Lyra, por ceder as informações ainda inétidas da idade dos fragmentos e também por elaborar o mapa da área de estudo.

Aos proprietários das áreas, por concederem permissão para a execução do projeto.

A todos os ajudantes de campo pela inestimável ajuda, dentre os quais menciono, em ordem cronológica de participação, Carlos Pallermo, Tales Jorge, Angélica Maran e Marcelo Pansonatto.

Ao Prof. Dr. Paulo Inácio de Knegt López de Prado, pelos conselhos e esclarecimentos sobre as análises.

À amiga Camila de Toledo Castanho pela ajuda com as análises na estapa final.

Ao colega Renato Lima, pelo auxílio na identificação de diversas espécies arbóreas.

Ao amigo Marcel Caritá Vaz, pela participação em todas as etapas do trabalho, por ter sido um ajudante de campo fiel e solícito, cuja companhia em campo sempre representou um diferencial na minha motivação. Companheiro desde 2007 (o primeiro estagiário a gente nunca esquece!), depois fez sua Iniciação Científica no projeto.

À amiga Juliana Lopes Vendrami, por ter se tornado uma fiel companheira de campo, ter escolhido fazer sua Iniciação Científica no projeto e assumido com muita competência a coleta 
de dados na minha ausência. Acima de tudo, obrigada por ser alguém com quem sempre pude contar.

À amiga de todas as horas Claúdia Guimarães, pelo apoio desde o início do projeto, ainda em 2006, quando passamos a dividir o Gol... Tiveste um papel fundamental durante todo o tempo em que estive em São Paulo!

Aos demais colegas que atuaram intensamente no campo, Gabriel Frey, Flávio Bonatti e Pablo Lastra.

A todos os pesquisadores que trabalharam com diferentes enfoques nos mesmos fragmentos e dividiram a Casa de Tapiraí, por atenuarem as mazelas dos trabalhos de campo com churrascos, jantas, conversas e até uma Festa Junina. Todos nós sabemos o valor de uma boa companhia após um dia árduo de campo. Além disso, trocamos inúmeras informações sobre os nossos objetos de estudo, de modo que aprendi muito com todos vocês. Como não posso mencionar todos, destaco os mais chegados: Ana Gabriela Bieber (Gabi) e ao Paulinho, pela maravilhosa companhia na Casa de Tapiraí (sem vocês os trabalhos de campo nunca seriam os mesmos!); Claudia Guimarães e companhia (quantos churrascos!); Karina Espartosa e Gustavo (dos mamíferos).

Aos colegas do Laboratório de Ecologia de Florestas Tropicais (LabTrop), que se tornaram a minha família em São Paulo, dentre os quais destaco as amigas Flávia Moraes de Jesus, Julia Stuart, Márcia Pannuti e Mariana Brando.

A Ivy Chiarelli, pelo auxílio em diversos momentos.

Aos colegas do laboratório do Emilio, por me receberem tão bem e também pela ajuda no trabalho: Christine Lucas, Ernane Vieira Neto, Paul Gagnon e Stella Copeland.

À colega Maria Vianna, pelo apoio e pela troca de valiosas informações.

Aos demais amigos de São Paulo, pelo apoio nas mais diversas horas: Anselmo Nogueira, Carolina Mariani, Karina Espartosa, Mariana Brando e Sheila Cardoso Silva.

Aos dois amigos da época do Curso de Campo Ecologia da Floresta Amazônica (EFA edição de 2001), que tiveram um papel fundamental na minha vinda para São Paulo, Felipe Bandoni Oliveira (Fino) e Maria Rosa Darrigo (Rosinha).

Aos amigos de Porto Alegre pelo apoio, em especial à amiga Mardiore Pinheiro, aos amigos da Fitocafeteria (Jorge, Lila, Silvia,...) e ao Fernando Rocha e Caroline Greve.

À minha família, pelo apoio em Porto Alegre e também à distância: minha mãe (Ilse), irmãs (Viviane, Daiane e Juliane) e sobrinhos (Guilherme e Marco Antônio).

Ao João André pelo apoio incondicional. Foste fundamental para que esta etapa tenha se concretizado. 
Resumo vi

Abstract vii

Apresentação $\quad$ viii

Introdução geral

Capítulo 1. Efeito da fragmentação inferido a partir de distribuições de tamanho em árvores: um teste com duas espécies arbóreas que diferem na tolerância à sombra 7

$\begin{array}{ll}\text { Resumo } & 8\end{array}$

Introdução 9

Material e métodos $\quad 12$

$\begin{array}{ll}\text { Resultados } & 17\end{array}$

Discussão 25

$\begin{array}{ll}\text { Referências bibliográficas } & 30\end{array}$

Capítulo 2. Resposta demográfica diferencial de duas espécies arbóreas aos atributos tamanho e estádio sucessional de fragmentos de Floresta Atlântica 35

$\begin{array}{ll}\text { Resumo } & 36\end{array}$

$\begin{array}{ll}\text { Introdução } & 37\end{array}$

Material e métodos $\quad 41$

Resultados 46

Discussão $\quad 50$

Referências bibliográficas $\quad 54$

Capítulo 3. Abertura do dossel e profundidade da serrapilheira no desempenho de plântulas em fragmentos florestais no Planalto Atlântico Paulista 59

$\begin{array}{lc}\text { Resumo } & 60\end{array}$

Introdução $\quad 61$

Material e métodos $\quad 63$

$\begin{array}{ll}\text { Resultados } & 67\end{array}$

$\begin{array}{ll}\text { Discussão } & 71\end{array}$

$\begin{array}{ll}\text { Referências bibliográficas } & 75\end{array}$

$\begin{array}{ll}\text { Conclusões gerais } & 80\end{array}$ 


\section{Resumo}

Entre os grandes desafios da ecologia está a previsão e o entendimento das flutuações que ocorrem nas populações biológicas. Quando agregamos as intervenções humanas a esse entendimento, podemos, ao mesmo tempo em que fazemos previsões acerca do futuro das populações, entender melhor seus processos naturais de regulação e controle. Neste trabalho, realizamos um estudo da ecologia de duas espécies arbóreas tolerantes à sombra (Guapira opposita (Vell.) Reitz, pertencente ao dossel e Rudgea jasminoides (Cham.) Müll.Arg., pertencente ao sub-bosque) a fim de responder à questão de como a estrutura, a dinâmica populacional e o desempenho de plântulas respondem à heterogeneidade ambiental causada por distúrbios relacionados à fragmentação e à sucessão secundária. No Capítulo 1, testamos se a estrutura populacional, medida pela distribuição de tamanhos, está relacionada ao tamanho e/ou ao estádio sucessional do fragmento. A partir das conclusões geradas nesse primeiro estudo, no Capítulo 2 verificamos se parâmetros da dinâmica populacional, como a taxa assintótica de crescimento e as taxas vitais, explicam as variações encontradas na densidade e na estrutura. No Capítulo 3, testamos se o desempenho das plântulas destas espécies é afetado pelos fatores abertura do dossel e profundidade da serapilheira, os quais são reconhecidamente promotores da heterogeneidade ambiental em fragmentos florestais secundários. Para tanto, marcamos e acompanhamos por dois anos (de 2007 a 2009) populações das duas espécies em seis fragmentos de floresta secundária de distintos estádios sucessionais no Planalto Atlântico Paulista. Quanto à estrutura populacional, Guapira mostrou uma variação associada ao grau de estruturação da floresta, enquanto que para Rudgea o tamanho do fragmento foi a variável explicativa mais importante, o que nos levou a hipotetizar que Rudgea corre risco de extinção local nos fragmentos médios. Com relação às análises de dinâmica populacional, Rudgea apresentou um tempo de duplicação da população 4,5 vezes maior nos fragmentos médios do que nos grandes, o que nos leva a concluir que o risco de extinção local pode ser atenuado ou mesmo revertido. Para Guapira, as taxas não diferiram entre os estádios sucessionais, sendo previstas populações estáveis para ambos $(\lambda \approx 1)$. As análises do efeito da abertura do dossel e da profundidade da serapilheira no desempenho das plântulas demonstraram a importância da interação entre os fatores e a relevância de se considerar as diferentes fases ontogenéticas das plântulas. Através de uma abordagem inédita, demonstramos a importância do emprego de enfoques complementares (estrutura e dinâmica) para que se possa de fato entender o que ocorre em nível populacional. Além disso, destacamos a importância dos estudos de dinâmica para se elucidar os mecanismos demográficos atuantes em cada população. Esse conhecimento é uma ferramenta fundamental para o planejamento de ações direcionais de manejo e conservação. 


\begin{abstract}
One of the greatest challenges of ecology is to understand and predict the fluctuations in the biological populations. When we consider the human intervention in this understanding, we can, at the same time, make predictions about the future of the populations and understand better their natural processes of regulation and control. In this work we carried out a study about the ecology of populations of two shade tolerant tree species (Guapira opposita (Vell.) Reitz, that occupies the canopy and Rudgea jasminoides (Cham.) Müll.Arg., that occupies the understory) to answer the question of how the structure, population dynamics and seedling performance respond to environmental heterogeneity caused by disturbances related with fragmentation and secondary succession. In the first chapter we tested if the population structure, measured by size distributions, is related to the size and/or to the successional stage of the fragment. From the conclusions generated in this first study, in the second chapter we evaluated if population dynamics parameters, such as asymptotic growth rate and vital rates explain the variation in density and structure. In the third chapter we tested if the seedling performance of these species is affected by canopy openness and litter depth, which are known promoters of environmental heterogeneity in secondary forest fragments. In order to achieve this goal we marked and followed by two years (2007-2009) populations of both species in six secondary forest fragments of different successional stages in the Southeast Atlantic Plateau. Regarding the population structure, Guapira showed variation associated to the degree of forest structuring, while for Rudgea the fragment size was the most important explanatory variable, what lead us to hypothesize that Rudgea is in risk of local extinction in the medium fragments. Regarding the analysis of population dynamics, Rudgea showed a population doubling time in the medium fragments 4.5 times greater than in the large ones, what lead us to conclude that this risk of local extinction can be mitigated or even reversed. For Guapira, the rates did not differ between the successional stages, being predicted stable populations in both $(\lambda \approx 1)$. The analysis of the effect of the canopy openness and the litter depth in the seedling performance showed the importance of the interaction between these factors and the relevance of considering the different seedling ontogenetic stages. Through a new approach, we demonstrated how important is to consider complementary studies (structure and dynamics) in order to really understand what happens at population level. Besides, we highlight the importance of studies with dynamics in order to elucidate the demographic mechanisms that occur in each population. This knowledge is a fundamental tool for planning more directional management and conservation actions.
\end{abstract}


Esta tese está estruturada na forma de capítulos, com a pretensão de apresentá-los como manuscritos a serem submetidos para a publicação. Os capítulos são independentes entre si, por isso há certa redundância na apresentação da área de estudo, bem como nos procedimentos amostrais empregados. Embora independentes, estão claramente interligados, de modo que as conclusões do Capítulo 1 servem de base para as questões testadas no capítulo 2, havendo citações eventuais de um capítulo em outro, mas procuramos evitar o excesso de autocitação. Buscamos ordená-los em termos da escala de organização biológica, partindo do mais geral para o mais específico, mas também procurando preservar a sequência de construção da argumentação lógica do estudo. Em princípio, esta mesma sequência será adotada para a submissão dos trabalhos. Provemos uma introdução geral, com o objetivo de contextualizar o tema central da tese, bem como brevemente cada um dos capítulos. Ao final, elaboramos uma conclusão geral, visando a integração das discussões e conclusões obtidas em cada capítulo. 


\section{Introdução geral}

Entre os grandes desafios da ecologia está a previsão e o entendimento das flutuações que ocorrem nas populações biológicas (May 1999). Quando agregamos as intervenções humanas a esse entendimento do processo de flutuação populacional, podemos, ao mesmo tempo em que fazemos previsões acerca do futuro das populações, entender melhor seus processos naturais de regulação e controle (Alvarez-Buylla 1994, Horvitz \& Schemske 1995, Batista et al. 1998, Bruna \& Oli 2005, Fortini et al. 2010, Tomitasu \& Ohara 2010, são alguns exemplos). Nesse sentido, a teoria e a instrumentação gerados pela ecologia de populações podem ser aplicadas tanto à conservação, prevendo trajetórias da população em diferentes cenários (Menges 2000, Morris \& Doak 2002, para revisões sobre análises de viabilidade populacional), quanto para entender processos inerentes à regulação dos sistemas naturais (Matos et al. 1999, Zuidema et al. 2009, Zuidema et al. 2010, são alguns exemplos).

A sucessão secundária em áreas originalmente cobertas por florestas é um excelente sistema para o teste de hipóteses sobre a resposta demográfica das espécies à heterogeneidade ambiental causada pelos distúrbios decorrentes da ação antrópica. Além disso, a cobertura de florestas secundárias nos trópicos tem aumentado muito nas últimas décadas (Wright 2005), de modo que em regiões como a Floresta Atlântica, uma das florestas tropicais mais ameaçadas do globo (Myers et al. 2000), florestas secundárias em estádio inicial a médio já predominam em área em relação aos remanescentes primários (Ribeiro et al. 2009). Diante desta realidade, o papel das florestas secundárias para a conservação da biodiversidade tem recebido crescente atenção, de modo que a relevância dos estudos nestes sistemas é cada vez mais reconhecida (Barlow et al. 2007, Norden et al. 2009).

Estudar a demografia de organismos de ciclo de vida longo é uma das fronteiras do conhecimento na ecologia de populações de plantas na atualidade. Como seria esperado, as teorias nesta área do conhecimento foram construídas a partir do estudo de espécies herbáceas de ciclo de vida curto, notadamente as anuais, o que se consolidou na publicação clássica de Harper (1977), uma referência obrigatória quando se trata da biologia das populações de plantas até os dias atuais. Embora mencione as plantas perenes e as lenhosas, fica clara nesta publicação a disparidade entre o grande volume de estudos das espécies de ciclo de vida curto, em comparação às de ciclo de vida longo, um predomínio que ainda se mantém (revisões em Crawley \& Ross 1990, Menges 2000, Franco \& Silvertown 2004). Nesse sentido, o principal desafio para o avanço dos estudos de demografia de espécies arbóreas, a sua elevada 
longevidade, deve ser encarado como um atributo instigante destes organismos. As árvores experimentam uma dinâmica populacional que se processa em um escala temporal muito distinta das plantas de ciclo de vida mais curto, o que confere a elas um papel fundamental na estruturação (DeWalt et al. 2003) e na resistência das comunidades florestais. Além disso, devemos considerar que o estudo da sua dinâmica populacional é estratégico do ponto de vista de questões tão amplas quanto o ciclo do carbono no planeta (Vieira et al. 2005), com implicações para as estimativas de aquecimento global, uma vez que cerca de $40 \%$ do carbono estocado na biomassa terrestre está nas florestas tropicais (Brown \& Lugo 1984).

Ao longo da ontogenia das espécies arbóreas, as taxas vitais de sobrevivência, crescimento e fertilidade são extremamente variáveis, sendo estas denominadas, portanto, populações estruturadas (Morris \& Doak 2002, Gotelli 2007). Em plantas de um modo geral, a estruturação por tamanho, ao invés da idade, apresenta maior afinidade com as diferentes fases ontogenéticas experimentadas ao longo do ciclo de vida dos indivíduos (Harper 1977, Silvertown et al. 1993, Gotelli 2007). No caso das árvores isso também ocorre, pois em geral os indivíduos maiores têm maiores probabilidades de sobrevivência e de reprodução (Harper 1977). Dessa forma, a estrutura de uma população, embora seja uma informação estática, é o resultado dos processos demográficos aos quais os indivíduos estão sujeitos, refletindo, em última análise, o balanço entre as taxas vitais (Coomes \& Allen 2007). Assim, por agregar uma série de informações, a estrutura pode ser empregada para avaliar a estabilidade das populações, como é o caso, em espécies arbóreas, das análises de distribuição de diâmetros (Condit et al. 1998).

Ao longo da sucessão secundária florestal, a distribuição de diâmetros torna-se progressivamente mais assimétrica e desigual, apresentando maiores coeficientes de variação à medida que se avança no tempo após o distúrbio (Clark 1996, Guariguata \& Ostertag 2001), pois o número de árvores com diâmetros grandes aumenta gradativamente (DeWalt et al. 2003). Do ponto de vista das populações, as espécies tolerantes à sombra apresentam, caracteristicamente, uma distribuição de diâmetros com forte assimetria à direita, resultado da concentração dos indivíduos nos menores tamanhos e uma longa cauda de relativamente poucos indivíduos maiores (Wright et al. 2003). Dessa forma, o fato de a floresta apresentar progressivamente uma distribuição de diâmetros mais assimétrica no decorrer da sucessão secundária, pode ser interpretado como um reflexo da substituição gradual das espécies mais dependentes de luz pelas mais tolerantes à sombra que ocorre no decorrer da sucessão (Guariguata \& Ostertag 2001, DeWalt et al. 2003, Norden et al. 2009). Nesse sentido, espera-se que, ao longo da sucessão secundária, as alterações na estrutura das populações de espécies tolerantes à sombra ocorram gradualmente conforme se avança o estádio sucessional. 
Alterações graduais na estrutura das populações são uma consequência das mudanças nas taxas demográficas, o que pode resultar em variações na taxa de crescimento populacional. Nesse sentido, em florestas secundárias de distintos estádios sucessionais espera-se uma resposta também em termos dos padrões demográficos. Quando consideradas as espécies de ciclo de vida longo em habitats florestais, podem ser encontrados exemplos de estudos da resposta demográfica aos mais variados níveis de distúrbio, desde clareiras (Tanaka et al. 2008) até furacões (Batista et al. 1998, Pascarella \& Horvitz 1998), assim como diferentes manchas de floresta representando fases da regeneração ou sucessão secundária (Horvitz \& Schemske 1995, Martínez-Ramos et al. 1998, Valverde \& Silvertown 1998), o efeito do fogo (Souza \& Martins 2004) e ainda os efeitos da fragmentação de um modo geral (revisões em Hobbs \& Yates 2003 e Bruna et al. 2009).

Já foi constatado para espécies arbóreas que cada fase do ciclo de vida responde de forma particular a determinada condição ambiental (Clark \& Clark 1992, Baraloto et al. 2005), sendo a fase de plântula uma das mais sensíveis na vida de uma espécie arbórea (Harper 1977). A heterogeneidade ambiental no sub-bosque cria diferentes nichos de regeneração para as espécies arbóreas, influenciando dessa forma a distribuição, a abundância e a composição da comunidade de plântulas (Garcia-Guzman \& Benitez-Malvido 2003). Dentre os fatores promotores da heterogenidade ambiental no sub-bosque de florestas, a luz e a profundidade da camada de serapilheira estão entre os principais (Nicotra et al. 1999, Facelli \& Pickett 1991).

Neste trabalho, abordaremos a demografia de duas espécies arbóreas tolerantes à sombra (Guapira opposita, pertencente ao dossel e Rudgea jasminoides, pertencente ao sub-bosque) em diferentes níveis a fim de responder à questão de como a estrutura e a dinâmica populacional respondem à heterogeneidade ambiental causada por distúrbios relacionados à fragmentação e à sucessão secundária. Mais especificamente, o Capítulo 1 avaliará se a estrutura populacional, medida pela distribuição de tamanhos, está mais relacionada ao tamanho do fragmento ou ao seu estádio sucessional, o que será avaliado pela força de evidência desses modelos concorrentes. A partir das conclusões do Capítulo 1, o Capítulo 2 abordará se parâmetros da dinâmica populacional, como a taxa assintótica de crescimento populacional e as taxas vitais, explicam as variações encontradas na densidade e na estrutura. Já o Capítulo 3 avaliará o desempenho das plântulas destas duas espécies em função dos fatores abertura do dossel e profundidade da serapilheira, os quais são reconhecidamente promotores da heterogeneidade ambiental em fragmentos florestais secundários. 


\section{Referências bibliográficas}

Alvarez-Buylla, E.R. 1994. Density dependence and patch dynamics in tropical rain forests: matrix models and applications to a tree species. The American Naturalist 143: 155-191.

Baraloto, C., Goldberg, D.E., Bonal, D. 2005. Performance trade-offs among tropical tree seedlings in contrasting microhabitats. Ecology 86: 2461-2472.

Barlow, J., et al. 2007. Quantifying the biodiversity value of tropical primary, secondary, and plantation forests. Proceedings of the National Academy of Sciences of the United States of America 104: 18555-18560.

Batista, W.B., Platt, W.J., Macchiavelli, R.E. 1998. Demography of a shade-tolerant tree (Fagus grandifolia) in a hurricane-disturbed forest. Ecology 79: 38-53.

Brown, S. \& Lugo, A.E. 1984. Biomass of tropical forests: a new estimate based on forest volumes. Science 223: 1290-1293.

Bruna, E.M. \& Oli, M.K. 2005. Demographic effects of habitat fragmentation on a tropical herb: life-table response experiments. Ecology 86: 1816-1824.

Bruna, E.M., Fiske, I.J., Trager, M.D. 2009. Habitat fragmentation and plant populations: is what we know demographically irrelevant? Journal of Vegetation Science 20: 569-576.

Clark, D.A. \& Clark, D.B. 1992. Life history diversity of a canopy and emergent trees in a neotropical rain forest. Ecological Monographs 62: 315-344.

Clark, D.B. 1996. Abolishing virginity. Journal of Tropical Ecology 12: 735-739.

Condit, R., Sukumar, R., Hubbell, S.P., Foster, R.B. 1998. Predicting Population Trends from Size Distributions: A Direct Test in a Tropical Tree Community. The American Naturalist 152: 495-509.

Coomes, D.A. \& Allen, R.B. 2007. Mortality and tree-size distributions in natural mixed-age forests. Journal of Ecology 95: 27-40.

Crawley, M.J. \& Ross, G.J.S. 1990. The population dynamics of plants [and discussion]. Philosophical Transactions of the Royal Society B: Biological Sciences 330: 125-140.

DeWalt, S.J., Maliakal, S.K., Denslow, J.S. 2003. Changes in vegetation structure and composition along a tropical forest chronosequence: implications for wildlife. Forest Ecology and Management 182: 139-151.

Facelli, J.M. \& Pickett, S.T.A. 1991. Plant litter - Its dynamics and effects on plant community structure. Botanical Review 57: 1-32.

Fortini, L.B., Bruna, E.M., Zarin, D.J., Vasconcelos, S.S., Miranda, I.S. 2010. Altered resource availability and the population dynamics of tree species in Amazonian secondary forests. Oecologia 162: 923-934. 
Franco, M. \& Silvertown, J. 2004. Comparative demography of plants based upon elasticities of vital rates. Ecology 85: 531-538.

Garcia-Guzman, G. \& Benitez-Malvido, J. 2003. Effect of litter on the incidence of leaf-fungal pathogens and herbivory in seedlings of the tropical tree Nectandra ambigens. Journal of Tropical Ecology 19: 171-177.

Gotelli, N. 2007. Ecologia. Londrina: Editora Planta.

Guariguata, M.R. \& Ostertag, R. 2001. Neotropical secondary forest succession: changes in structural and functional characteristics. Forest Ecology and Management 148: 185-206.

Harper, J.L. 1977. Population biology of plants. London: Academic Press.

Hobbs, R.J. \& Yates, C.J. 2003. Impacts of ecosystem fragmentation on plant populations: generalising the idiosyncratic. Australian Journal of Botany 51: 471-488.

Horvitz, C.C. \& Schemske, D.W. 1995. Spatiotemporal variation in demographic transitions of a tropical understory herb: projection matrix analysis. Ecological Monographs 65: 155-192.

Martinez-Ramos, M., Sarukhan, J., Pinero, D. 1998. The demography of tropical trees in the context of forest gap dynamics: the case of Astrocaryum mexicanum at Los Tuxtlas tropical rain forest. In: Davy, D.J., Hutchings, R.W., Watkinson, A.R., (eds). Plant population ecology. Oxford: Blackwell, p. 293-313.

Matos, D.M.S., Freckleton, R.P., Watkinson, A.R. 1999. The role of density dependence in the population dynamics of a tropical palm. Ecology 80: 2635-2650.

May, R. 1999. Unanswered questions in ecology. Philosophical Transactions of the Royal Society B: Biological Sciences 354: 1951-1959.

Menges, E.S. 2000. Population viability analyses in plants: challenges and opportunities. Trends in Ecology \& Evolution 15: 51-56.

Morris, W.F. \& Doak, D.F. 2002. Quantitative conservation biology: theory and practice of population viability analysis. Massachusetts: Sinauer Associates.

Myers, N., Mittermeier, R.A., Mittermeier, C.G., Fonseca, G.A.B., Kent, J. 2000. Biodiversity hotspots for conservation priorities. Nature 403: 853-858.

Nicotra, A.B., Chazdon, R.L., Iriarte, S.V.B. 1999. Spatial heterogeneity of light and woody seedling regeneration in tropical wet forests. Ecology 80: 1908-1926.

Norden, N., Chazdon, R.L., Chao, A., Jiang, Y.-H., Vílchez-Alvarado, B. 2009. Resilience of tropical rain forests: tree community reassembly in secondary forests. Ecology Letters 12: 385-394.

Pascarella, J.B. \& Horvitz, C.C. 1998. Hurricane disturbance and the population dynamics of a tropical understory shrub: megamatrix elasticity analysis. Ecology 79: 547-563. 
Ribeiro, M.C., Metzger, J.P., Martensen, A.C., Ponzoni, F.J., Hirota, M.M. 2009. The Brazilian Atlantic Forest: how much is left, and how is the remaining forest distributed? Implications for conservation. Biological Conservation 142: 1141-1153.

Silvertown, J., Franco, M., Pisanty, I., Mendoza, A. 1993. Comparative plant demography-relative importance of life-cycle components to the finite rate of increase in woody and herbaceous perennials. Journal of Ecology 81: 465-476.

Souza, A.F. \& Martins, F.R. 2004. Population structure and dynamics of a neotropical palm in fire-impacted fragments of the Brazilian Atlantic Forest. Biodiversity and Conservation 13: 1611-1632.

Tanaka, H., Shibata, M., Masaki, T., Iida, S., Niiyama, K., Abe, S., Kominami, Y., Nakashizuka, T. 2008. Comparative demography of three coexisting Acer species in gaps and under closed canopy. Journal of Vegetation Science 19: 127-138.

Tomimatsu, H. \& Ohara, M. 2010. Demographic response of plant populations to habitat fragmentation and temporal variability. Oecologia 162: 903-911.

Valverde, T. \& Silvertown, J. 1998. Variation in the demography of a woodland understorey herb (Primula vulgaris) along the forest regeneration cycle: projection matrix analysis. The Journal of Ecology 86: 545-562.

Vieira, S., Trumbore, S., Camargo, P.B., Selhorst, D., Chambers, J.Q., Higuchi, N., Martinelli, L.A. 2005. Slow growth rates of Amazonian trees: Consequences for carbon cycling. Proceedings of the National Academy of Sciences of the United States of America 102: 1850218507.

Wright, S.J. 2005. Tropical forests in a changing environment. Trends in Ecology \& Evolution 20: $553-560$.

Wright, S.J., Muller-Landau, H.C., Condit, R., Hubbell, S.P. 2003. Gap-dependent recruitment, realized vital rates, and size distributions of tropical trees. Ecology 84: 3174-3185.

Zuidema, P.A., Brienen, R.J.W., During, H.J., Güneralp, B. 2009. Do persistently fast-growing juveniles contribute disproportionately to population growth? A new analysis tool for matrix models and its application to rainforest trees. The American Naturalist 174: 709-719.

Zuidema, P.A., Yamada, T., During, H.J., Itoh, A., Yamakura, T., Ohkubo, T., Kanzaki, M., Tan, S., Ashton, P.S. 2010. Recruitment subsidies support tree subpopulations in nonpreferred tropical forest habitats. Journal of Ecology 98: 636-644. 
Capítulo 1

Efeito da fragmentação inferido a partir de distribuições de tamanho em árvores: um teste com duas espécies que diferem na tolerância à sombra

Effect of fragmentation inferred from size distributions in trees: a test with two arboreal species that differ in shade tolerance 


\section{Resumo}

Espécies tolerantes à sombra apresentam uma curva de distribuição de diâmetros mais desigual e assimétrica à direita quanto mais avançado for o estádio sucessional. Testamos esta expectativa para as distribuições de diâmetro de duas espécies comuns que diferem no grau de tolerância à sombra, Guapira opposita (Vell.) Reitz, espécie de dossel com tolerância intermediária, e Rudgea jasminoides (Cham.) Müll.Arg., espécie umbrófila de sub-bosque, em seis fragmentos de floresta secundária no Planalto Atlântico Paulista, classificados a priori em dois tamanhos (médio e grande) e dois estádios sucessionais (inicial e tardio). Através de um procedimento de seleção de modelos baseado na máxima verossimilhança, avaliamos se as variações na distribuição de diâmetros eram melhor explicadas pelo tamanho ou pelo estádio sucessional do fragmento. Para tanto, inicialmente testamos, dentre três distribuições de densidade probabilística (Exponencial Negativa, Log-normal e Weibull), a com melhor ajuste aos dados. A estrutura dos fragmentos foi amostrada para produzir uma variável explicativa contínua, representando o grau de estruturação da floresta e uma medida mais acurada do estádio sucessional. A partir da distribuição de melhor ajuste, avaliamos se a inclusão das variáveis categóricas classificadas a priori, ou da variável contínua de estruturação da floresta, representavam algum ganho no ajuste do modelo aos dados. Os modelos selecionados para cada uma das espécies foram completamente distintos. Para Guapira, foi selecionado o modelo para a distribuição Log-normal, contendo a variável contínua de estruturação da floresta. Conforme esperado, a espécie demonstrou uma variação gradual da sua estrutura conforme o estádio sucessional. Para Rudgea, foi selecionado o modelo para a distribuição Weibull, mas, surpreendentemente, o tamanho do fragmento, e não o estádio sucessional, explicou melhor as variações dos dados de distribuição de diâmetro. Concluímos que Guapira demonstra uma plasticidade demográfica em florestas secundárias em distintos estádios sucessionais, estando bem adaptada a paisagens fragmentadas. Em outro extremo, hipotetizamos que Rudgea jasminoides corre risco de extinção local nos fragmentos médios, o que necessita ser testado em estudos de dinâmica populacional, e também em outros fragmentos e paisagens na sua área de ocorrência. 


\section{Introdução}

Ao longo da sucessão secundária, a dinâmica estrutural da floresta tem se mostrado um processo determinístico (Guariguata \& Ostertag 2001, Chazdon et al. 2007), havendo um progressivo aumento da área basal, da altura e do fechamento do dossel, em contraposição a uma diminuição da densidade de árvores e da disponibilidade de luz no sub-bosque (Guariguata \& Ostertag 2001, DeWalt et al. 2003, Chazdon et al. 2007, Piotto et al. 2009). A distribuição de diâmetros torna-se progressivamente mais assimétrica e desigual, apresentando maiores coeficientes de variação à medida que se avança no tempo após o distúrbio (Clark 1996, Guariguata \& Ostertag 2001), pois o número de árvores com diâmetros grandes aumenta gradativamente (DeWalt et al. 2003).

A mudança na composição de espécies, no entanto, é um processo mais controverso, pois embora haja evidências de determinismo, que corroborem um modelo de equilíbrio baseado no conceito de nicho (De Walt et al. 2003, Norden et al. 2009, Piotto et al. 2009), segundo o qual a composição florística em florestas secundárias converge para a composição encontrada em florestas maduras, outros resultados desviam do que seria esperado para uma cronosseqüência (Chazdon et al. 2007). A explicação para tal seria a complexidade gerada pela interação entre os processos que atuam em uma escala local, somados às características ecológicas das espécies, com os atributos da paisagem e o conjunto regional de espécies (Chazdon et al. 2007). De uma forma geral, no entanto, há uma mudança nos padrões de recrutamento ao logo da sucessão, de modo que as espécies pioneiras passam a ficar restritas a clareiras e que a proporção entre espécies secundárias iniciais e tardias diminui (Guariguata \& Ostertag 2001, De Walt et al. 2003, Norden et al. 2009).

Do ponto de vista de cada população, a forma da curva de distribuição de diâmetros é considerada uma boa indicadora da posição relativa das espécies arbóreas num contínuo desde a total dependência da luz até a tolerância à sombra (Wright 2003). As espécies tolerantes à sombra apresentam, caracteristicamente, uma distribuição de diâmetros com forte assimetria à direita, resultado da concentração dos indivíduos nos menores tamanhos e uma longa cauda de relativamente poucos indivíduos maiores (Wright 2003). Dessa forma, o fato de a floresta apresentar progressivamente uma distribuição de diâmetros mais assimétrica no decorrer da sucessão secundária, pode ser interpretado como um reflexo desta substituição gradual das espécies mais dependentes de luz pelas mais tolerantes à sombra.

Dentre as espécies tolerantes à sombra, uma diferenciação pode ser feita entre as que permanecem todo o ciclo de vida no sub-bosque e as que atingem o dossel na maturidade. Enquanto para as espécies típicas de sub-bosque espera-se uma curva do tipo "J invertido" 
(Exponencial Negativa típica), resultante da elevada capacidade dos jovens de persistirem nesse estrato da floresta, acumulando em proporção aos adultos (Hubbell \& Foster 1987), para as espécies que atingem o dossel o padrão de distribuição é difícil de definir, podendo ou não ocorrer curvas típicas em "J invertido" (Poorter et al. 1996).

Por muito tempo, os estudos da distribuição de diâmetros em florestas enfocaram a descrição de quais distribuições de densidade probabilística melhor se ajustariam aos dados (Wang et al. 2009). Muitos avanços teóricos têm sido feitos, porém, no sentido de substituir esta abordagem fenomenológica por uma abordagem teórica que permita a interpretação biológica das distribuições e de seus parâmetros. Nesse sentido, a Teoria Metabólica da Ecologia, bastante cogitada como a teoria geral que se aplicaria tanto a animais quanto a plantas (Enquist \& Niklas 2001), foi veementemente descartada em um estudo de ampla escala espacial, utilizando dados de parcelas permanentes em florestas tropicais espalhadas por todo o globo (Muller-Landau et al. 2006) e em um estudo em floresta temperada (Wang et al. 2009). Em seu lugar, é proposta e corroborada a Teoria do Equilíbrio Demográfico, segundo a qual as distribuições de tamanho em equilíbrio seriam uma consequência demográfica de taxas de crescimento e mortalidade tamanho-dependentes (Muller-Landau et al. 2006, Wang et al. 2009).

Neste contexto, as distribuições de densidade probabilística que apresentam bons ajustes aos dados de diâmetro, tais como a Exponencial Negativa (Muller-Landau et al. 2006), a Lognormal (Chen 2004) e a Weibull (Bailey \& Dell 1973), têm seus parâmetros interpretados do ponto de vista biológico. Dessa forma, uma distribuição Exponencial Negativa, que possui apenas um parâmetro $(\alpha)$, é esperada quando as taxas de crescimento em diâmetro e as taxas de mortalidade são constantes, independentemente do diâmetro considerado (Muller-Landau et al. 2006). Se assumirmos um certo grau de estruturação da população, e considerarmos que o crescimento é uma função de potência do diâmetro, mas a mortalidade é constante, a distribuição diamétrica assumirá a forma da distribuição Weibull, a qual tem no mínimo dois parâmetros, denominados forma (s) e escala (a) (Muller-Landau et al. 2006). Por outro lado, se considerarmos que as taxas de crescimento variam no tempo de forma aditiva, a distribuição diamétrica assumirá a forma de uma distribuição Log-normal, a qual possui dois parâmetros, a média $(m)$ e o desvio $\left(s^{2}\right)$ (Otto \& Day 2007).

O tipo de distribuição que melhor se ajusta aos dados de diâmetro é bastante variável e depende do estrato na floresta ao qual a espécie pertence (Muller-Landau et al. 2006, Wang et al. 2009). Nesse sentido, a distribuição Exponencial Negativa ajustou-se melhor aos dados de espécies de dossel, em uma floresta temperada na China (Wang et al. 2009). Nesta mesma 
floresta, a distribuição Weibull apresentou os melhores ajustes aos dados de distribuição diamétrica tanto para espécies de sub-bosque quanto de subdossel (Wang et al. 2009).

A Weibull é uma distribuição bastante flexível, pois pode ou não apresentar assimetria (Otto \& Day 2007). Independentemente do valor do parâmetro escala (a), quanto menor for o seu parâmetro forma $(s<<1)$, mais desigual ela será, havendo forte concentração nas primeiras classes. Se a forma for igual a $1(s=1)$, ela se iguala a uma distribuição Exponencial (Crawley 2007). Por outro lado, quanto maior for o seu parâmetro forma $(s>>1)$, mais ela se aproximará de uma distribuição normal (Otto \& Day 2007). Considerando este efeito do parâmetro forma (s), não surpreende a forte correlação negativa encontrada entre este e os coeficientes de variação e de Gini (Knox et al. 1989), este último correspondente a uma medida de desigualdade de uso consagrado em distribuições de tamanho em plantas (Weiner \& Solbrig 1984).

Da mesma forma, para a distribuição Log-normal, é possível estabelecer uma relação entre o grau de desigualdade da distribuição e os parâmetros da curva. Assim, a distribuição Log-normal, que é assimétrica com uma longa cauda para a direita, torna-se mais semelhante à curva normal à medida que o desvio padrão diminui (Otto \& Day 2007). Quanto maior for o desvio padrão $\left(s^{2}>>1\right)$, ou seja, quanto maior o coeficiente de variação, maior a desigualdade da distribuição e portanto mais a curva se aproxima do formato de "J invertido" (Otto \& Day 2007).

Considerando que a estrutura da floresta, em comparação a florestas maduras, é recuperada mais rapidamente do que a composição florística ao longo da sucessão secundária (Guariguata \& Ostertag 2001, DeWalt 2003), esperamos que as populações em florestas secundárias de distintos estádios sucessionais apresentem uma resposta demográfica a essas variações estruturais. Esperamos ainda que esta resposta demográfica se reflita na estrutura da população e propomos avaliá-la com base nas distribuições de tamanhos (diâmetros). Para tanto, realizaremos um procedimento de seleção de modelos utilizando os dados populacionais de duas espécies arbóreas tolerantes à sombra, uma secundária tardia ocupante do sub-bosque (Rudgea jasminoides) e outra secundária inicial pertencente ao dossel (Guapira opposita) em seis fragmentos florestais em distintos estádios sucessionais. Incorporaremos aos modelos, na forma de covariáveis dos parâmetros das distribuições de densidade probabilística testadas, variáveis categóricas classificadas a priori relacionadas a características relevantes dos fragmentos (tamanho e estádio sucessional) e uma variável contínua, obtida a posteriori, representando o grau de estruturação da floresta, que assumimos ser uma aproximação mais acurada do estádio sucessional. Mais especificamente, elaboramos as seguintes expectativas:

1. Considerando a tolerância à sombra, para ambas as espécies, a curva de distribuição de diâmetros apresentará maior desigualdade e assimetria à direita à medida que se 
avança no estádio sucessional da floresta. Isto equivale a dizer que, à medida que se avança no estádio sucessional: $i$. maior será o parâmetro taxa $(\alpha)$, se distribuição Exponencial Negativa for selecionada; ii. menor será o parâmetro forma $(s)$, se a distribuição Weibull for selecionada; ou iii. ou maior será o parâmetro desvio $\left(s^{2}\right)$, se a distribuição Log-normal for selecionada;

2. A mesma variação gradual esperada para a estrutura de tamanhos ocorrerá com a densidade destas populações, de modo que esta aumentará à medida que se avança no estádio sucessional da floresta, sendo este efeito mais intenso para a espécie secundária tardia (sub-bosque) em comparação à espécie secundária inicial (dossel);

3. Como as espécies diferem no seu grau de tolerância à sombra, esperamos que isso se reflita ou no tipo de distribuição de densidade probabilística, podendo ser selecionadas diferentes distribuições conforme a espécie, ou nos próprios parâmetros da distribuição selecionada, de modo que a espécie secundária tardia (sub-bosque) apresente um efeito mais acentuado em relação às previsões elaboradas no item anterior;

4. Independentemente da distribuição de densidade probabilística selecionada, o ajuste será melhor quanto maior o grau de complexidade das covariáveis incluídas no modelo, ou seja, esperamos que a variável contínua que representa a estrutura da floresta melhore o ajuste do modelo aos dados em comparação às variáveis categóricas tamanho e estádio sucessional.

\section{Material e Métodos}

\section{Área de estudo}

O estudo foi desenvolvido no Planalto de Ibiúna, o qual faz parte do Planalto Atlântico Paulista. Esta região, situada acima das Serras do Mar e de Paranapiacaba, está sob embasamentos cristalinos, entre 800 e 1.100 m.n.m. (Ponçano et al. 1981). O clima, segundo a classificação de Köppen é do tipo $\mathrm{Cfb}$, nas maiores altitudes, ou Cfa, mais próximo da Depressão Periférica, sendo a precipitação média anual em torno de 1.300 mm (SABESP 1997). A vegetação florestal que cobria originalmente a região é classificada como Floresta Ombrófila Densa Montana e locais de transição entre esta e a Floresta Estacional Semidecidual (Veloso et al. 1991). A área de estudo é uma das "paisagens" (12 km x $9 \mathrm{~km})$ delimitadas pela equipe do Laboratório de Ecologia da Paisagem e Conservação (LEPaC) do Instituto de Biociências da USP para o desenvolvimento de pesquisas com enfoque em Ecologia da Paisagem, sob a coordenação do Prof. Dr. Jean Paul Metzger. A cobertura florestal desta paisagem ( $\approx 45 \%)$ é 
composta por um mosaico de fragmentos em variados estádios sucessionais, circundados por áreas de agricultura e residências (Figura 1). Nesta, seis fragmentos florestais foram selecionados para o presente estudo, os quais pertencem aos municípios de Tapiraí e Piedade (Figura 1, Tabela 1). A escolha destes fragmentos levou em conta a presença das espécies de interesse, seu tamanho e a acessibilidade e concordância do proprietário.

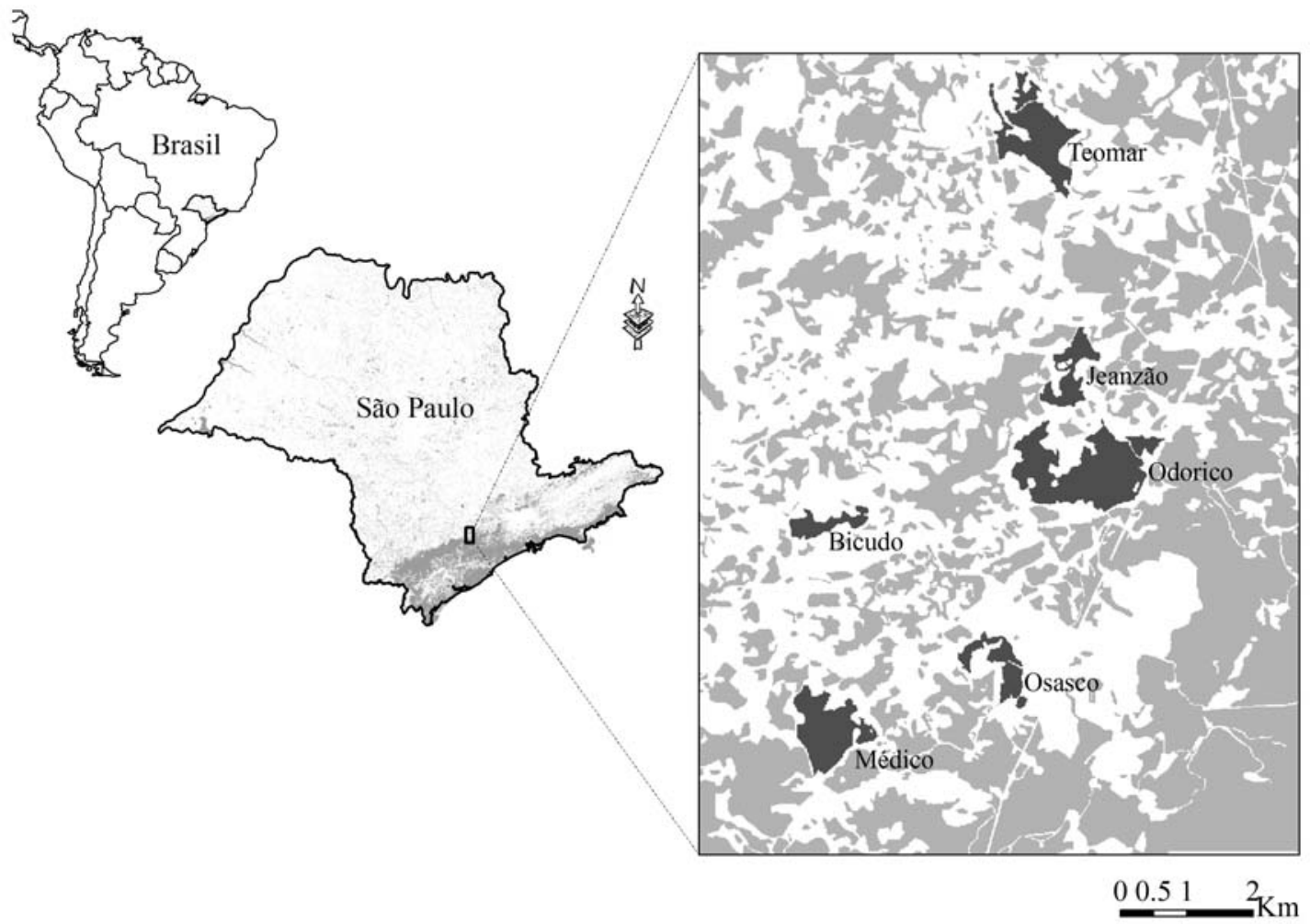

Figura 1. Localização dos fragmentos estudados (em preto) em relação ao Estado de São Paulo e, em detalhe, a paisagem fragmentada da região do Planalto Atlântico Paulista, entre os municípios de Tapiraí e Piedade. Em cinza é representada a cobertura florestal.

Tabela 1. Características dos fragmentos estudados na região do Planalto Atlântico Paulista entre os municípios de Piedade e Tapiraí (Figura 1).

\begin{tabular}{|c|c|c|c|c|c|}
\hline Fragmento & Coordenadas & $\begin{array}{l}\text { Altitude } \\
\text { (m.n.m.) }\end{array}$ & $\begin{array}{c}\text { Área } \\
\text { (ha) }\end{array}$ & Tamanho* & Estádio sucessional** \\
\hline Bicudo & $\mathrm{S} 23^{\circ} 53,18^{\prime} \mathrm{W} 47^{\circ} 28,99^{\prime}$ & 861 & 26,7 & médio & tardio \\
\hline Teomar & $\mathrm{S} 23^{\circ} 49,89^{\prime} \mathrm{W} 47^{\circ} 26,82^{\prime}$ & 1038 & 97,6 & grande & tardio \\
\hline Osasco & $\mathrm{S} 23^{\circ} 54,50^{\prime} \mathrm{W} 47^{\circ} 27,24^{\prime}$ & 927 & 39,9 & médio & inicial \\
\hline Jeanzão & $\mathrm{S} 23^{\circ} 52,15^{\prime} \mathrm{W} 47^{\circ} 26,66^{\prime}$ & 948 & 41,3 & médio & inicial \\
\hline Médico & $\mathrm{S} 23^{\circ} 54,89^{\prime} \mathrm{W} 47^{\circ} 28,78^{\prime}$ & 952 & 85,3 & grande & inicial \\
\hline Odorico & $\mathrm{S} 23^{\circ} 52,83^{\prime} \mathrm{W} 47^{\circ} 26,14^{\prime}$ & 1006 & 167,1 & grande & inicial \\
\hline \multicolumn{6}{|c|}{$\begin{array}{l}{ }^{*} \text { Classificação de tamanhos adaptada das classes empregadas na literatura, que freqüentemente distingue fragmentos com até } 50 \text { ha dos demais } \\
\text { (Ribeiro et al. 2009), tendo valor apenas comparativo. }\end{array}$} \\
\hline \multicolumn{6}{|c|}{$\begin{array}{l}\text { ** Classificação baseada nas observações de campo combinadas às análises de mudança da paisagem a partir de fotografias aéreas de } 1962,1978 \\
\text { e } 2005 \text { (Metzger et al., dados não publicados). Os termos 'tardio' e 'inicial' só tem significado comparativamente. Conforme as análises destas } \\
\text { fotografias, as áreas classificadas como 'tardias' têm no mínimo } 65 \text { anos de idade, enquanto que as classificadas como 'iniciais' podem ter entre } \\
25 \text { e } 45 \text { anos, aproximadamente. }\end{array}$} \\
\hline
\end{tabular}




\section{Espécies-alvo}

As duas espécies selecionadas para os estudos populacionais são muito comuns na Floresta Atlântica (Scudeller et al. 2001). Apesar de não ter sido encontrado nenhum levantamento específico nas proximidades das áreas de estudo, em levantamentos referentes à mesma formação florestal em uma região adjacente (município de Ibiúna), as duas espécies estão entre as mais freqüentes e abundantes (Alves \& Metzger 2006, Catharino et al. 2006, Durigan et al. 2008), situação semelhante ao observado na paisagem estudada (Observação pessoal).

Guapira opposita (Vell.) Reitz (Nyctaginaceae), é uma espécie de ampla distribuição na Floresta Atlântica, ocorrendo desde a Bahia até o Rio Grande do Sul (Scudeller et al. 2001, Oliveira-Filho et al. 2006). Apresenta elevada plasticidade ecológica, pois ocorre em todas as formações florestais que fazem parte do Domínio Atlântico (Oliveira-Filho \& Fontes 2000), sendo muito comum também em levantamentos em formações florestais secundárias, onde ocupa o dossel (Catharino et al. 2006). É uma espécie zoocórica (Catharino et al. 2006), classificada como secundária inicial (Gandolfi 2000), ou seja, uma espécie que tem uma dependência intermediária da luz, que desenvolve-se em bordas, clareiras e no sub-bosque, mas preferencialmente em áreas menos sombreadas, estando ausente em áreas de sombra densa. Conhecida popularmente como "maria-mole" (Reitz 1970), não possui madeira de interesse comercial (Souza \& Lorenzi 2005).

Rudgea jasminoides (Cham.) Müll.Arg. (Rubiaceae), é uma arvore de sub-bosque de pequeno porte, popularmente conhecida como "jasmim-do-mato" (Zappi 2003). Apresenta ampla distribuição nas florestas úmidas no sul e sudeste do Brasil, passando pelo Mato Grosso e chegando até a Argentina e o Paraguai (Zappi 2003). A espécie é polimórfica, apresentando diversos ecótipos que são reconhecidos em um nível subespecífico (Zappi 2003). Assim como Guapira opposita, é classificada quanto à síndrome de dispersão como zoocórica (Catharino et al. 2006). Com relação à categoria sucessional, é classificada como umbrófila (Catharino et al. 2006) ou secundária tardia (Alves \& Metzger 2006).

\section{Coleta de dados}

\section{Estrutura das populações}

Foram instaladas seis parcelas de 0,5 ha (exceto no fragmento Teomar, no qual a área total foi de 0,45 ha) no interior de cada fragmento florestal para amostrar a estrutura das populações das duas espécies-alvo. Para facilitar o inventário em campo, estas parcelas foram subdivididas em subparcelas contíguas de $10 \mathrm{~m}$ x $10 \mathrm{~m}$. De acordo com a forma do fragmento e a presença de trilhas, a forma desta parcela de 0,5 ha foi ajustada, implicando em algumas descontinuidades entre as subparcelas. Em cada subparcela, foram inventariados todos os 
indivíduos de Rudgea e Guapira com diâmetro à altura do peito (DAP - 1,3 m a partir do solo) igual ou superior à $10 \mathrm{~mm}$. Complementarmente, as plantas com DAP $<10 \mathrm{~mm}$ e altura mínima de $1 \mathrm{~m}$ também foram inventariadas, sendo medido seu diâmetro ao nível do solo (DAS). As medidas foram tomadas com um paquímetro digital, para caules com diâmetro entre 10 e 70 mm, e com uma fita métrica graduada para os demais, sendo, neste caso, registrado o perímetro do indivíduo. Considerando-se que a secção transversal do caule normalmente não é perfeitamente cilíndrica, padronizamos a tomada da medida do maior diâmetro. Plantas com múltiplos caules tiveram todos os seus caules medidos, desde que pelo menos um deles satisfizesse o critério de inclusão.

\section{Estrutura do componente arbóreo}

No entorno da área onde foram amostradas as duas populações, foram distribuídas dez parcelas de $10 \mathrm{~m}$ x $10 \mathrm{~m}$ para a caracterização da estrutura do componente arbóreo. Esta caracterização não foi realizada nas mesmas parcelas para evitar interferências como quebra de regenerantes e pisoteio, pois nestas está em andamento um estudo de dinâmica populacional. Foram amostrados todos os indivíduos arbóreos com perímetro à altura do peito (PAP) igual ou superior à $15 \mathrm{~cm}$, sendo medidos os seus perímetros e a altura máxima. Da mesma forma que para as populações-alvo, árvores perfilhadas tiveram todos os seus caules medidos, desde que pelo menos um deles estivesse de acordo com o critério de inclusão adotado. As medidas de PAP foram tomadas com uma fita métrica graduada e a medida da altura máxima (para o indivíduo) com uma trena eletrônica. Todos os indivíduos amostrados foram classificados em morfoespécies, sendo que algumas espécies foram determinadas por serem de fácil reconhecimento, como é o caso das pioneiras. Esta classificação foi realizada com auxílio de bibliografia especializada, como a Flora do Estado de São Paulo (Wanderley et al. 2002, Wanderley et al. 2003, Wanderley et al. 2005, Melhem et al. 2007), além das listas de espécies já publicadas para regiões adjacentes à área de estudo (Catharino et al. 2006, Durigan et al. 2008), das quais se obteve a classificação das espécies na categoria sucessional pioneira, aqui definidas como plantas dependentes de luz para germinar, crescer e sobreviver (sensu Gandolfi 2000).

\section{Análise dos dados}

Para obtermos um valor único de diâmetro para as plantas que apresentaram mais de um caule, a área basal de cada caule foi calculada separadamente, sendo posteriormente somada e convertida novamente em diâmetro. As medidas de perímetro à altura do peito também foram convertidas em diâmetro. Este procedimento foi empregado tanto nos dados das duas populações, quanto do componente arbóreo no entorno. 
No que diz respeito aos dados do componente arbóreo, para cada fragmento foram calculadas a área basal e a densidade totais, a somatória da área basal de pioneiras, o número total de plantas com mais de um caule (perfilhadas) e a altura do dossel (média da altura máxima por parcela). Com estas variáveis foi realizada uma Análise de Componentes Principais (PCA) (Legendre \& Legendre 1998) a fim de ordenar os fragmentos conforme seu grau de estruturação. Esperamos que esta ordenação seja mais representativa da variação estrutural existente entre os fragmentos, gerando um critério mais acurado e objetivo para que a classificação em estádios sucessionais (inicial e tardio) seja refinada. Esta expectativa está embasada no fato de as variáveis empregadas no PCA serem reconhecidamente importantes para a definição de estádios em florestas secundárias (revisão em Guariguata \& Ostertag 2001).

Seleção de modelos para as distribuições de diâmetro das populações-alvo

Empregamos um procedimento de seleção de modelos para verificar qual tipo de distribuição de densidade probabilística melhor se ajustava aos dados distribuição de diâmetro de cada espécie. Nesta análise foram incluídos somente os indivíduos com medida de DAP. Baseamos a seleção de modelos no Critério de Informação de Akaike (AIC), o qual representa, em termos gerais, uma ponderação entre o número de parâmetros e o ganho em explicabilidade do modelo, a partir do cálculo da verossimilhança (Crawley 2007). O AIC estima o valor esperado da distância de Kullback-Lieber, a qual representa a distância do modelo selecionado a um "modelo verdadeiro" (Hobbs \& Hilborn 2006). Por isso, quanto menor o AIC, melhor é considerado o modelo, sendo necessário, porém, um $\Delta$ AIC $\geq 2$ entre dois modelos para estes sejam considerados diferentes (Bolker 2008).

Foram testadas três distribuições densidade probabilística, comumente empregadas em florestas, para descrever a variação dos dados de diâmetro das populações arbóreas: a distribuição Exponencial (Otto \& Day 2007), a Lognormal (Otto \& Day 2007) e a Weibull (Bailey \& Dell 1973). O ajuste aos dados destas distribuições foi realizado considerando-se o critério inclusão adotado (DAP $\geq 1 \mathrm{~cm})$, ou seja, truncando-se a distribuição à esquerda nesse valor, e também sem truncá-la. Como os modelos truncados, sem exceções, apresentaram melhor desempenho, os resultados dos modelos não-truncados serão omitidos.

A partir da melhor distribuição de densidade probabilística, o mesmo procedimento de seleção de modelos descrito anteriormente foi empregado com o intuito de verificar se a inclusão das variáveis categóricas, tamanho do fragmento (médio ou grande - Tabela 1) ou estádio sucessional (inicial ou tardio - Tabela 1), ou da variável contínua de estruturação da floresta (definida a partir do PCA), representavam algum ganho no ajuste do modelo aos dados. Estas variáveis foram incluídas como covariáveis dos parâmetros das distribuições de densidade 
probabilística empregadas, respeitando-se uma relação linear. As análises foram realizadas no software R versão 2.10.1 (R Development Core Team 2009), utilizando-se o pacote vegan "Community Ecology Package" (Oksanen et al. 2010), para a Análise de Componentes Principais, e o pacote bbmle - "Tools for general maximum likelihood estimation" (Bolker 2009), para a seleção de modelos.

\section{Resultados}

O diagrama de ordenação para os dois primeiros eixos do PCA mostra uma forte congruência com a classificação prévia dos fragmentos nas duas categorias de estádios sucessionais (Tabela 1), de modo que os fragmentos considerados tardios (Bicudo e Teomar) estão ordenados a partir de um dos extremos em relação ao primeiro eixo, enquanto os demais seguem em direção ao outro extremo (Figura 2). No entanto, conforme esperado, fica evidente que, em um nível maior de detalhamento, estes fragmentos podem ser considerados como representantes de um contínuo em termos de estruturação. Todas as variáveis estruturais empregadas apresentaram elevada correlação com o primeiro eixo, iniciando pela densidade (96\%), seguida da média das alturas máximas (90\%), do número de indivíduos com caules múltiplos (89\%), da área basal (84\%) e, por último, a área basal de pioneiras (63\%) (Figura 2). Considerando essa elevada correlação das variáveis selecionadas com o primeiro eixo, somado ao fato de que este explica $73 \%$ da variação total dos dados, optamos por empregar seus escores como a covariável representante do grau de estruturação dos fragmentos (Tabela 2), o que assumimos como diretamente relacionado ao seu estádio sucessional.

Tabela 2. Variáveis descritoras do grau de estruturação dos fragmentos estudados no Planalto Atlântico Paulista empregadas na Análise de Componentes Principais (PCA) e o escore resultante para o primeiro eixo (PC1, Figura 2), cuja explicação corresponde a $73 \%$ da variação contida nos dados.

\begin{tabular}{lrrrrrr}
\hline Fragmento & $\begin{array}{r}\text { Área basal } \\
\left(\mathrm{mm}^{2} .0,1 \mathrm{ha}^{-1}\right)\end{array}$ & $\begin{array}{r}\text { Densidade } \\
\left(\text { ind.0,1 ha } \mathrm{ha}^{-1}\right)\end{array}$ & $\begin{array}{r}\text { Área basal de } \\
\text { pioneiras } \\
\left(\mathrm{mm}^{2} .0,1 \mathrm{ha}^{-1}\right)\end{array}$ & $\begin{array}{r}\text { Caules múltiplos } \\
(\text { ind.0,1 ha }\end{array}$ & $\begin{array}{r}\text { Altura } \\
\text { máxima do } \\
\text { dossel (m) }\end{array}$ & $\begin{array}{r}\text { Escore PCA } \\
(\text { eixo 1) }\end{array}$ \\
\hline Bicudo & $59.653,40$ & 176 & 0 & 26 & $19,0 \pm 2,1$ & $-1,69$ \\
Teomar & $48.234,73$ & 197 & 0 & 93 & $16,1 \pm 1,8$ & $-0,62$ \\
Odorico & $38.032,12$ & 246 & $3.644,70$ & 96 & $16,1 \pm 1,5$ & 0.05 \\
Osasco & $46.858,81$ & 251 & $6.532,88$ & 136 & $14,3 \pm 1,6$ & 0,55 \\
Jeanzão & $27.956,83$ & 273 & $10.295,62$ & 119 & $15,5 \pm 2,4$ & 0,81 \\
Médico & $41.000,37$ & 294 & 912,24 & 189 & $13,9 \pm 0,9$ & 0,90 \\
\hline
\end{tabular}

* Corresponde à média das alturas máximas por parcela. 


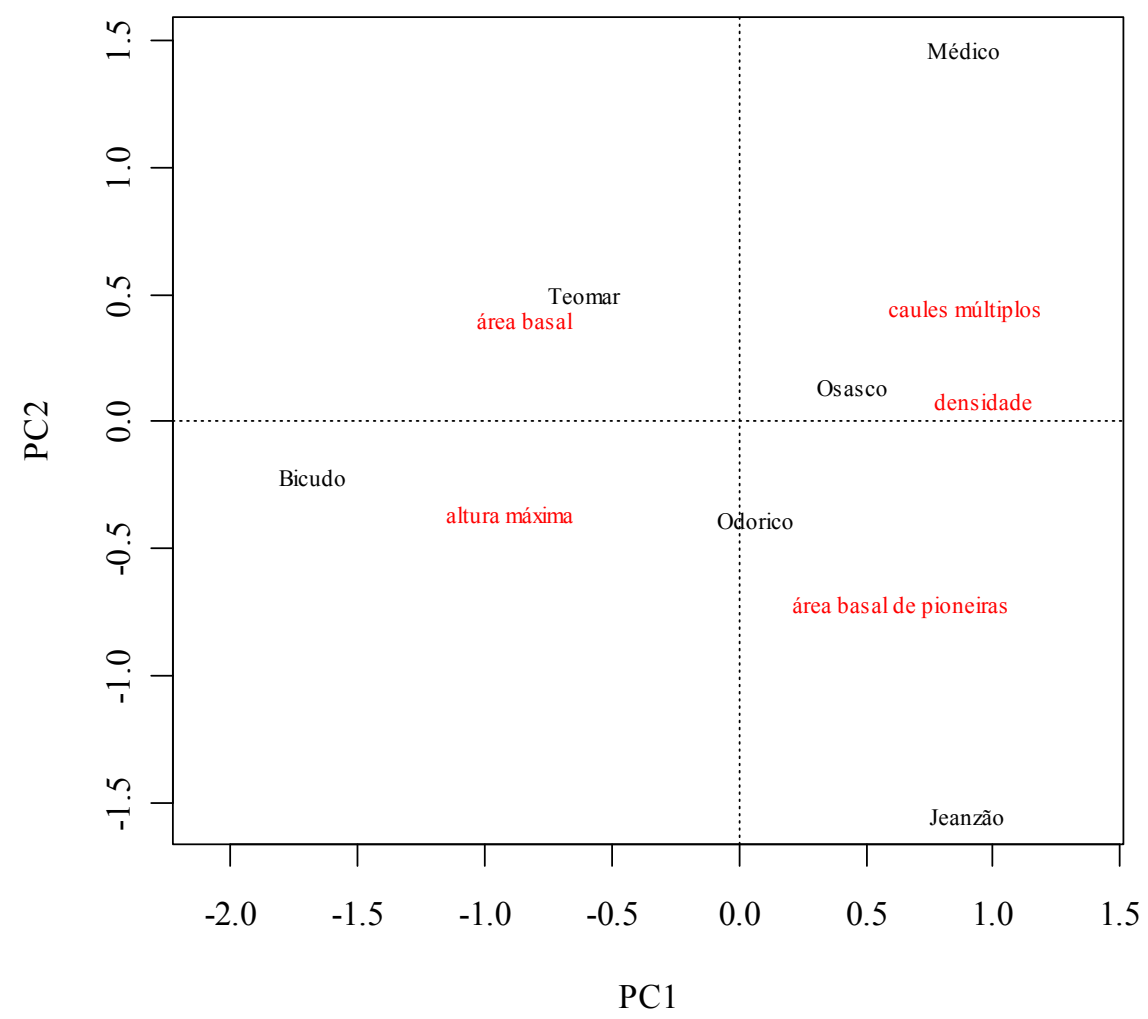

Figura 2. Diagrama de ordenação representando os dois primeiros eixos da Análise de Componentes Principais (PCA) realizada com as variáveis descritoras do grau de estruturação dos fragmentos estudados no Planalto Atlântico Paulista. A proporção da variação explicada pelo eixo 1 (PC1) foi de $73 \%$, enquanto a variação explicada pelo eixo 2 (PC2) foi de $20 \%$.

\section{Espécie de dossel}

As densidades registradas para os indivíduos de Guapira com DAP não apresentaram a relação esperada com o grau de estruturação da floresta, o que pode ser constatado, por exemplo, pela discrepância entre os valores para os dois fragmentos mais estruturados (Bicudo e Teomar) (Tabela 3). No entanto, quando ordenados de forma crescente e consideradas as classificações prévias de tamanho e estádio sucessional, os valores de densidade são maiores nos fragmentos grandes do que nos médios, não havendo relação com os estádios inicial e tardio, embora a maior densidade tenha sido registrada no fragmento grande tardio (Teomar) (Figura 3a). Já para as plantas com DAS, mesmo que a relação direta entre os escores e as densidades não seja exatamente como esperada, pode-se notar que os fragmentos nas três primeiras posições de escore têm densidades mais altas do que os demais (Tabela 3). Quando a densidade é ordenada de forma crescente, o efeito do tamanho do fragmento, observado para as plantas com DAP, não é encontrado, tampouco algum efeito do estádio sucessional (Figura 3b). Mais uma vez, o fragmento grande tardio (Teomar) apresentou a maior densidade registrada (Figura 3b). 
Tabela 3. Densidades registradas dos indivíduos com DAP e DAS de Guapira e Rudgea em cada fragmento estudado no Planalto Atlântico Paulista. Os fragmentos são apresentados em ordem decrescente de estruturação.

\begin{tabular}{|c|c|c|c|c|c|}
\hline \multirow[b]{2}{*}{ Fragmento } & \multirow[b]{2}{*}{ Escore PCA (eixo 1) } & \multicolumn{2}{|c|}{ Guapira - Densidade (ind.0.5 ha ${ }^{-1}$ ) } & \multicolumn{2}{|c|}{ Rudgea - Densidade (ind.0.5 ha ${ }^{-1}$ ) } \\
\hline & & DAP & DAS & DAP & DAS \\
\hline Bicudo & $-1,69$ & 184 & 390 & 136 & 20 \\
\hline Teomar & $-0,62$ & 714 & 711 & 933 & 533 \\
\hline Odorico & 0,05 & 564 & 422 & 284 & 98 \\
\hline Osasco & 0,55 & 204 & 216 & 136 & 102 \\
\hline Jeanzão & 0,81 & 290 & 96 & 108 & 190 \\
\hline Médico & 0,90 & 472 & 132 & 394 & 78 \\
\hline
\end{tabular}
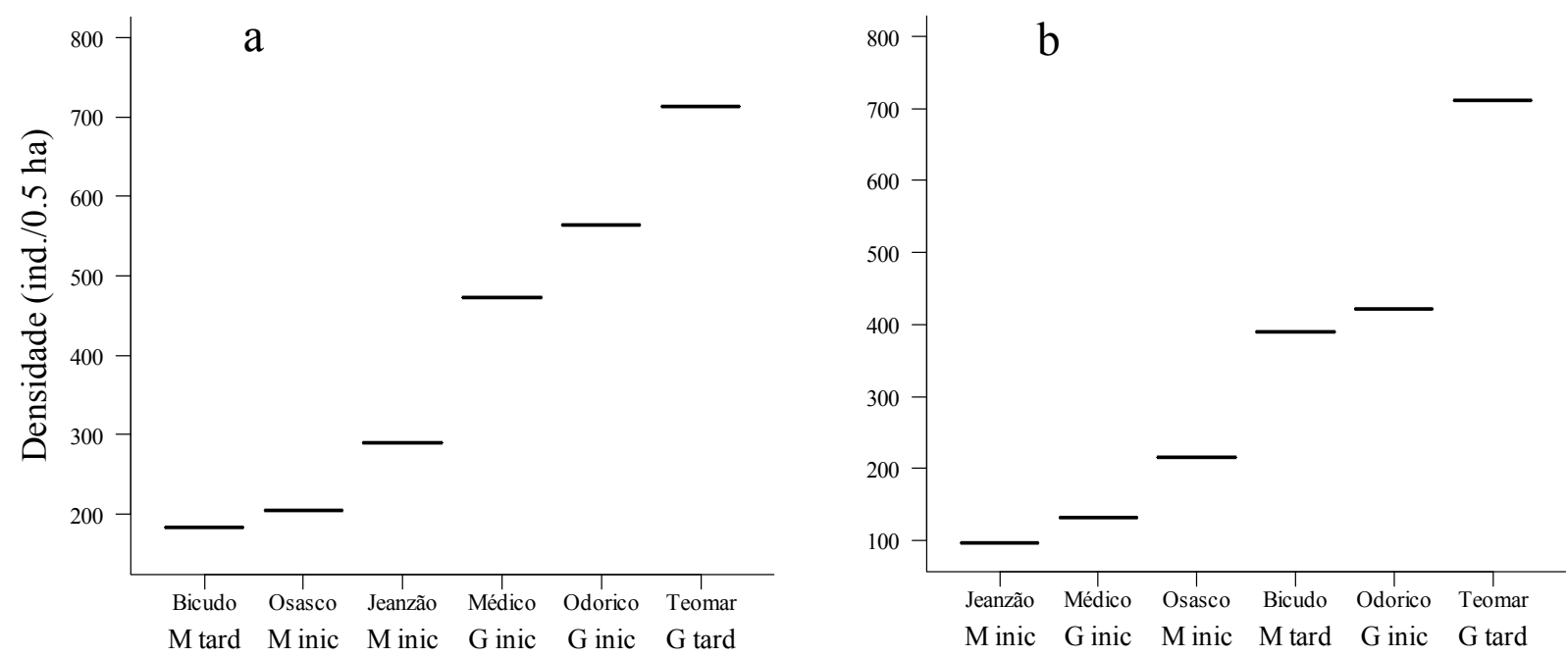

Figura 3. Densidade registrada para Guapira em cada fragmento florestal estudado no Planalto Atlântico Paulista. Os fragmentos estão em ordem crescente de densidade, sendo em (a) as plantas com DAP e em (b) as plantas com DAS. A classificação prévia dos fragmentos em tamanho e estádio sucessional é apresentada logo abaixo de cada fragmento, sendo "M" = tamanho médio, "G" = tamanho grande, "inic"= estádio inicial e "tard" = estádio tardio.

Com relação à distribuição diamétrica de Guapira, o modelo que empregou a distribuição Log-normal apresentou um melhor ajuste aos dados do que as demais distribuições (Weibull $\triangle \mathrm{AIC}=10,7$ e Exponencial Negativa $-\Delta \mathrm{AIC}=157,8)$, sendo, portanto, a distribuição de densidade probabilística selecionada (Tabela 4, Figura 4). Ao adicionarmos as covariáveis ao modelo nulo da distribuição Log-normal, o tamanho, representado pelas categorias médio e grande, foi a única variável que não representou uma melhora no ajuste do modelo aos dados (Tabela 4). O modelo para a covariável contínua (escore do PCA), representando a variação estrutural dos fragmentos, foi o modelo selecionado, pois destacou-se em relação aos demais apresentando o menor AIC e um $\triangle \mathrm{AIC}$ de 23,4 quando comparado ao segundo colocado (estádio sucessional - duas categorias: inicial e tardio) (Tabela 4). Conforme previmos, embora a consideração de duas categorias de estádio sucessional melhore o grau de explicabilidade do modelo, a covariável contínua reflete as diferenças de distribuição diamétrica entre os 
fragmentos com maior acurácia, sendo um modelo ainda melhor. No entanto, quando analisado visualmente o desempenho do modelo selecionado em relação à proporção cumulativa de indivíduos por diâmetro para cada fragmento, percebemos uma variação na qualidade do ajuste (Figura 5).

Tabela 4. Resultado da seleção de modelos para o tipo de distribuição de densidade probabilística com melhor ajuste aos dados de distribuição diamétrica de Guapira e Rudgea nos fragmentos florestais estudados no Planalto Atlântico Paulista. Abaixo deste é apresentado o modelo da distribuição selecionada contendo a covariável com melhor ajuste aos dados. As covariáveis tamanho e estádio sucessional foram classificadas a priori (Tabela 1) e a estrutura corresponde ao escore do primeiro eixo da Análise de Componentes Principais (PCA) (Tabela 2, Figura 2). O modelo nulo é um modelo sem nenhuma covariável, correspondendo, portanto, ao modelo da distribuição selecionada.

\begin{tabular}{|c|c|c|c|c|c|c|c|}
\hline \multicolumn{4}{|c|}{ Guapira } & \multicolumn{4}{|c|}{ Rudgea } \\
\hline \multicolumn{4}{|c|}{ Distribuição de densidade probabilística } & \multicolumn{4}{|c|}{ Distribuição de densidade probabilística } \\
\hline & AIC & $\mathrm{gl}$ & $\Delta \mathrm{AIC}$ & & AIC & $\mathrm{gl}$ & $\Delta \mathrm{AIC}$ \\
\hline Log-normal & $11.413,0$ & 2 & 0,0 & Weibull & $7.977,2$ & 2 & 0,0 \\
\hline Weibull & $11.423,6$ & 2 & 10,7 & Exponencial Negativa & 8.002 .9 & 1 & 25,0 \\
\hline Exponencial Negativa & $11.570,8$ & 1 & 157,8 & Log-normal & $8.188,2$ & 2 & 210,3 \\
\hline $\begin{array}{l}\text { Modelo da covariável } \\
\text { (Log-normal) }\end{array}$ & AIC & gl & $\Delta \mathrm{AIC}$ & $\begin{array}{l}\text { Modelo da covariável } \\
\text { (Weibull) }\end{array}$ & AIC & $\mathrm{gl}$ & $\Delta \mathrm{AIC}$ \\
\hline Estrutura & $11.380,0$ & 4 & 0,0 & Tamanho & $7.917,5$ & 4 & 0,0 \\
\hline Estádio sucessional & $11.403,4$ & 4 & 23,4 & Estrutura & 7.963 .8 & 4 & 46,4 \\
\hline Tamanho & $11.412,3$ & 4 & 32,3 & Estádio sucessional & $7.964,9$ & 4 & 47,5 \\
\hline Nulo & $11.413,0$ & 2 & 33,0 & Nulo & $7.977,2$ & 2 & 60,5 \\
\hline
\end{tabular}

Ao incorporarmos a estrutura dos fragmentos ao modelo da distribuição Log-normal, assumimos uma relação linear entre esta e os parâmetros da distribuição (média e desvio padrão - Tabela 5) e, o fato deste ser considerado o modelo mais plausível, é um indicativo de que se trata de uma boa aproximação. Quanto à direção desta relação, esperávamos que os fragmentos mais estruturados apresentassem um desvio padrão maior em relação aos menos estruturados, o que se confirmou, pelo menos em parte, já que o fragmento Bicudo, classificado previamente como tardio e em um extremo dos valores do escore do PCA, apresentou o maior desvio, enquanto que os desvios mais baixos foram para os fragmentos Jeanzão e Médico, ambos previamente classificados como iniciais e nas duas últimas posições em termos do escore (Tabela 5).

Tabela 5. Parâmetros do modelo selecionado para a distribuição de diâmetro de Guapira (distribuição Log-normal) nos fragmentos florestais estudados no Planalto Atlântico Paulista. Os fragmentos são apresentados em ordem de estruturação conforme o escore do primeiro eixo da Análise de Componentes Principais (PCA).

\begin{tabular}{lrrr}
\hline & & \multicolumn{2}{c}{ Parâmetros da Log-normal } \\
\cline { 3 - 4 } Fragmento & Escore PCA (eixo 1) & Média $(m)$ & Desvio padrão $\left(s^{2}\right)$ \\
\hline Bicudo & $-1,69$ & 3,91 & 4,16 \\
Teomar & $-0,62$ & 3,57 & 3,84 \\
Odorico & 0,05 & 3,64 & 3,95 \\
Osasco & 0,55 & 3,78 & 3,85 \\
Jeanzão & 0,81 & 4,17 & 3,51 \\
Médico & 0,90 & 4,23 & 3,72 \\
\hline
\end{tabular}




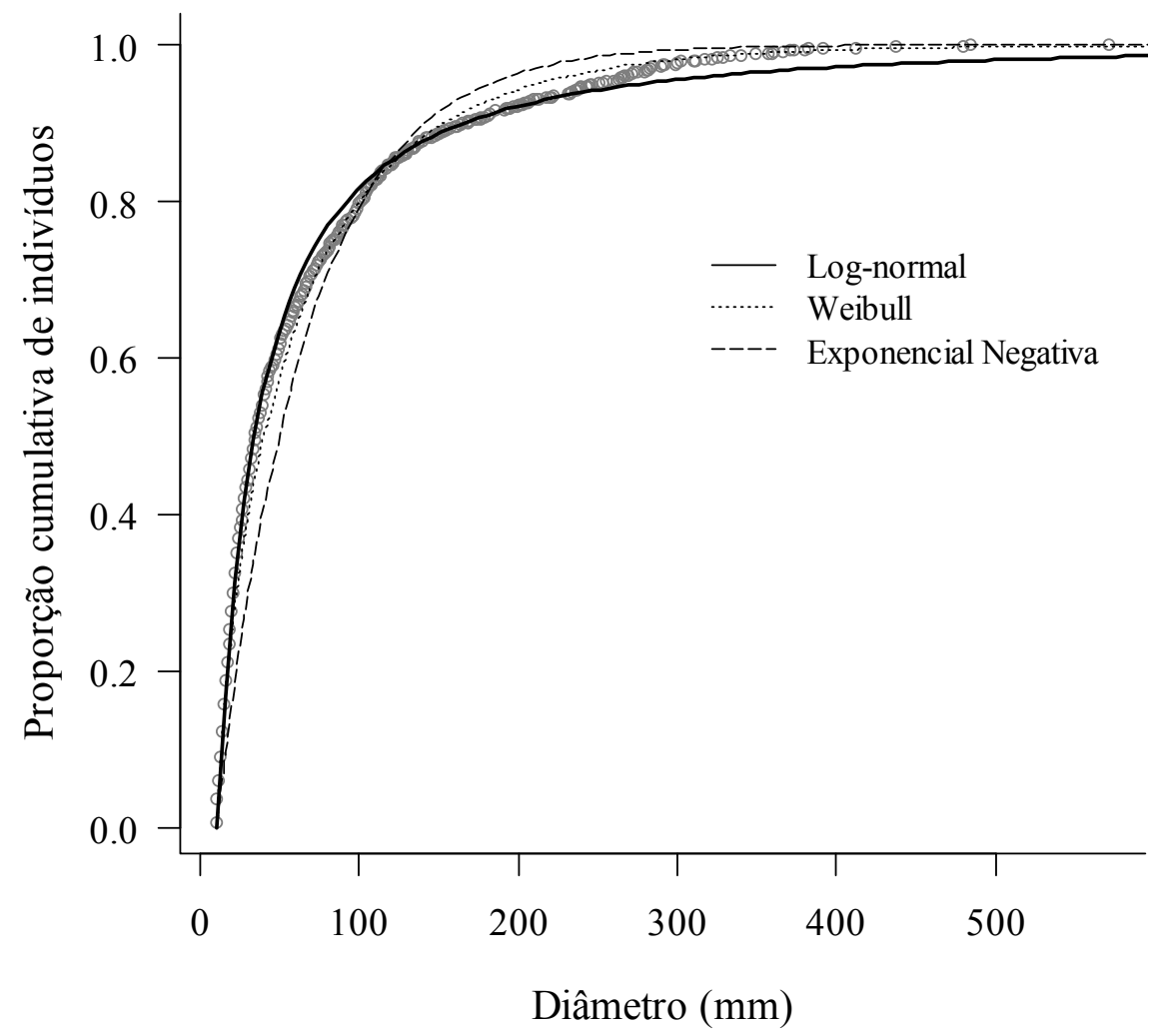

Figura 4. Distribuições de densidade probabilística ajustadas aos dados de proporção cumulativa de indivíduos de Guapira, estudados nos fragmentos florestais no Planalto Atlântico Paulista, por diâmetro. A distribuição Lognormal apresentou o melhor ajuste, seguida da distribuição Weibull e, por último, a Exponencial Negativa (Tabela 4).

\section{Espécie de sub-bosque}

As densidades registradas para os indivíduos de Rudgea com DAP não apresentaram relação com os escores do PCA, da mesma forma que para Guapira (Tabela 3). Quando organizados em ordem crescente, os valores de densidade também são mais altos nos fragmentos maiores, da mesma forma havendo destaque para o fragmento grande tardio (Teomar) (Figura 6a). Outra constatação que cabe ressaltar diz respeito às diferenças de variância entre os valores de densidade para fragmentos médios e grandes, sendo que nos grandes a variância é muito maior, impulsionada principalmente pelo fragmento Teomar (Figura 6a). Para as plantas com DAS, da mesma forma, a relação com o escore não foi observada, nem tampouco a relação com o tamanho ou estádio sucessional (Tabela 3, Figura 6b). Para estas plantas, fica ainda mais evidente a discrepância entre a densidade registrada para o fragmento grande tardio (Teomar) e os demais (Tabela 3, Figura 6b). Além disso, chama a atenção a baixíssima densidade de plantas com DAS encontrada no fragmento médio tardio (Bicudo) (Tabela 3, Figura 6b). 
Bicudo



Médico

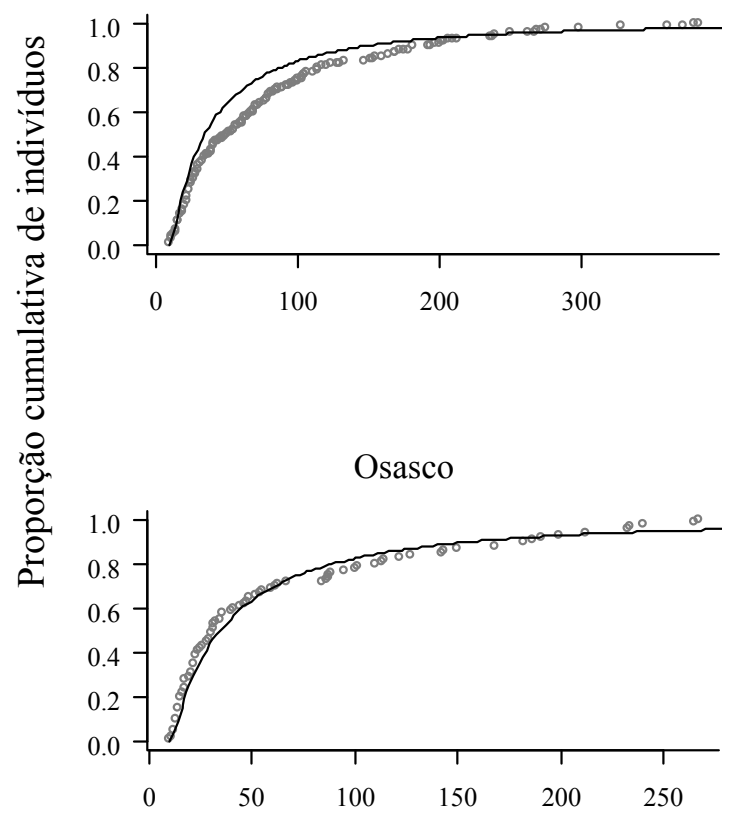

Jeanzão

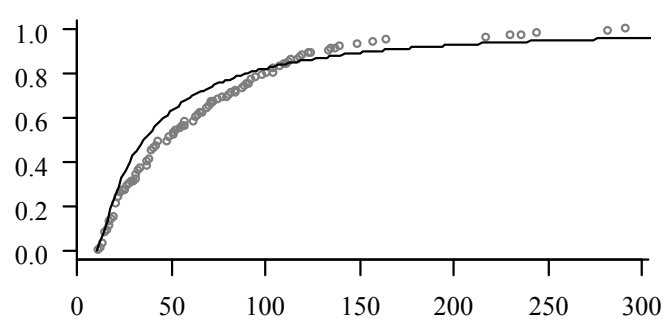

Odorico

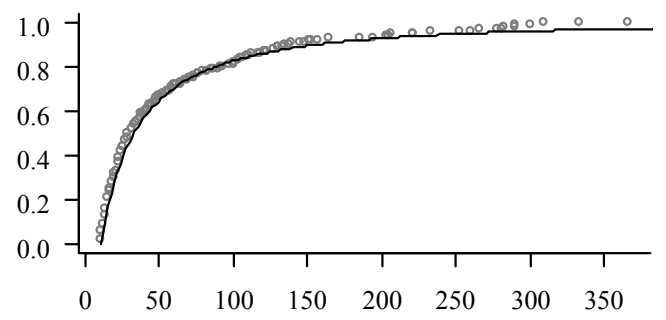

Teomar

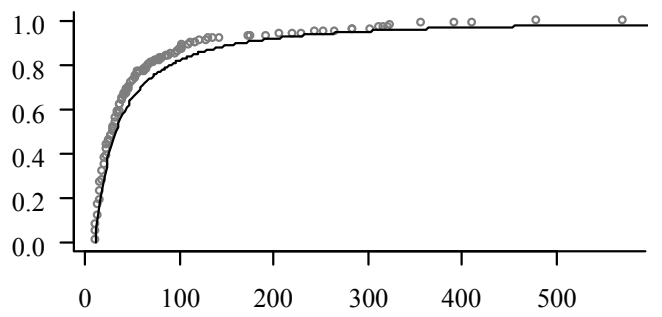

Diâmetro (mm)

Figura 5. Ajuste do modelo selecionado (distribuição Log-normal com a covariável estrutura - Tabela 3) aos dados de proporção cumulativa de indivíduos de Guapira por diâmetro para cada fragmento estudado no Planalto Atlântico Paulista. Note que, em função das variações no diâmetro máximo atingido pela espécie em cada fragmento, a escala para o diâmetro não é a mesma em todos os gráficos.

Para Rudgea, a Weibull foi a distribuição de densidade probabilística com melhor ajuste aos dados de distribuição de diâmetro (Tabela 4, Figura 7). A distribuição Exponencial Negativa ficou em segundo lugar $(\triangle \mathrm{AIC}=25,0)$, enquanto que a Log-normal, selecionada para Guapira, apresentou o pior desempenho $(\triangle \mathrm{AIC}=210,3)$ (Tabela 4, Figura 7). Quando incorporadas as covariáveis ao modelo nulo para a Weibull, todas representaram uma melhora no ajuste do modelo aos dados, sendo que modelo para o tamanho (dois níveis - médio e grande), o único que não apresentara melhora em relação ao modelo nulo para Guapira, apresentou o melhor desempenho (Figura 8). A estrutura (escore do PCA) e o estádio sucessional empataram em termos de AIC (Tabela 4). Quanto aos parâmetros da distribuição selecionada, para os fragmentos grandes, os valores dos parâmetros forma (s) e escala (a) foram, respectivamente, $s=$ $-0,13$ e $a=-20,45$, enquanto que para os fragmentos médios, os valores foram muito maiores, 
sendo, respectivamente, $s=1,30$ e $a=48,36$. Quanto menor o parâmetro forma, maior é a assimetria e desigualdade da distribuição de diâmetros por isso a curva cumulativa para os fragmentos grandes apresenta maior inclinação (Figura 8), o que seria equivalente em uma curva não cumulativa, a um "J invertido". Isto quer dizer que a curva da distribuição diamétrica está mais de acordo com o esperado para uma espécie de sub-bosque nos fragmentos grandes do que para os médios.
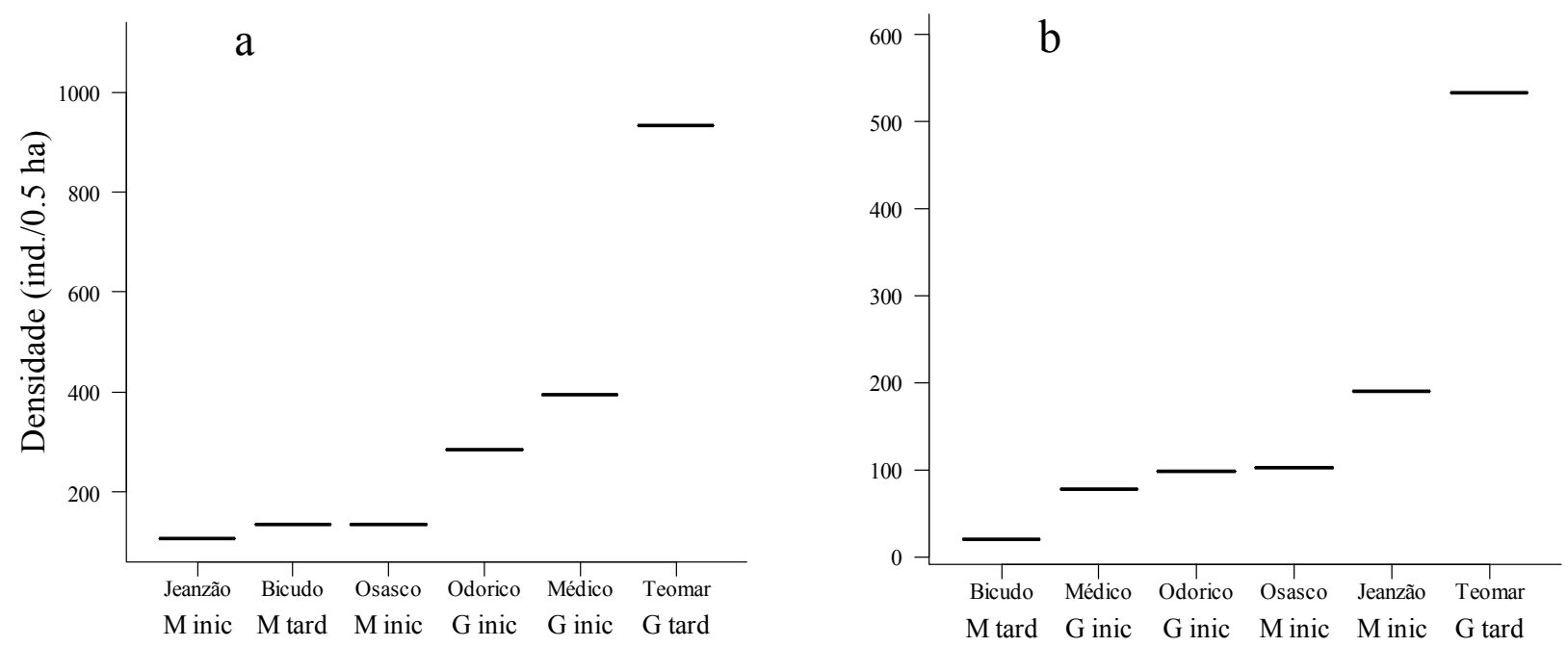

Figura 6. Densidade registrada para Rudgea em cada fragmento florestal estudado no Planalto Atlântico Paulista. Os fragmentos estão em ordem crescente de densidade, sendo em (a) as plantas com DAP e em (b) as plantas com DAS. A classificação prévia dos fragmentos em tamanho e estádio sucessional é apresentada logo abaixo de cada fragmento, sendo "M" = tamanho médio, "G" = tamanho grande, "inic"= estádio inicial e "tard" = estádio tardio. 


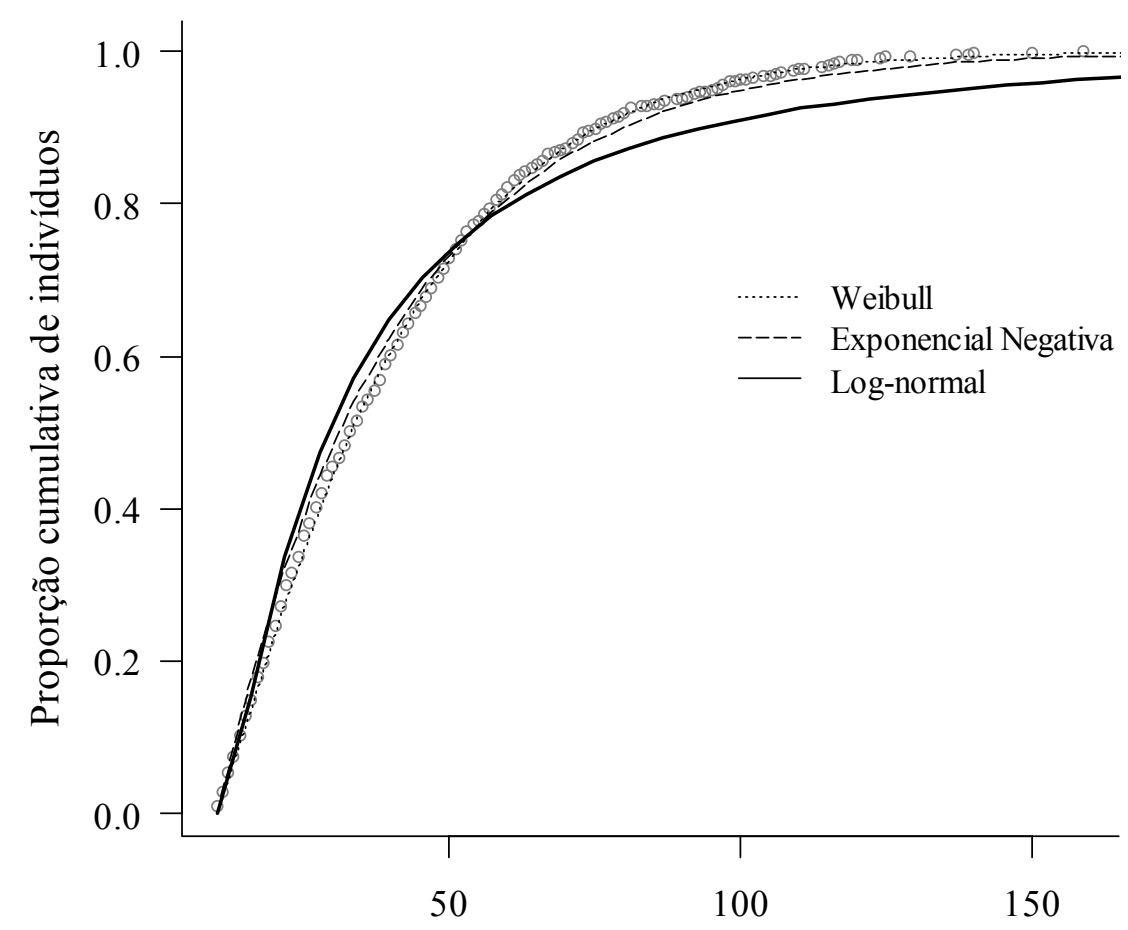

Diâmetro (mm)

Figura 7. Distribuições de densidade probabilística ajustadas aos dados de proporção cumulativa de indivíduos de Rudgea, estudados nos fragmentos florestais no Planalto Atlântico Paulista, por diâmetro. A distribuição Weibull apresentou o melhor ajuste, seguida da Exponencial Negativa e da Log-normal (Tabela 3).



Diâmetro (mm)

Figura 8. Ajuste do modelo selecionado (distribuição Weibull com a covariável tamanho - Tabela 3) aos dados de proporção cumulativa de indivíduos de Rudgea por diâmetro para cada tamanho de fragmento estudado no Planalto Atlântico Paulista. 


\section{Discussão}

Neste trabalho, demonstramos que informações sobre a estrutura de tamanhos das populações podem fornecer indícios da sua resposta aos processos de fragmentação e sucessão secundária. Ambas as espécies ocorrem em menor densidade nos menores fragmentos, corroborando, portanto, um efeito já bem documentado na literatura (revisão em Hobbs \& Yates 2003) e constatado como forte para plantas tolerantes à sombra (Tabarelli et al. 1999, ArroyoRodriguez et al. 2007, são alguns exemplos). Com relação à estrutura de tamanhos das populações, no entanto, dois padrões distintos emergem e se relacionam ao grau de tolerância à sombra de cada espécie. De um lado, Guapira opposita, a espécie de dossel, mostrou uma resposta às mudanças na estrutura de fragmentos florestais em distintos estádios sucessionais, indicando uma capacidade de adaptação (plasticidade) na sua estrutura populacional que suplanta o efeito da área do fragmento. Já Rudgea jasminoides, a espécie de sub-bosque, mostrou-se mais sensível aos efeitos da área, tendo a densidade e a estrutura populacionais alteradas conforme o tamanho do fragmento, o que pode vir a ter implicações drásticas para a sua conservação a longo prazo na Floresta Atlântica. Para o nosso conhecimento, é a primeira vez que é demonstrado que diferentes atributos das florestas secundárias, relacionados aos processos de fragmentação e de sucessão, explicam melhor as variações encontradas na estrutura populacional de espécies arbóreas que diferem no grau de tolerância à sombra.

O grau de estruturação da floresta foi o atributo mais importante para explicar as diferenças na estrutura das populações da espécie com tolerância intermediária à sombra (secundária inicial de dossel). Embora o tamanho do fragmento tenha apresentado efeito na sua densidade, este sequer representou alguma melhora no ajuste do modelo aos dados. De fato, esperávamos que a estrutura de tamanhos das populações acompanhasse as mudanças na estrutura dos fragmentos em distintos estádios sucessionais (revisão em Guariguata \& Ostertag 2001), uma vez que esta espécie é uma das principais constituintes do dossel em florestas secundárias na região (Observação pessoal). A direção destas mudanças, observada a partir do parâmetro desvio da distribuição Log-normal, também está de acordo com as expectativas para espécies tolerantes à sombra, ou seja, aumento na assimetria e desigualdade da distribuição de diâmetros, pois quanto mais avançada a sucessão secundária mais próximo a espécie está da estrutura de tamanhos prevista para este grupo funcional (Wright 2003).

Esse tipo de abordagem, enfocando as variações na distribuição de diâmetros de determinada população em relação às variações na estrutura da floresta é muito comum nos estudos de silvicultura, impulsionados pela tentativa de modelagem e previsão da produtividade de madeira e dos impactos do manejo (Goordburn \& Lorimer 1999, Schwartz et al. 2005, são 
alguns exemplos), sendo, no entanto, ainda incipiente nos estudos de sucessão secundária e dinâmica florestal (mas veja Clark 1991 e Coomes \& Allen 2007), embora muitos avanços teóricos tenham sido feitos recentemente (para detalhes ver Muller-Landau et al. 2006). O potencial desse enfoque é imenso, uma vez que os parâmetros podem ser modelados e as previsões acerca da direção da sucessão, tanto do ponto de vista da comunidade, quanto das populações, podem ser testadas. É interessante notar o quão imprevisível parece ser a distribuição de densidade probabilística com melhor ajuste aos dados de distribuição de diâmetros de espécies arbóreas, mesmo quando considerado o grupo das tolerantes à sombra, por ser uma característica peculiar da espécie, o que foi constatado também por Wang et al. (2009).

Já a estrutura de tamanhos da espécie de sub-bosque apresentou uma resposta mais contundente ao tamanho dos fragmentos do que ao grau de estruturação da floresta que os compõem, diferentemente do esperado. Considerando que o efeito da área do fragmento está diretamente relacionado aos efeitos de borda, ou seja, a série de alterações abióticas e estruturais provocadas pela fragmentação que, última análise, altera drasticamente a estrutura dos fragmentos florestais (revisão em Laurance et al. 2002), seria razoável esperar que o grau de estruturação fosse o modelo selecionado, pois previmos uma resposta gradual da estrutura da população à estrutura da floresta. De fato, nos estudos em que o efeito da área do fragmento sobre as populações arbóreas tolerantes à sombra é demonstrado (Arroyo-Rodrigues et al. 2007, Brum et al. 2008), este está diretamente relacionado ao efeito de borda. Por isso, esperávamos que, embora existam tantos indícios dos efeitos da área sobre a densidade das populações (revisões em Hobbs \& Yates 2003 e Brum et al. 2008 e também no presente estudo), ainda assim o grau de estruturação da floresta seria um melhor preditor da estrutura de tamanhos para a espécie estudada. Outra constatação que contribuiu para a nossa expectativa, foi o fato de que atributos da paisagem como conectividade e complexidade têm um efeito decisivo na resposta das espécies arbóreas à fragmentação (Metzger 1997), notadamente as tolerantes à sombra (Metzger 2000). Nesse sentido, a paisagem estudada apresenta uma elevada porcentagem de cobertura florestal $(\approx 45 \%)$, de modo que pressupomos que parte dos efeitos da área do fragmento sobre estas populações fossem atenuados por esta característica peculiar que se sobressai em relação a regiões adjacentes do Planalto de Ibiúna, como uma área próxima à cidade de São Paulo, cuja cobertura florestal é de cerca de 30\% (Metzger et al. 2009). Além disso, a abordagem voltada para o grau de estruturação da floresta que compõem os fragmentos não significa que pretendíamos negar a importância da área, mas sim incorporar maior complexidade à variável preditora, já que, nessa paisagem, o tamanho do fragmento não necessariamente tem relação com o seu grau de estruturação (vide Bicudo e Teomar, por 
exemplo, ambos com estrutura de floresta tardia e tamanhos contrastantes). Este tipo de situação é bastante comum na Floresta Atlântica, onde uma multiplicidade de históricos de uso e de regeneração agrega ainda mais complexidade aos estudos em fragmentos florestais, fazendo com que fragmentos maiores não necessariamente tenham uma floresta mais estruturada (Metzger et al. 2009), como no presente estudo. Esta característica tem sido apontada como uma das principais responsáveis para que as previsões sobre o efeito da área na riqueza e composição de espécies arbóreas falhem na região da Floresta Atlântica (Santos et al. 2007). Em função disso, é sugerida uma combinação entre área e distúrbio para compor uma variável com maior poder de predição dos padrões de composição florística em fragmentos florestais na região sudeste do Brasil (Santos et al. 2007).

Abordagens sobre o efeito da área do fragmento na estrutura de tamanhos das populações arbóreas são bem mais escassas na literatura do que os efeitos sobre a densidade. No entanto, pelos trabalhos já realizados em diferentes fases do ciclo de vida de espécies arbóreas, sabe-se que a fragmentação reduz as taxas de polinização e a capacidade reprodutiva das árvores (Aizen \& Feisinger 1994, Lopes et al. 2009), altera os processos de dispersão e predação (Galetti et al. 2006, Chacoff et al. 2004), reduz o recrutamento de plântulas (Benitez-Malvido 1998, BenitezMalvido \& Martínez-Ramos 2003), aumenta a frequência de danos e de mortalidade de árvores adultas (Ferreira \& Laurance 1997), alterando a densidade (Arroyo-Rodrigues et al. 2007) e, em última análise, a demografia (Brum et al. 2008) das espécies arbóreas.

Conforme já comentado, a complexidade da paisagem é um fator crucial (Metzger 1997) que faz com que os efeitos da fragmentação sejam dependentes do grupo funcional analisado, pois conforme as características ecológicas da espécie diferentes atributos da paisagem podem ser mais relevantes (Metzger 2000, Metzger et al. 2009). Nesse sentido, para o grupo funcional das espécies arbóreas de sub-bosque, a área é considerada uma característica relevante, tendo um efeito positivo na riqueza e abundância (Arroyo-Rodrigues et al. 2007, Metzger et al. 2009). Metzger et al. (2009) que investigaram o tempo de resposta à fragmentação para diversos grupos de organismos, mostraram que a área pretérita e atual do fragmento, bem como a dinâmica da paisagem, tiveram um efeito positivo na riqueza e na abundância de espécies arbóreas subbosque, principalmente devido à baixa capacidade de dispersão em comparação a outros táxons de maior mobilidade, como as aves, nas quais esse efeito não foi observado. Nesta mesma direção, Arroyo-Rodrigues et al. (2007), em um contexto de paisagem semelhante à Floresta Atlântica, encontraram um efeito positivo da área sobre a densidade da palmeira arbórea de subbosque Astrocaryum mexicanum. Dois mecanismos principais foram apontados pelos autores como responsáveis pela redução da abundância: os que aumentam a mortalidade (como os 
efeitos de borda) e os que reduzem o recrutamento (como problemas na dispersão) (ArroyoRodrigues et al. 2007). Nenhum destes estudos, no entanto, aprofunda a análise para a estrutura de tamanhos das populações em questão. Trabalhos com herbáceas de ciclo de vida longo apontam para a mesma direção dos efeitos nas arbóreas (Jules 1998, Bruna \& Kress 2002, Tomimatsu \& Ohara 2010).

Contudo, para a espécie de sub-bosque estudada, qualquer tentativa de explicar os mecanismos pelos quais a fragmentação provocou as alterações na densidade e estrutura populacionais seria meramente especulativa. Porém, o fato de o efeito da área não ter sido tão contundente na densidade de plantas regenerantes (indivíduos com DAS), somado ao fato de que a densidade de plântulas (indivíduos menores do que $1 \mathrm{~m}$ de altura) não tem relação com o tamanho ou o estádio sucessional dos fragmentos (Jurinitz et al., dados não publicados), nos leva a supor que os adultos presentes nos fragmentos menores são em sua maioria relictos de um período pré-fragmentação e que o efeito observado nos indivíduos com DAP provém de um atraso na resposta à fragmentação, já demonstrado para árvores de sub-bosque numa paisagem adjacente (Metzger et al. 2009). Embora não haja, portanto, problemas evidentes de regeneração, o que nos faz supor que a dispersão e a colonização de novas áreas não seja um problema, provavelmente a velocidade da perda de indivíduos adultos é maior do que a reposição de jovens presentes no componente regenerante destes fragmentos.

O resultado encontrado de fato não indica que apenas a área do fragmento é importante, já que os padrões para a densidade tanto de indivíduos com DAP quanto com DAS (regenerantes) mostram um efeito combinado da área e do estádio sucessional, evidenciado pelas densidades muito maiores encontradas no fragmento grande tardio (Teomar). Por outro lado, o fato da estrutura de tamanhos da espécie de sub-bosque ser mais relacionada ao tamanho do fragmento é um resultado que merece destaque, pois embora não estejamos abordando diretamente os efeitos da fragmentação, isto é um indício de que, para esta espécie, previsões em termos de conservação a longo prazo podem ser muito mais simples. Assim, esta constatação têm implicações importantes para a conservação da espécie, pois indica que ela está sendo perdida, extinta localmente nos menores fragmentos, uma vez que a sua densidade é fortemente diminuída e a sua estrutura de tamanhos desvia da esperada para uma espécie de sub-bosque em equilíbrio demográfico. Mesmo considerando que a distribuição Weibull é comumente selecionada para espécies de sub-bosque em florestas maduras (Wang et al. 2009, por exemplo), as previsões quanto ao seu parâmetro forma, que denota a assimetria e desigualdade da distribuição (Knox et al. 1989), demonstram que nos fragmentos médios o número de indivíduos nas menores classes de tamanho é menor do que nos fragmentos grandes. Assim, mesmo que um 
fragmento médio tenha uma estrutura correspondente ao estádio sucessional tardio (como o Bicudo, por exemplo), esta espécie de sub-bosque não está conseguindo manter uma densidade e estrutura populacionais adequadas a sua persistência a longo prazo. A extinção local de espécies arbóreas de sub-bosque é um fato já documentado na Floresta Atlântica por Tabarelli et al. (1999) e se esta constatação for confirmada para outros fragmentos de mesmo tamanho, isto quer dizer que, para esta espécie, fragmentos com uma área entre 20 e 40 ha, já não comportam populações com a densidade e estrutura adequadas. As implicações para a conservação desta espécie podem ser drásticas, já que estimativas recentes apontam que $83 \%$ do número total fragmentos na Floresta Atlântica são menores do que 50 ha (Ribeiro et al. 2009). Além disso, as consequências podem ser ainda mais graves se padrões semelhantes forem comprovados para outras espécies com características ecológicas similares, um alerta já feito para a região da Floresta Atlântica (Silva \& Tabarelli 2000, Tabarelli et al. 2004).

A partir do exposto, concluímos que a Guapira opposita, espécie de dossel, demonstra uma plasticidade demográfica em florestas secundárias em distintos estádios sucessionais. A espécie parece bem adaptada a paisagens fragmentadas, uma vez que outrora ocupava o subbosque de florestas primárias e passa a ser uma das principais constituintes do dossel em florestas secundárias em estádio mais avançado. Dessa forma, demonstramos que o entendimento da estrutura e dinâmica das populações desta espécie depende diretamente da complexidade estrutural dos fragmentos florestais. Esse entendimento é de extrema relevância, se considerarmos a sua grande amplitude de ocorrência na Floresta Atlântica (Scudeller et al. 2001), somada à elevada cobertura de florestas secundárias da região (Ribeiro et al. 2009). Em outro extremo, as predições acerca da iminência de extinção local da espécie de sub-bosque Rudgea jasminoides nos menores fragmentos necessitam ser testadas em estudos de dinâmica populacional e ainda para outros fragmentos e paisagens na sua área de ocorrência.

Independentemente de qual atributo do fragmento de floresta secundária tenha sido mais importante para cada espécie, é interessante ressaltar a importância de diferentes distribuições de densidade probabilística apresentarem um melhor ajuste às distribuições de tamanhos, uma vez que cada distribuição representa uma interpretação biológoca distinta, à luz da Teoria do Equilíbrio Demográfico (Muller-Landau et al. 2006). Dentre as informações demográficas que são necessárias para se entender a dinâmica das populações de plantas, a distribuição de tamanhos é facilmente acessível em campo, tendo portanto muito potencial para auxiliar a responder questões biológicas interessantes. 


\section{Referências bibliográficas}

Aizen, M.A. \& Feinsinger, P. 1994. Forest fragmentation, pollination, and plant reproduction in a Chaco dry forest, Argentina. Ecology 75: 330-351.

Alves, L.F. \& Metzger, J.P. 2006. A regeneração florestal em áreas de floresta secundária na Reserva Florestal do Morro Grande, Cotia, SP. Biota Neotropica 6: 26p. URL: http://www.biotaneotropica.org.br/v6n2/pt/abstract?article+bn00406022006

Arroyo-Rodrigues, V., Aguirre, A., Benitez-Malvido, J., Mandujano, S. 2007. Impact of rain forest fragmentation on the population size of a structurally important palm species: Astrocaryum mexicanum at Los Tuxtlas, Mexico. Biological Conservation 138: 198-206.

Bailey, R.L. \& Dell, T.R. 1973. Quantifying diameter distributions with the Weibull function. Forest Science 19: 97-104.

Benitez-Malvido, J. 1998. Impact of forest fragmentation on seedling abundance in a tropical rain forest. Conservation Biology 12: 380-389.

Benitez-Malvido, J. \& Martinez-Ramos, M. 2003. Impact of forest fragmentation on understory plant species richness in Amazonia. Conservation Biology 17: 389-400.

Bolker, B.M. 2008. Ecological Models and Data in R. New Jersey: Princeton University Press.

Bolker, B.M. 2009. bbmle: Tools for general maximum likelihood estimation. R package version 0.9.3, based on stats4 by the $\mathrm{R}$ Development Core Team. URL: http://CRAN.Rproject.org/package $=$ bbmle

Brum, H.D., Nascimento, H.E.M., Laurance, W.F., Andrade, A.C.S., Laurance, S.G., Luiza R.C.C. 2008. Rainforest fragmentation and the demography of the economically important palm Oenocarpus bacaba in central Amazonia. Plant Ecology 199: 209-215.

Bruna, E.M. \& Kress, W.J. 2002. Habitat fragmentation and the demographic structure of an amazonian understory herb (Heliconia acuminata). Conservation Biology 16: 1256-1266.

Catharino, E.L.M., Bernacci, L.C., Franco, G.A.D.C., Durigan, G., Metzger, J.P. 2006. Aspectos da composição e diversidade do componente arbóreo das florestas da Reserva Florestal do Morro Grande, Cotia, SP. Biota Neotropica 6: 28p. URL: http://www.biotaneotropica.org.br/v6n2/pt/abstract?article+bn00306022006

Chacoff, N.P., Morales, J.M., Vaquera, M.D. 2004. Effects of fragmentation on amount of aborted and predated seed in the Chaco Serrano Argentina. Biotropica 36: 109-117.

Chazdon, R.L., Letcher, S.G., van Breugel, M., Martinez-Ramos, M., Bongers, F., Finegan, B. 2007. Rates of change in tree communities of secondary Neotropical forests following major disturbances. Philosophical Transactions of the Royal Society B-Biological Sciences 362: 273-289. 
Chen, W.J. 2004. Tree size distribution functions of four boreal forest types for biomass mapping. Forest Science 50: 436-449.

Clark, D.B. 1996. Abolishing virginity. Journal of Tropical Ecology 12: 735-739.

Clark, J.S. 1991. Disturbance and population-structure on the shifting mosaic landscape. Ecology 72: 1119-1137.

Coomes, D.A. \& Allen, R.B. 2007. Mortality and tree-size distributions in natural mixed-age forests. Journal of Ecology 95: 27-40.

Crawley, M.J. 2007. The R Book. Chichester: Wiley.

DeWalt, S.J., Maliakal, S.K., Denslow, J.S. 2003. Changes in vegetation structure and composition along a tropical forest chronosequence: implications for wildlife. Forest Ecology and Management 182: 139-151.

Durigan, G., Bernacci, L.C., Franco, G.A.D.C., Arbocz, G.F., Metzger, J.P., Catharino, E.L.M. 2008. Estádio sucessional e fatores geográficos como determinantes da similaridade florística entre comunidades florestais no Planalto Atlântico, Estado de São Paulo, Brasil. Acta botanica brasilica 22: 51-62.

Enquist, B.J. \& Niklas, K.J. 2001. Invariant scaling relations across tree-dominated communities. Nature 410: 655-660.

Ferreira, L.V. \& Laurance, W.F. 1997. Effects of forest fragmentation on mortality and damage of selected trees in central Amazonia. Conservation Biology 11: 797-801.

Galetti, M., Donatti, C.I., Pires, A.S., Guimaraes, P.R., Jordano, P. 2006. Seed survival and dispersal of an endemic Atlantic forest palm: the combined effects of defaunation and forest fragmentation. Botanical Journal of the Linnean Society 151: 141-149.

Gandolfi, S. 2000. História natural de uma floresta estacional semidecidual no município de Campinas (São Paulo, Brasil). Tese (Doutorado em Biologia Vegetal). Universidade Estadual de Campinas, Campinas.

Goodburn, J.M. \& Lorimer, C.G. 1999. Population structure in old-growth and managed northern hardwoods: an examination of the balanced diameter distribution concept. Forest Ecology and Management 118: 11-29.

Guariguata, M.R. \& Ostertag, R. 2001. Neotropical secondary forest succession: changes in structural and functional characteristics. Forest Ecology and Management 148: 185-206.

Guilherme, F.A.G., Morellato, L.P.C., Assis, M.A. 2004. Horizontal and vertical tree community structure in a lowland Atlantic Rain Forest, Southeastern Brazil. Revista Brasilieira de Botânica 27: 725-737. 
Hobbs, N.T. \& Hilborn, R. 2006. Alternatives to statistical hypothesis testing in Ecology: a guide to self teaching. Ecological Applications 16: 5-19.

Hobbs, R.J. \& Yates, C.J. 2003. Impacts of ecosystem fragmentation on plant populations: generalising the idiosyncratic. Australian Journal of Botany 51: 471-488.

Hubbell, S.P. \& Foster, R.B. 1987. Large-scale spatial structure of a neotropical forest. Revista de Biologia Tropical 35: 7-22.

Jules, E.S. 1998. Habitat fragmentation and demographic change for a common plant: Trillium in old-growth forest. Ecology 79: 1645-1656.

Knox, R.G., Peet, R.K., Christensen, N.L. 1989. Population-dynamics in loblolly-pine stands changes in skewness and size inequality. Ecology 70: 1153-1166.

Laurance, W.F., Lovejoy, T.E., Vasconcelos, H.L., Bruna, E.M., Didham, R.K., Stouffer, P.C., Gascon, C., Bierregaard, R.O., Laurance, S.G., Sampaio, E. 2002. Ecosystem decay of Amazonian forest fragments: a 22-year investigation. Conservation Biology 16: 605-618.

Legendre, P. \& Legendre, R. 1998. Numerical Ecology. Amsterdam: Elsevier.

Lopes, A.V., Girão, L.C., Santos, B.A., Peres, C.A., Tabarelli, M. 2009. Long-term erosion of tree reproductive trait diversity in edge-dominated Atlantic forest fragments. Biological Conservation 142: 1154-1165.

Melhem, T.S., Wanderley, M.G.L., Martins, A.B., Jung-Mendaçolli, S.L., Shepherd, G.J., Kirizawa, M. (eds). 2007. Flora Fanerogâmica do Estado de São Paulo São Paulo: Volume 5. São Paulo: FAPESP, Instituto de Botânica.

Metzger, J.P. 1997. Relationships between landscape structure and tree species diversity in tropical forests of South-East Brazil. Landscape and Urban Planning 37: 29-35.

Metzger, J.P. 2000. Tree functional group richness and landscape structure in a Brazilian tropical fragmented landscape. Ecological Applications 10: 1147-1161.

Metzger, J.P., Martensen, A.C., Dixo, M., Bernacci, L.C., Ribeiro, M.C., Teixeira, A.M.G., Pardini, R. 2009. Time-lag in biological responses to landscape changes in a highly dynamic Atlantic forest region. Biological Conservation 142: 1166-1177.

Muller-Landau, H.C., et al. 2006. Comparing tropical forest tree size distributions with the predictions of metabolic ecology and equilibrium models. Ecology Letters 9: 589-602.

Norden, N., Chazdon, R.L., Chao, A., Jiang, Y.-H., Vílchez-Alvarado, B. 2009. Resilience of tropical rain forests: tree community reassembly in secondary forests. Ecology Letters 12: 385-394. 
Oksanen, J., Blanchet, F.G., Kindt, R., Legendre, P., O'Hara, R.G., Simpson, G.L., Solymos, P., Stevens, M.H.H., Wagner, H. 2010. vegan: Community Ecology Package. R package version 1.17-0. URL: http://CRAN.R-project.org/package=vegan

Oliveira-Filho, A.T. \& Fontes, M.A.L. 2000. Patterns of floristic differentiation among Atlantic Forests in Southeastern Brazil and the influence of climate. Biotropica 32: 793-810.

Oliveira-Filho, A.T., Jarenkow, J.A., Rodal, M.J.N. 2006. Floristic relationships of Seasonally Dry Forests of Eastern South America based on tree species distribution patterns. In: Pennington, R.T., Lewis, G.P., Ratter, J.A. (eds). Neotropical savannas and dry forests: plant diversity, biogeography and conservation. Boca Raton: CRC Press, p.159-192.

Otto, S.P. \& Day, T. 2007. A biologist's guide to mathematical modelling in Ecology and Evolution. Princeton: Princeton University Press.

Piotto, D., Montagnini, F., Thomas, W., Ashton, M., Oliver, C. 2009. Forest recovery after swidden cultivation across a 40 -year chronosequence in the Atlantic forest of southern Bahia, Brazil. Plant Ecology 205: 261-272.

Ponçano, W.L., Carneiro, C.D.R., Bistrichi, C.A., Almeida, F.F.A., Prandini, F.L. 1981. Mapa geomorfológico do Estado de São Paulo. ITP Monografias 1.

Poorter, L., Bongers, F., vanRompaey, R.S.A.R., deKlerk, M. 1996. Regeneration of canopy tree species at five sites in West African moist forest. Forest Ecology and Management 84: 61-69.

R Development Core Team. 2009. R: A language and environment for statistical computing. Vienna, Austria: R Foundation for Statistical Computing.

Reitz, R. 1970. Nictagináceas. In: Reitz, R. (ed). Flora Ilustrada Catarinense. Itajaí: Herbário Barbosa Rodrigues.

Ribeiro, M.C., Metzger, J.P., Martensen, A.C., Ponzoni, F.J., Hirota, M.M. 2009. The Brazilian Atlantic Forest: How much is left, and how is the remaining forest distributed? Implications for conservation. Biological Conservation 142: 1141-1153.

SABESP. 1997. Programa de Conservação do Sistema Cotia. Relatório Conclusivo (tomo 3): Avaliação Ambiental. São Paulo: SABESP/Fundação Brasileira para o Desenvolvimento Sustentável.

Santos, K., Kinoshita, L.S., Santos, F.A.M. 2007. Tree species composition and similarity in semideciduous forest fragments of southeastern Brazil. Biological Conservation 135: 268277.

Schwartz, J.W., Nagel, L.M., Webster, C.R. 2005. Effects of uneven-aged management on diameter distribution and species composition of northern hardwoods in Upper Michigan. Forest Ecology and Management 211: 356-370. 
Scudeller, V.V., Martins, F.R., Shepherd, G.J. 2001. Distribution and abundance of arboreal species in the atlantic ombrophilous dense forest in Southeastern Brazil. Plant Ecology 152: 185-199.

Silva, J.M.C. \& Tabarelli, M. 2000. Tree species impoverishment and the future flora of the Atlantic forest of northeast Brazil. Nature 404: 72-74.

Souza, V.C. \& Lorenzi, H. 2005. Botânica sistemática: guia ilustrado para identificação das famílias de Angiospermas da flora brasileira, baseada em APG II. Nova Odessa: Plantarum.

Tabarelli, M., Mantovani, W., Peres, C.A. 1999. Effects of habitat fragmentation on plant guild structure in the montane Atlantic forest of southeastern Brazil. Biological Conservation 91: $119-127$

Tabarelli, M., Silva, J.M.C., Gascon, C. 2004. Forest fragmentation, synergisms and the impoverishment of neotropical forests. Biodiversity and Conservation 13: 1419-1425.

Tomimatsu, H. \& Ohara, M. 2010. Demographic response of plant populations to habitat fragmentation and temporal variability. Oecologia 162: 903-911.

Veloso, H.P., Rangel-Filho, A.L.R., Lima, J.C.A. 1991. Classificação da vegetação brasileira adaptada a um sistema universal. Rio de Janeiro: IBGE.

Wanderley, M.G.L., Shepherd, G.J., Melhem. T.S., Giulietti, A.M., Kirizawa, M., (eds). 2003. Flora Fanerogâmica do Estado de São Paulo São Paulo: Volume 3. São Paulo: FAPESP, RiMa

Wanderley, M.G.L., Shepherd, G.J., Giulietti, A.M., Melhem, T.S., Bittrich, V., Kameyama, C., (eds). 2002. Flora Fanerogâmica do Estado de São Paulo São Paulo: Volume 2. São Paulo: FAPESP, Editora HUCITEC.

Wanderley, M.G.L., Shepherd, G.J., Melhem, T.S., Martins, S.E., Kirizawa, M., Giulietti, A.M., (eds). 2005. Flora Fanerogâmica do Estado de São Paulo: Volume 4. São Paulo: FAPESP, RiMa.

Wang, X.G., Hao, Z.Q., Zhang, J., Lian, J.Y., Li, B.H., Ye, J., Yao, X.L. 2009. Tree size distributions in an old-growth temperate forest. Oikos 118: 25-36.

Weiner, J. \& Solbrig, O.T. 1984. The meaning and measurement of size hierarquies in plant populations. Oecologia 61: 334-336.

Wright, S.J., Muller-Landau, H.C., Condit, R., Hubbell, S.P. 2003. Gap-dependent recruitment, realized vital rates, and size distributions of tropical trees. Ecology 84: 3174-3185.

Zappi, D. 2003. Revision of Rudgea (Rubiaceae) in Southeastern and Southern Brazil. Kew Bulletin 58: 513-596. 
Capítulo 2

Resposta demográfica diferencial de duas espécies arbóreas aos atributos tamanho e estádio sucessional de fragmentos de Floresta Atlântica

Demographic differential response of two tree species to successional stage and size attributes of Atlantic forest fragments 


\section{Resumo}

A resposta demográfica das plantas à heterogeneidade ambiental causada por um distúrbio é uma questão chave na ecologia de populações. Nas regiões tropicais, a fragmentação e a sucessão secundária subsequente estão entre as maiores fontes de distúrbio. Em uma área de Floresta Atlântica no Planalto Paulista investigamos como a dinâmica populacional de duas espécies arbóreas que diferem no grau de tolerância à sombra responde aos atributos tamanho e estádio sucessional dos fragmentos. Testamos a hipótese de que a dinâmica populacional da espécie de sub-bosque (Rudgea jasminoides (Cham.) Müll.Arg.) será afetada positivamente pelo tamanho do fragmento, uma vez que sua estrutura e densidade populacional o foram e a espécie estaria, portanto, em risco de extinção local nos fragmentos de tamanho médio. Já para a espécie de dossel (Guapira opposita (Vell.) Reitz), testamos a hipótese de que sua dinâmica populacional será favorecida em florestas de estádio sucessional mais inicial, mas estará estável nas florestas de estádio tardio, uma vez que a espécie apresenta tolerância intermediária à sombra. Em seis fragmentos de floresta secundária de dois tamanhos (médio e grande) e em dois estádios sucessionais (inicial e tardio), marcamos e acompanhamos por dois anos todos os indivíduos pertencentes às duas espécies em parcelas de 0,5 ha. Para cada espécie, os dados dos fragmentos foram agrupados pelo fator de interesse (tamanho ou estádio sucessional), sendo aplicados modelos matriciais lineares e determinísticos e calculadas as taxas assintóticas de crescimento populacional $(\lambda)$ e as elasticidades das transições. Supreendentemente, para a espécie de subbosque a taxa assintótica de crescimento populacional indica que a população está crescendo (entre 1,2 e 1,7\% por ano) nos fragmentos médios, estando estável nos fragmentos grandes $(\lambda \approx 1)$. Embora possa parecer pequena, essa diferença faz com que o tempo estimado de duplicação da população nos fragmentos médios seja 4,5 vezes maior do que nos grandes. As taxas vitais fertilidade e crescimento foram maiores nos fragmentos médios em comparação aos grandes, assim como a elasticidade das transições. Para a espécie de dossel, as taxas assintóticas de crescimento populacional não diferiram entre os dois estádios sucessionais considerados, de modo que em ambos as populações estão estáveis $(\lambda \approx 1)$, embora tenham havido diferenças nas taxas vitais. Para ambas as espécies, as conclusões são otimistas do ponto de vista da conservação, já que a espécie de dossel demonstra estar bem adaptada a paisagens fragmentadas e a maior taxa de crescimento populacional encontrada para a espécie de sub-bosque nos fragmentos médios pode retardar ou mesmo reverter o risco de extinção local. Além disso, demonstramos que mesmo que as taxas de crescimento populacional sejam muito similares, os mecanismos demográficos responsáveis por elas podem diferir. 


\section{Introdução}

A resposta demográfica das plantas à heterogeneidade ambiental causada por um distúrbio é considerada uma questão chave na ecologia de populações (Horvitz \& Schemske 1995, Tomimatsu \& Ohara 2010). Considerando-se as espécies de ciclo de vida longo em habitats florestais, podem ser encontrados exemplos de estudos da resposta demográfica aos mais variados níveis de distúrbio, desde clareiras (Tanaka et al. 2008) até furacões (Batista et al. 1998, Pascarella \& Horvitz 1998), assim como diferentes manchas de floresta representando fases da regeneração ou sucessão secundária (Horvitz \& Schemske 1995, Martinez-Ramos et al. 1998, Valverde \& Silvertown 1998), o efeito do fogo (Souza \& Martins 2004) e ainda os efeitos da fragmentação de um modo geral (revisões em Hobbs \& Yates 2003 e Bruna et al. 2009).

A fragmentação pode alterar direta ou indiretamente os habitats florestais de diversas formas, dentre as quais a redução da área e a alteração da qualidade, principalmente em função do efeito de borda, são alguns dos efeitos mais abordados na literatura (revisões em Laurance et al. 2002 e Fahrig 2003). Embora ambos já tenham sido amplamente investigados em populações de plantas (revisão em Hobbs \& Yates 2003), poucos avanços foram feitos no sentido de se elucidar os mecanismos demográficos responsáveis pelas alterações observadas (Bruna 2003, Bruna et al. 2009).

Dentre as espécies arbóreas, o grupo das tolerantes à sombra é considerado particularmente sensível aos efeitos da fragmentação (Henle et al. 2004). Um dos efeitos diretos mais amplamente constatados é o efeito da área sobre a densidade das populações (ArroyoRodrígues et al. 2007, Metzger et al. 2009, ver também Capítulo 1), o que leva à uma perda gradual das espécies, notadamente as de sub-bosque, nos fragmentos menores (Tabarelli et al. 1999, Oliveira et al. 2008, Metzger et al. 2009). Investigar as alterações demográficas sofridas por estas espécies é crucial para o entendimento dos mecanismos ecológicos responsáveis por essas extinções (Bruna et al. 2009), logo, é necessário que os efeitos da fragmentação sejam avaliados do ponto de vista das alterações que provocam nas taxas vitais (fertilidade, crescimento e sobrevivência) (Bruna 2003, Hobbs \& Yates 2003), as quais, por sua vez, determinam o desempenho da espécie (Caswell et al. 1996, Morris \& Doak 2002).

O efeito negativo da fragmentação sobre a fertilidade das populações tem sido reportado por diversos autores como um dos responsáveis pela redução na abundância que pode levar à perda de espécies (revisão em Aguilar et al. 2006, Girão et al. 2007, Lopes et al. 2009). As alterações na capacidade reprodutiva já foram investigadas desde o ponto de vista da polinização, da produção e dispersão dos frutos, até o recrutamento de plântulas (revisão em Hobbs \& Yates 2003). Para as plantas de ciclo de vida longo, no entanto, essas alterações podem 
ser pouco relevantes para o desempenho populacional em comparação às alterações em outras taxas vitais (Bruna et al. 2009). Nestes organismos, a sobrevivência, principalmente dos indivíduos adultos, é a taxa vital que apresenta as maiores elasticidades, ou seja, o maior potencial para alterar a taxa assintótica de crescimento populacional $(\lambda)$ (Franco \& Silvertown 2004). Portanto, é de se esperar que os efeitos negativos da fragmentação sobre a sobrevivência de adultos sejam mais danosos em longo prazo para a persistência de determinada espécie do que os relativos a alterações na capacidade reprodutiva (revisão em Crone 2001).

Nesse sentido, poucos estudos buscaram uma relação entre a mortalidade de árvores adultas e a fragmentação, sendo que nenhum deles foi realizado em nível populacional (Ferreira \& Laurance 1997, Laurance et al. 1998, mas veja Brum et al. 2008). Nestes trabalhos, os autores encontraram que o efeito de borda decorrente da fragmentação é responsável pelo aumento na mortalidade dos adultos, não havendo relação direta com a área ou a idade do fragmento (Ferreira \& Laurance 1997, Laurance et al. 1998), embora fragmentos menores tenham proporcionalmente mais área de borda, e, portanto, pode-se supor que apresentem maior mortalidade de adultos em relação aos fragmentos maiores.

$\mathrm{O}$ crescimento dos indivíduos é a segunda taxa vital em importância em termos de elasticidade para as plantas de ciclo de vida longo, logo atrás da sobrevivência (Franco \& Silvertown 2004). A despeito disso, poucos testes específicos foram realizados sobre como o crescimento pode ser alterado pela fragmentação, apenas um estudo com uma espécie herbácea (Bruna et al. 2002) e um relativo a espécies arbóreas (McDonald \& Urban 2004). Os resultados são bastante dependentes da biologia da espécie, de modo que a espécie herbácea, transplantada experimentalmente, foi fortemente afetada pela fragmentação, tendo "encolhido" nos fragmentos em relação à floresta contínua, onde apresentou crescimento positivo (Bruna et al. 2002). Já no trabalho envolvendo quatro espécies arbóreas de dossel, foi realizada uma comparação entre a taxa de crescimento dos indivíduos (diâmetro $>10 \mathrm{~cm}$ ) nas bordas em relação ao interior dos fragmentos, tendo sido encontrado um efeito positivo para duas das espécies estudadas (McDonald \& Urban 2004).

Embora os efeitos da fragmentação sobre determinadas taxas vitais tenham sido abordados tanto para espécies arbóreas quanto herbáceas de ciclo de vida longo, somente para as herbáceas estes efeitos já foram investigados de forma integrada para todo o ciclo de vida de determinada planta (mas veja Brum et al. 2008). Nesse sentido, apenas três trabalhos, dois deles com o mesmo organismo, foram encontrados com o objetivo de verificar através de análises prospectivas (elasticidades) ou retrospectivas (experimentos de resposta de tabela de vida LTRE's, Caswell 2001) quais taxas vitais teriam de fato maior efeito na taxa assintótica de 
crescimento populacional (Bruna 2003, Bruna \& Oli 2005 e Tomimatsu \& Ohara 2010). Destes, a comparação da dinâmica populacional da espécie herbácea de sub-bosque Heliconia acuminata entre fragmentos florestais ( 1 e 10 ha) e áreas de floresta contínua, demonstra o quão complexa pode ser a resposta demográfica das espécies à fragmentação (Bruna \& Oli 2005). Neste trabalho, os autores encontraram um efeito negativo da fragmentação na taxa assintótica de crescimento populacional $(\lambda)$ muito similar tanto para fragmentos de 1 ha quanto de 10 ha, porém, demonstraram através de análises retrospectivas (LTRE's), que as diferenças encontradas entre os lambdas tinham causas demográficas diferentes de acordo com o tamanho do fragmento (reduções na fertilidade para fragmentos de 10 ha e reduções nas taxas reprodutivas e de crescimento nos fragmentos de 1 ha) (Bruna \& Oli 2005). Em contraste, o estudo sobre o efeito da fragmentação de outra herbácea de sub-bosque de ciclo de vida longo, Trillium camschatcense, não encontrou relação entre o lambda e o tamanho dos fragmentos, mas por meio também de análises retrospectivas demonstrou que as diferenças encontradas entre os lambdas, conforme esperado, foram principalmente devido à permanência na mesma classe e ao crescimento, a despeito de terem encontrado grande variação na fertilidade per capita entre as populações (Tomimatsu \& Ohara 2010).

Quando analisadas as respostas demográficas das espécies tolerantes à sombra de ciclo de vida longo às alterações diretas na estrutura da floresta, a abertura do dossel é a medida mais comumente empregada, sendo a resposta, no entanto, extremamente variável e dependente de características biológicas da espécie, como o hábito (Horvitz \& Schemske 1995, Batista et al. 1998, Martinez-Ramos et al. 1998, Pascarella \& Horvitz 1998, Valverde \& Silvertown 1998, são alguns exemplos).

Nesse sentido, os dois estudos encontrados que enfocaram a resposta de plantas arborescentes (uma arbórea e uma palmeira) têm em comum o fato de que não foram detectadas alterações na taxa assintótica de crescimento populacional $(\lambda)$. No estudo referente à espécie arbórea, a dinâmica populacional de Fagus grandifolia, uma árvore de dossel tolerante à sombra que ocorre em florestas sujeitas à furacão, foi comparada em um período pré e pós-furacão, não tendo sido encontradas diferenças na sua densidade, estrutura, ou taxa assintótica de crescimento populacional $(\lambda)$, somente nos padrões de elasticidade (Batista et al. 1998). Assim, no período pré-furacão (dossel mais fechado), a sobrevivência concentrou 83,3\% da elasticidade calculada para os elementos da matriz de transição, sendo $14,4 \%$ referentes a crescimento e 2,3\% para a fecundidade, enquanto que no período pós-furacão (dossel mais aberto), a elasticidade das transições foi menor para a sobrevivência $(70,7 \%)$ e maior para o crescimento $(24,9 \%)$ e para a fecundidade (4,4\%) (Batista et al. 1998). Portanto, mesmo que os valores de lambda não tenham 
apresentado diferenças entre os períodos, a análise dos padrões de elasticidade demonstra que a contribuição de cada tipo de transição com maior potencial para alterar a taxa assintótica de crescimento populacional é diferente, havendo maior contribuição do crescimento e da fecundidade em detrimento da sobrevivência no período em que o dossel esteve mais aberto (pós furacão) (Batista et al. 1998). Já no estudo referente à palmeira tolerante à sombra Astrocaryum mexicanum, cuja dinâmica populacional foi comparada em áreas mais iniciais da sucessão (isto é, com menos de 30 anos) e áreas maduras, as taxas vitais crescimento e fertilidade foram mais altas nas áreas mais iniciais, enquanto a sobrevivência foi menor, embora essas diferenças não tenham se refletido na taxa assintótica de crescimento populacional (Martinez-Ramos et al. 1998).

Por outro lado, alguns estudos que relacionaram a dinâmica de populações de espécies herbáceas e arbustivas, igualmente de ciclo de vida longo e tolerantes à sombra, a diferentes ambientes representando a sucessão de habitats após determinado distúrbio (clareira, sucessão secundária ou furacão), encontraram uma relação positiva entre a taxa assintótica de crescimento populacional $(\lambda)$ e a porcentagem de abertura do dossel, e também variações no padrões de elasticidade conforme o ambiente considerado (Horvitz \& Schemske 1995, Pascarella \& Horvitz 1998, Valverde \& Silvertown 1998). De uma forma geral, as alterações nos padrões de elasticidade observadas nestes estudos foram no sentido de no ambiente de dossel mais fechado, no qual a taxa de crescimento é menor (podendo ser nula ou negativa), a permanência nas classes adultas apresentar as maiores elasticidades, enquanto que no ambiente com dossel mais aberto e, portanto, menor limitação ao crescimento, as elasticidades das transições referentes ao crescimento e à fecundidade terem sido comparativamente maiores (Horvitz \& Schemske 1995, Pascarella \& Horvitz 1998, Valverde \& Silvertown 1998).

Neste trabalho, propomos uma abordagem inédita, pois investigaremos a resposta demográfica de espécies arbóreas tolerantes à sombra à heterogeneidade ambiental causada por distúrbios decorrentes da fragmentação (tamanho do fragmento) e da sucessão secundária (estádio sucessional do fragmento) na Floresta Atlântica. Baseados no conhecimento gerado previamente sobre a densidade e estrutura de duas espécies arbóreas, Rudgea jasminoides e Guapira opposita, em fragmentos de floresta secundária no Planalto Atlântico Paulista (Capítulo 1), testaremos as seguintes hipóteses sobre a sua dinâmica populacional: 1. R. jasminoides, espécie de umbrófila de sub-bosque, terá sua dinâmica populacional afetada positivamente pelo tamanho do fragmento, uma vez que a espécie também apresentou uma resposta positiva em termos de densidade e estrutura populacionais a esse fator; 2. G. opposita, espécie de tolerância intermediária à sombra pertencente ao dossel, terá sua dinâmica populacional favorecida em 
florestas de estádio sucessional mais inicial, mas estará estável nas florestas de estádio tardio. A espécie apresentou uma resposta gradual da estrutura populacional ao estádio sucessional da floresta, mas, por ser de tolerância intermediária à sombra, espera-se que sua taxa de crescimento populacional seja maior nos fragmentos de estádio inicial em relação aos tardios. Mais precisamente, elaboramos as seguintes previsões (quadro abaixo) para os parâmetros demográficos de cada uma das espécies em cada situação:

\begin{tabular}{|c|c|c|c|c|}
\hline & \multicolumn{2}{|c|}{ Rudgea } & \multicolumn{2}{|c|}{ Guapira } \\
\hline & $\begin{array}{l}\text { Fragmentos } \\
\text { médios }\end{array}$ & $\begin{array}{l}\text { Fragmentos } \\
\text { grandes }\end{array}$ & $\begin{array}{l}\text { Fragmentos } \\
\text { iniciais }\end{array}$ & $\begin{array}{l}\text { Fragmentos } \\
\text { tardios }\end{array}$ \\
\hline Taxa assintótica de crescimento populacional $(\lambda)$ & $\lambda<1$ & $\lambda \approx 1$ & $\lambda>1$ & $\lambda \approx 1$ \\
\hline Taxas vitais: & & & & \\
\hline sobrevivência & menor & maior & menor & maior \\
\hline crescimento & maior & menor & maior & menor \\
\hline fertilidade & menor & maior & maior & menor \\
\hline \multicolumn{5}{|l|}{ Importância proporcional da elasticidade*: } \\
\hline permanência & menor & maior & menor & maior \\
\hline crescimento & maior & menor & maior & menor \\
\hline fertilidade & menor & maior & maior & menor \\
\hline
\end{tabular}

* elasticidade referente aos elementos da matriz

\section{Material e Métodos}

\section{Área e espécies estudadas}

O presente trabalho foi conduzido em fragmentos florestais secundários situados no Planalto Atlântico Paulista. O clima na região pode ser do tipo $\mathrm{Cfa}$ ou $\mathrm{Cfb}$, de acordo com a altitude e apresenta uma precipitação média anual de 1.300mm (SABESP 1997). As florestas originais da região são classificadas como de transição entre a Floresta Ombrófila Densa e a Floresta Estacional Semidecidual (Veloso et al. 1991).

Foram selecionados seis fragmentos de propriedade particular entre as coordenadas $23^{\circ} 49^{\prime}$ a $24^{\circ} 02^{\prime}$ S e $47^{\circ} 22^{\prime}$ a $47^{\circ} 42^{\prime} \mathrm{W}$, mais precisamente nos municípios de Piedade e Tapiraí, situados entre 800 e 1.100 m.n.m (Ponçano et al. 1981). Com relação ao tamanho, estes fragmentos podem ser agrupados em duas categorias, cada uma com três fragmentos: fragmentos médios (Bicudo - 26,7 ha, Osasco - 39,9 ha e Jeanzão - 41,3 ha) e grandes (Médico - 85,3 ha, Teomar - 97,6 ha e Odorico - 167,1 ha). Em termos de estádio sucessional, estes fragmentos também podem ser classificados em duas categorias amplas: o estádio inicial, ao qual pertencem quatro fragmentos (Jeanzão, Osasco, Médico e Odorico) e o tardio, com dois fragmentos (Bicudo 
e Teomar). Ambas as classificações têm valor apenas comparativo, mais detalhes sobre a classificação dos fragmentos, assim como da área de estudo, podem ser obtidos no Capítulo 1.

As duas espécies arbóreas estudadas são muito comuns na Floresta Atlântica (Scudeller et al. 2001), diferindo no grau de tolerância à sombra e no estrato que ocupam: Guapira opposita (Vell.) Reitz (Nyctaginaceae), de tolerância intermediária à sombra (Gandolfi 2000), ocupa o dossel nas florestas secundárias do Planalto Atlântico Paulista, enquanto Rudgea jasminoides (Cham.) Müll.Arg. (Rubiaceae), espécie umbrófila, ocupa o sub-bosque nestas florestas (Catharino et al. 2006) (para detalhes ver Capítulo 1). As espécies serão denominadas apenas pelo nome do gênero daqui em diante.

\section{Dados demográficos}

No interior de cada fragmento florestal foi instalada uma parcela permanente $(0,5$ ha, exceto em um dos fragmentos, no qual a parcela foi de 0,45 ha), na qual foram identificados, numerados e mapeados todos os indivíduos pertencentes às duas espécies, com altura igual ou superior a $100 \mathrm{~cm}$. Destes, foram medidos o diâmetro à altura do peito (DAP - a 1,3 $\mathrm{m}$ do solo) ou à altura do solo (DAS - para plantas com DAP $\leq 10 \mathrm{~mm}$ ), a altura e registrada a presença de estruturas reprodutivas. Para todos os indivíduos, o local da medida foi marcado com tinta spray, a fim de assegurar que a medida fosse realizada no mesmo ponto no censo seguinte. Além disso, foi padronizada a tomada da maior medida de diâmetro, uma vez que a secção transversal dos caules nem sempre é cilíndrica. Dentro de cada uma destas parcelas, foram distribuídas sistematicamente 30 parcelas de $4 \mathrm{~m}^{2}$ para o acompanhamento das plântulas (indivíduos com altura entre 10 e $100 \mathrm{~cm}$ ), as quais foram igualmente numeradas e medidas (DAS e altura). Todas as plantas foram medidas em $2007\left(\mathrm{t}_{\text {zero }}\right), 2008\left(\mathrm{t}_{1}\right)$ e $2009\left(\mathrm{t}_{2}\right)$ no mesmo período do ano (entre janeiro e julho). Nos censos de 2008 e 2009 foram registradas as plantas mortas e as recrutadas, de acordo com os critérios de inclusão. O período do censo corresponde ao período de floração e início da frutificação de Rudgea, de modo que foi possível, concomitantemente aos censos, registrar quais indivíduos estavam reprodutivos. Já para Guapira, a floração normalmente inicia-se em meados de setembro (Observação pessoal), não coincidindo, portanto, com o período do censo. Em função disso, foi necessário vistoriar todos os indivíduos de Guapira nos meses de outubro de 2007 e de 2008 para verificar a presença de estruturas reprodutivas.

\section{Construção das matrizes de transição}

Utilizamos um modelo matricial linear determinístico com matrizes de transição baseadas em tamanho (Caswell 2001). Os modelos matriciais projetam a dinâmica populacional através de álgebra matricial, basedos na equação $\mathrm{n}_{(\mathrm{t}+1)}=\mathbf{A} \mathrm{n}_{(\mathrm{t})}$, em que $\mathbf{A}$ é a matriz de transição, 
composta por elementos $a_{i j}$, que descrevem as probabilidades de transição dos indivíduos de determinada classe (de $j$ para $i$ ), e $n$ é o vetor coluna, que descreve o número de indivíduos nas classes de tamanho no tempo $t$ (Caswell 2001). Elementos ao longo da diagonal representam as probabilidades de permanência na mesma classe, enquanto os elementos abaixo da diagonal representam as probabilidades de crescimento (progressão para as classes maiores) e, os acima, as probabilidades de retrogressão (retrocesso para as classes menores).

Para Rudgea, a matriz de transição foi construída a partir de 5 classes de tamanho, sendo igualmente as duas primeiras baseadas na altura (plântulas 1 e 2), a terceira classe baseada no diâmetro à altura do solo (jovem) e as duas últimas no diâmetro à altura do peito das plantas (subadultos e adultos) (Tabela 1). Para Guapira, a matriz de transição foi construída a partir de seis classes de tamanho, sendo igualmente as duas primeiras baseadas na altura (plântulas 1 e 2), as duas seguintes no diâmetro à altura do solo (jovens 1 e 2) e duas últimas no diâmetro à altura do peito das plantas (subadultos e adultos) (Tabela 2). No caso de indivíduos que apresentaram caules múltiplos (mais freqüentes em Rudgea do que em Guapira), a classe de tamanho foi atribuída ao tamanho total do indivíduo, obtido a partir da soma das áreas basais de cada um dos caules, posteriormente transformada em um diâmetro final. As delimitações das classes foram baseadas na estrutura de tamanhos de cada uma das populações, analisadas a partir de histogramas. Para ambas as espécies, os adultos foram definidos com base no tamanho mínimo reprodutivo observado em campo, o qual no caso de Rudgea foi diferente para os fragmentos médios e grandes (Tabela 1), enquanto que para Guapira este não diferiu entre os estádios inicial e tardio dos fragmentos florestais (Tabela 2).

Tabela 1. Classes de tamanho utilizadas para a análise da dinâmica populacional de Rudgea em fragmentos de floresta secundária no Planalto Atlântico Paulista, sua descrição $(\mathrm{A}=$ altura, $\mathrm{DAS}=$ diâmetro à altura do solo, DAP $=$ diâmetro à altura do peito, $\mathrm{DAP}_{\text {mín. reprod. fragmentos médios }}=18,9 \mathrm{~mm}$ e $\mathrm{DAP}_{\text {mín. reprod. }}$ fragmentos grandes $=12,3$ $\mathrm{mm}$ ), o número inicial de indivíduos (Ni) e a densidade (em ind. $\mathrm{m}^{-2}$ para as classes definidas por altura, e em ind.ha ${ }^{-1}$, para as demais).

\begin{tabular}{|c|c|c|c|c|c|}
\hline \multirow[t]{2}{*}{ Classe } & \multirow[t]{2}{*}{ Descrição } & \multicolumn{2}{|c|}{ Fragmentos médios } & \multicolumn{2}{|c|}{ Fragmentos grandes } \\
\hline & & $\mathrm{Ni}$ & Densidade & $\mathrm{Ni}$ & Densidade \\
\hline 1 (plântula 1) & $\mathrm{A}<15 \mathrm{~cm}$ & 117 & 0,33 & 69 & 0,19 \\
\hline 2 (plântula 2) & $\mathrm{A} \geq 15 \mathrm{e}<100 \mathrm{~cm}$ & 186 & 0,52 & 91 & 0,25 \\
\hline 3 (jovem) & $\operatorname{DAS}(\mathrm{A} \geq 100 \mathrm{~cm}$ e $\mathrm{DAP}<10 \mathrm{~mm})$ & 125 & 83,33 & 279 & 192,42 \\
\hline 4 (subadulto) & $\mathrm{DAP}<\mathrm{DAP}_{\text {mín. reprod. }}$ & 22 & 14,67 & 44 & 30,35 \\
\hline 5 (adulto) & $\mathrm{DAP} \geq \mathrm{DAP}_{\text {mín. reprod. }}$ & 162 & 108,00 & 650 & 448,28 \\
\hline
\end{tabular}

Para obtermos uma boa parametrização da matriz, combinamos as populações de cada espécie por fator (tamanho do fragmento para Rudgea e estádio sucessional para Guapira) em uma única matriz de transição, cujo intervalo considerado foi de dois anos, uma vez que as taxas 
de crescimento são lentas, o que é típico de espécies arbóreas tolerantes à sombra (Zuidema \& Zagt 2000). Esses procedimentos são recomendados por Zuidema \& Zagt (2000) para que se obtenha melhores estimativas das taxas vitais e são amplamente empregados em trabalhos desta natureza (Chien et al. 2008, Farrington et al. 2009, por exemplo). Como estamos interessados no efeito da variabilidade espacial, ou seja, em comparar a dinâmica das espécies em diferentes fragmentos florestais, e não na variabilidade temporal, acreditamos que essa é a solução com melhor custo-benefício, pois melhora a parametrização das taxas vitais. No entanto, para nos certificarmos de que não estávamos juntando anos muito discrepantes, realizamos análises preliminares considerando as transições anuais. Além disso, os resultados apresentados, tais como a taxa assintótica de crescimento populacional e as taxas vitais, foram convertidos para uma base anual para facilitar a interpretação.

Tabela 2. Classes de tamanho utilizadas para a análise da dinâmica populacional de Guapira em fragmentos de floresta secundária no Planalto Atlântico Paulista, sua descrição $(\mathrm{A}=$ altura, $\mathrm{DAS}=$ diâmetro à altura do solo, DAP = diâmetro à altura do peito), o número inicial de indivíduos $(\mathrm{Ni})$ e a densidade (em ind. $\mathrm{m}^{-2}$ para as classes definidas por altura e em ind.ha ${ }^{-1}$ para as demais).

\begin{tabular}{|c|c|c|c|c|c|}
\hline \multirow[t]{2}{*}{ Classe } & \multirow[t]{2}{*}{ Descrição } & \multicolumn{2}{|c|}{ Fragmentos de floresta inicial } & \multicolumn{2}{|c|}{ Fragmentos de floresta tardia } \\
\hline & & $\mathrm{Ni}$ & Densidade & $\mathrm{Ni}$ & Densidade \\
\hline 1 (plântula 1) & $\mathrm{A}<20 \mathrm{~cm}$ & 97 & 0,20 & 54 & 0,22 \\
\hline 2 (plântula 2) & $\mathrm{A} \geq 20 \mathrm{e}<100 \mathrm{~cm}$ & 37 & 0,08 & 40 & 0,17 \\
\hline 3 (jovem 1) & $\begin{array}{l}\text { DAS }<20 \mathrm{~mm} \\
\quad(A \geq 100 \mathrm{~cm} \text { e DAP }<10 \mathrm{~mm})\end{array}$ & 302 & 151,00 & 338 & 355,79 \\
\hline 4 (jovem 2) & $\begin{array}{l}\text { DAS } \geq 20 \mathrm{~mm} \\
\quad(A \geq 100 \mathrm{~cm} \text { e DAP }<10 \mathrm{~mm})\end{array}$ & 95 & 47,50 & 108 & 113,68 \\
\hline 5 (subadulto) & $\mathrm{DAP} \geq 10 \mathrm{e}<110 \mathrm{~mm}$ & 619 & 309,50 & 310 & 326,32 \\
\hline 6 (adulto) & $\mathrm{DAP} \geq 110$ & 127 & 63,50 & 55 & 57,89 \\
\hline
\end{tabular}

Para a construção de cada matriz de transição, calculamos as taxas vitais específicas de cada classe de tamanho para cada espécie por nível do fator considerado, de modo que foram calculadas duas matrizes de transição por espécie. É importante ressaltar que as taxas vitais são as unidades básicas das análises demográficas e não os elementos $\left(\mathrm{a}_{\mathrm{ij}}\right)$ da matriz (Morris \& Doak 2002). Assim, a combinação adequada das taxas vitais (sobrevivência $-\sigma$, crescimento $-\gamma \mathrm{e}$ fertilidade $-\mathrm{F}_{\mathrm{i}}$ ) gera os valores referentes às probabilidades de transição que compõem a matriz. Dessa forma, a probabilidade de crescimento $\left(\mathrm{C}_{\mathrm{ij}}\right)$ está condicionada à probabilidade de sobrevivência $\left(\sigma_{\mathrm{j}}\right)$; a probabilidade de permanência $\left(\mathrm{P}_{\mathrm{ij}}\right)$ está condicionada às probabilidades de sobrevivência $\left(\sigma_{\mathrm{j}}\right)$, de não-crescimento $\left(1-\gamma_{\mathrm{j}}\right)$ e de não-retrogressão $\left(1-\mathrm{R}_{\mathrm{j}}\right)$; a probabilidade de retrogressão $\left(R_{i j}\right)$ está condicionada às probabilidades de sobrevivência $\left(\sigma_{j}\right)$ e de retrogressão $\left(R_{\mathrm{j}}\right)$, esta por sua vez calculada tendo como base o número de indivíduos que não cresceram (indivíduos que retrogrediram, mais os indivíduos que permaneceram na mesma classe). Como a 
base do modelo é a classificação dos indivíduos por tamanho, é possível que haja retrogressão, e esta foi mais frequente nas primeiras classes para ambas as espécies, ou seja, plântulas estruturadas por altura, nas quais danos por quebra são comuns. Além das classes de plântulas, retrogressões de classe ocorreram também nas classes de subadultos e adultos devido à perda de algum caule (plantas com caules múltiplos).

O cálculo das taxas vitais empregadas para compor a matriz, no entanto, não foi baseado nas probabilidades de transição e sim nos padrões gerais de crescimento e mortalidade tamanhodependentes, como recomendam Zuidema \& Zagt (2000). Assim, as probabilidades de crescimento e de retrogressão dos indivíduos de cada classe foram baseadas na taxa média de crescimento de cada classe de tamanho (Poorter et al. 2005). Já a sobrevivência foi calculada a partir de uma regressão logística para cada um dos tipos de medida empregados no censo (altura, DAS e DAP) (Morris \& Doak 2002). Para os casos em que nenhum evento de morte foi registrado em determinada medida, empregamos a solução de Cruz-Rodriguez et al. (2009) para estimar a sobrevivência, a qual se baseou no tamanho máximo atingido pelos indivíduos da espécie em questão e a sua taxa de crescimento.

Os valores de fertilidade, correspondentes aos elementos da primeira e/ou segunda linha da matriz na classe adulta, não são probabilidades. Neste caso, eles representam a contribuição média, em números de plântulas, de cada indivíduo da classe adulta para a classe de plântula 1 e/ou 2, no tempo seguinte $(\mathrm{t}+1)$. Para o cálculo da fertilidade, assumimos a premissa de que todos os indivíduos reprodutivos produziram em média o mesmo número de plântulas, independentemente do seu tamanho. Embora não ideal, esta premissa é frequentemente necessária em estudos de espécies arbóreas tropicais (Chien et al. 2008). O cálculo foi realizado assumindo-se uma reprodução anônima, ou seja, quando não é possível ligar diretamente a prole aos indivíduos genitores (Caswell 2001).

\section{Análises das matrizes de transição}

Para cada uma das matrizes, foram calculadas a taxa assintótica de crescimento populacional $(\lambda)$, a distribuição tamanho-estável (w) e o valor reprodutivo (v). Considerando-se a dinâmica assintótica, estes valores são calculados por álgebra matricial, onde $\lambda$ é o autovalor dominante da matriz A e, associados a ele, os autovetores dominantes direito e esquerdo proporcionais, respectivamente, à distribuição tamanho-estável (w) e ao valor reprodutivo (v) (Caswell 2001). A taxa assintótica de crescimento populacional $(\lambda)$ define se a população está crescendo $(\lambda>1)$, decrescendo $(\lambda<1)$ ou estável no tempo $(\lambda=1)$. Para cada valor de lambda, foram calculados os intervalos de confiança de $95 \%$ através do procedimento de bootstrapping (subamostragens do conjunto de dados com reposição a cada repetição, neste caso 1000 
repetições), sendo os valores de lambda considerados diferentes quando não houve sobreposição entre seus intervalos (Caswell 2001). Para a definição dos limites inferior e superior do intervalo de $95 \%$ foi utilizada a correção proposta por Caswell (2001). A distribuição tamanho-estável (w) representa a distribuição proporcional dos indivíduos na população, nas classes de tamanho, quando for atingida a dinâmica assintótica. A distribuição tamanho-estável teve sua escala alterada para porcentagem para facilitar sua interpretação. Calculamos uma medida de distância entre a distribuição tamanho-estável e a proporção atual dos indivíduos por classe de tamanho (Keyfitz's $\Delta$ ) (Caswell 2001), o que nos dá uma indicação da relevância da dinâmica assintótica para aquela população (Horvitz \& Schemske 1995). O valor reprodutivo (v) representa a contribuição relativa que é esperada de um indivíduo de determinada classe de tamanho para o crescimento populacional futuro (Caswell 2001, Morris \& Doak 2002), padronizada pela contribuição da primeira classe.

Para cada espécie, também foram aplicadas análises de perturbação prospectivas, as quais medem mudanças proporcionais no lambda de acordo com mudanças proporcionais nos elementos da matriz de transição (elasticidades) e, portanto, indicam qual elemento da matriz, se alterado, provocaria maiores mudanças no lambda (Kroon et al. 2000, Caswell 2001, Zuidema \& Franco 2001). As análises foram realizadas programa R versão 2.10.1 (R Development Core Team 2009) com os códigos escritos especificamente para tal finalidade, disponíveis em: http://ecologia.ib.usp.br/labtrop/doku.php?id=labtrop:mat_apoio.

\section{Resultados}

\section{Rudgea em fragmentos médios e grandes}

De uma forma geral, a sobrevivência dos indivíduos de Rudgea foi superior a 90\%, tendo apresentado o mesmo padrão de variação para as diferentes classes independentemente do tamanho do fragmento (Tabela 3), contrariamente ao esperado. Nos fragmentos médios, nenhum evento de morte foi registrado no período de acompanhamento para as classes de subadulto e adulto, o mesmo tendo ocorrido para a classe de subadulto nos fragmentos grandes, sendo a parametrização da sobrevivência realizada conforme consta em 'Material e Métodos'. Conforme esperávamos, o crescimento foi maior nos fragmentos médios em relação aos grandes, quando consideradas as classes de plântula 2 (2,6 vezes maior), jovem ( 3 vezes maior) e subadulto (1,5 vezes maior) (Tabela 3). A fertilidade, no entanto, foi quase cinco vezes maior nos fragmentos de tamanho médio do que nos fragmentos de tamanho grande, contrariando nossas previsões iniciais (Tabela 3). 
Tabela 3. Taxas vitais calculadas por classe de tamanho para a análise da dinâmica populacional de Rudgea em fragmentos de floresta secundária no Planalto Atlântico Paulista. A sobrevivência e o crescimento são probabilidades $(\%)$, enquanto a fertilidade representa a contribuição de cada indivíduo adulto para as classes de plântula na transição seguinte.

\begin{tabular}{|c|c|c|c|c|c|c|}
\hline \multirow{2}{*}{ Rudgea } & \multicolumn{3}{|c|}{ Fragmentos de tamanho médio } & \multicolumn{3}{|c|}{ Fragmentos de tamanho grande } \\
\hline & Sobrevivência & Crescimento & Fertilidade & Sobrevivência & Crescimento & Fertilidade \\
\hline \multicolumn{7}{|l|}{ Classe } \\
\hline 1 (plântula 1) & 0,9111 & 0,1193 & 0 & 0,8981 & 0,0938 & 0 \\
\hline 2 (plântula 2) & 0,9528 & 0,0382 & 0 & 0,9909 & 0,0145 & 0 \\
\hline 3 (jovem) & 0,9879 & 0,0709 & 0 & 0,9964 & 0,0228 & 0 \\
\hline 4 (subadulto) & 0,9997 & 0,1005 & 0 & 0,9939 & 0,0641 & 0 \\
\hline 5 (adulto) & 0,9931 & 0 & 0,1235 & 0,9981 & 0 & 0,0269 \\
\hline
\end{tabular}

Quanto às taxas assintóticas de crescimento populacional, surpreendentemente, encontramos um padrão inverso ao esperado, de modo que o lambda nos fragmentos médios foi maior do que o nos fragmentos grandes. Assim, para os fragmentos de tamanho médio, o lambda calculado foi de 1,018 (IC 95\% = 1,012 - 1,023), enquanto para os fragmentos grandes o lambda foi de 1,004 (IC $95 \%=1,000-1,006)$. Portanto, subtraindo-se os valores inferiores e superiores do intervalo de confiança para ambos os tamanhos de fragmento, temos um lambda no mínimo 1,2\% e no máximo 1,7\% superior nos fragmentos médios em relação aos grandes. Embora possa parecer pequena, essa diferença faz com que o tempo estimado de duplicação da população nos fragmentos médios seja 4,5 vezes maior do que nos grandes.

As matrizes de transição para ambos os tamanhos de floresta são apresentadas na Tabela 4. A distância entre a proporção de indivíduos em cada classe de tamanho (P) e a distribuição tamanho-estável (DTE) (Tabela 4) foi de 0,15 para os fragmentos médios e 0,22 para os fragmentos grandes, valores que podem ser considerados baixos e que portanto indicam que as análises da dinâmica assintótica são relevantes.

A importância proporcional da elasticidade referente à permanência na mesma classe, conforme previmos, foi menor nos fragmentos médios $(94,5 \%)$ do que nos grandes $(98,3 \%)$, e, de forma compensatória, a elasticidade referente ao crescimento apresentou o padrão contrário, sendo três vezes maior nos fragmentos médios $(4,1 \%)$ do que nos grandes $(1,4 \%)$. Já a elasticidade da fertilidade, contrariamente ao esperado, foi três vezes maior nos fragmentos médios $(1,2 \%)$ do que nos grandes $(0,4 \%)$. Quando analisada a distribuição dos valores de elasticidade da permanência nas classes de tamanho, o padrão é praticamente o mesmo para os dois tamanhos de floresta, havendo destaque para a permanência na classe de adulto, que ficou em torno de $60 \%$ (Figura 1 ). 
Tabela 4. Matrizes de transição para as populações de Rudgea acompanhadas em fragmentos florestais secundários de tamanho médio $(\lambda=1,018$; IC $95 \%=1,012-1,023)$ e grande $(\lambda=1,004$; IC $95 \%=1,000-1,006)$ no Planalto Atlântico Paulista no período de 2007 a 2009, conforme as classes de tamanho definidas na Tabela 1 (pl $1=$ plântula 1, pl 2 = plântula 2 , jov = jovem, subad = subadulto, ad = adulto), $\mathrm{N}=$ tamanho amostral da classe, $\mathrm{P}=$ proporção de indivíduos amostrados em cada classe em relação ao $\mathrm{N}_{\text {total }}$, DTE = distribuição tamanho-estável $(\%)$, VR = valor reprodutivo.

\begin{tabular}{|c|c|c|c|c|c|c|c|c|c|c|}
\hline \multicolumn{6}{|c|}{ Fragmentos de tamanho médio } & \multicolumn{5}{|c|}{ Fragmentos de tamanho grande } \\
\hline & pl 1 & $\mathrm{pl} 2$ & jov & subad & $\mathrm{ad}$ & pl 1 & pl 2 & jov & subad & $\mathrm{ad}$ \\
\hline pl 1 & 0.802 & 0.001 & 0 & 0 & 0.074 & 0.814 & 0.004 & 0 & 0 & 0.017 \\
\hline pl 2 & 0.109 & 0.915 & 0.003 & 0 & 0.049 & 0.084 & 0.973 & 0 & 0 & 0.010 \\
\hline jov & 0 & 0.036 & 0.915 & 0 & 0 & 0 & 0.014 & 0.973 & 0 & 0 \\
\hline subad & 0 & 0 & 0.070 & 0.900 & 0 & 0 & 0 & 0.023 & 0.930 & 0 \\
\hline ad & 0 & 0 & 0 & 0.100 & 0.993 & 0 & 0 & 0 & 0.064 & 0.998 \\
\hline $\mathrm{N}$ & 117 & 186 & 125 & 22 & 162 & 69 & 91 & 279 & 44 & 650 \\
\hline $\mathrm{P}$ & 0,19 & 0,30 & 0,20 & 0,04 & 0,26 & 0,06 & 0,08 & 0,25 & 0,04 & 0,57 \\
\hline DTE & 0,13 & 0,32 & 0,11 & 0,07 & 0,37 & 0,05 & 0,29 & 0,14 & 0,04 & 0,48 \\
\hline VR & 1,0 & 2,0 & 5,6 & 8,1 & 9,6 & 1,0 & 2,3 & 4,6 & 6,1 & 7,0 \\
\hline
\end{tabular}

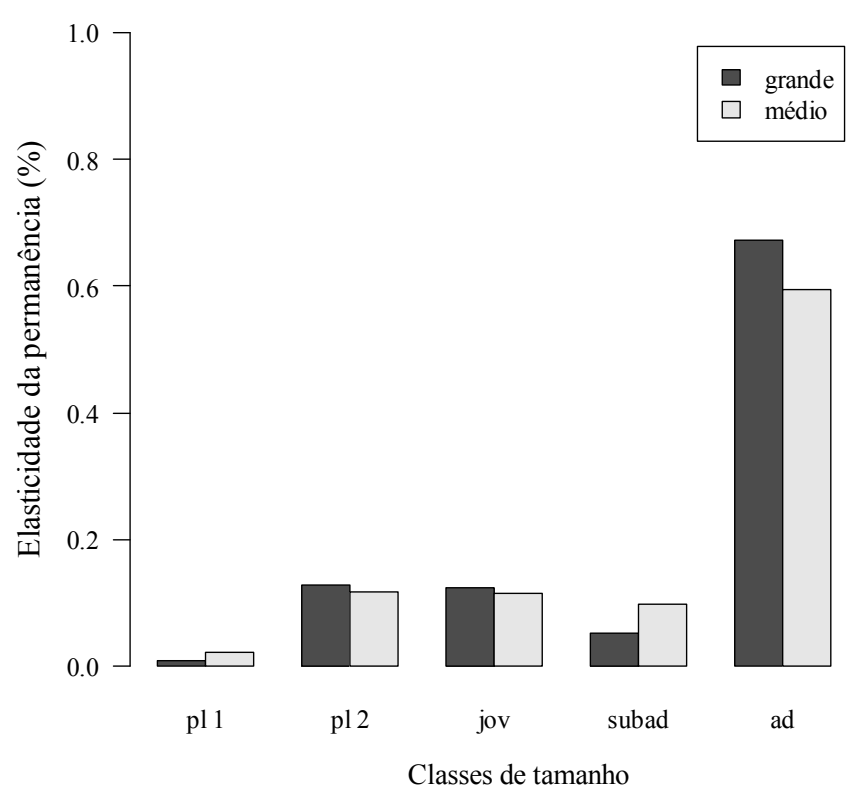

Figura 1. Elasticidades referentes à permanência por classe de tamanho para as populações de Rudgea estudadas nos fragmentos de floresta secundária de dois tamanhos (médio e grande) no Planalto Atlântico Paulista.

\section{Guapira em fragmentos de estádio inicial e tardio}

Em termos gerais, as taxas vitais calculadas para Guapira diferiram muito pouco entre os fragmentos de floresta inicial e tardia, contrariamente ao esperado (Tabela 5). A sobrevivência foi superior a $90 \%$ em ambas as florestas, sendo menor para as fases de plântula nos fragmentos de floresta inicial em relação à tardia (Tabela 5). Nenhum indivíduo adulto morreu durante o tempo de acompanhamento, em ambos os estádios sucessionais. Dessa forma, assim como para 
Rudgea, a parametrização da sobrevivência dos adultos foi realizada conforme consta em 'Material e Métodos'. O maior crescimento esperado para as florestas iniciais foi constatado em magnitude muito pequena apenas para as classes de plântula 1 e jovem 1 (Tabela 5). Contrariamente ao esperado, os indivíduos das florestas tardias apresentaram o dobro da fecundidade registrada para os indivíduos das florestas iniciais (Tabela 5).

Tabela 5. Taxas vitais calculadas por classe de tamanho para a análise da dinâmica populacional de Guapira em fragmentos de floresta secundária no Planalto Atlântico Paulista. A sobrevivência e o crescimento são probabilidades $(\%)$, enquanto a fertilidade representa a contribuição de cada indivíduo adulto para as classes de plântula na transição seguinte.

\begin{tabular}{|c|c|c|c|c|c|c|}
\hline \multirow{2}{*}{ Guapira } & \multicolumn{3}{|c|}{ Fragmentos de floresta inicial } & \multicolumn{3}{|c|}{ Fragmentos de floresta tardia } \\
\hline & Sobrevivência & Crescimento & Fertilidade & Sobrevivência & Crescimento & Fertilidade \\
\hline Classe & & & & & & \\
\hline 1 (plântula 1) & 0,9019 & 0,0548 & 0 & 0,9540 & 0,0379 & 0 \\
\hline 2 (plântula 2) & 0,9599 & 0,0214 & 0 & 0,9855 & 0,0214 & 0 \\
\hline 3 (jovem 1 ) & 0,9879 & 0,0505 & 0 & 0,9879 & 0,0403 & 0 \\
\hline 4 (jovem 2) & 0,9907 & 0,0245 & 0 & 0,9821 & 0,0222 & 0 \\
\hline 5 (subadulto) & 0,9976 & 0,0090 & 0 & 0,9987 & 0,0087 & 0 \\
\hline 6 (adulto) & 0,999999 & 0 & 0,1102 & 0,9981 & 0 & 0,2273 \\
\hline
\end{tabular}

No entanto, novamente em contraposição às nossas previsões, estas diferenças encontradas nas taxas vitais não se refletiram nas taxas assintóticas de crescimento populacional ( $\lambda$ ) calculadas para as populações de Guapira em ambos os estádios sucessionais, de modo que o lambda foi muito próximo de 1. Para os fragmentos de floresta inicial, o lambda calculado foi de 1,004 (IC 95\%: 1,002 - 1,007) e para os fragmentos de floresta tardia foi de 1,005 (IC 95\%: $1,000-1,010)$. As semelhanças entre as probabilidades de transição calculadas para ambos os estádios sucessionais evidenciam que os valores de lambda seriam muito próximos (Tabela 6). A distância entre a estrutura populacional observada (proporção de indivíduos em cada classe de tamanho - P) e a estrutura prevista pelo modelo (distribuição tamanho estável - DTE) (Tabela 6) foi de 0,41 para os fragmentos de floresta inicial e de 0,52 para os fragmentos de floresta tardia.

Com relação às elasticidades das transições, não houve diferença entre os estádios sucessionais em termos do padrão geral, de modo que crescimento e fertilidade apresentaram valores extremamente baixos, todos menores do que $2 \%$. A permanência na mesma classe teve os maiores valores de elasticidade, somando $97,6 \%$ para as florestas iniciais e $98,4 \%$ para as florestas tardias. Ao decompor essas elasticidades entre as diferentes classes de tamanho, em ambos os estádios os maiores valores estão na classe de adulto, embora a concentração seja maior nos fragmentos de floresta inicial do que nos tardios (Figura 2). 
Tabela 6. Matrizes de transição para as populações de Guapira acompanhadas em fragmentos de floresta secundária inicial e tardia no Planalto Atlântico Paulista no período de 2007 a 2009 ( $\lambda \approx 1$ para ambos os estádios sucessionais), conforme as classes de tamanho definidas na Tabela 1 (pl 1 = plântula 1 , pl 2 = plântula 2 , jov $1=$ jovem 1 , jov $2=$ jovem 2, subad = subadulto, ad = adulto). $\mathrm{N}=$ tamanho amostral da classe, $\mathrm{P}=$ proporção de indivíduos amostrados em cada classe em relação ao $\mathrm{N}_{\text {total }}, \mathrm{DTE}=$ distribuição tamanho-estável (\%), $\mathrm{VR}=$ valor reprodutivo.

\begin{tabular}{|c|c|c|c|c|c|c|c|c|c|c|c|c|}
\hline & \multicolumn{6}{|c|}{ Fragmentos de floresta inicial } & \multicolumn{6}{|c|}{ Fragmentos de floresta tardia } \\
\hline & pl 1 & pl 2 & jov 1 & jov 2 & subad & $\mathrm{ad}$ & pl 1 & pl 2 & jov 1 & jov 2 & subad & $\mathrm{ad}$ \\
\hline pl 1 & 0,853 & 0,004 & 0 & 0 & 0 & 0,083 & 0,918 & 0,019 & 0 & 0 & 0 & 0,209 \\
\hline pl 2 & 0,050 & 0,935 & 0,0007 & 0 & 0 & 0,028 & 0,036 & 0,946 & 0,002 & 0 & 0 & 0,018 \\
\hline jov 1 & 0 & 0,021 & 0,937 & 0,0003 & 0 & 0 & 0 & 0,021 & 0,946 & 0,002 & 0 & 0 \\
\hline jov 2 & 0 & 0 & 0,050 & 0,966 & 0,0005 & 0 & 0 & 0 & 0,040 & 0,958 & 0,001 & 0 \\
\hline subad & 0 & 0 & 0 & 0,024 & 0,988 & 0,0003 & 0 & 0 & 0 & 0,022 & 0,989 & 0,001 \\
\hline Ad & 0 & 0 & 0 & 0 & 0,009 & 0,9997 & 0 & 0 & 0 & 0 & 0,009 & 0,997 \\
\hline $\mathrm{N}$ & 97 & 37 & 302 & 95 & 619 & 127 & 54 & 40 & 338 & 108 & 310 & 55 \\
\hline $\mathrm{P}$ & 0,08 & 0,03 & 0,24 & 0,07 & 0,48 & 0,10 & 0,06 & 0,04 & 0,37 & 0,12 & 0,34 & 0,06 \\
\hline DTE & 0,16 & 0,23 & 0,07 & 0,10 & 0,15 & 0,29 & 0,35 & 0,25 & 0,09 & 0,08 & 0,11 & 0,12 \\
\hline VR & 1,0 & 3,07 & 10,12 & 13,55 & 21,15 & 37,42 & 1,0 & 2,4 & 6,0 & 8,7 & 18,3 & 32,3 \\
\hline
\end{tabular}

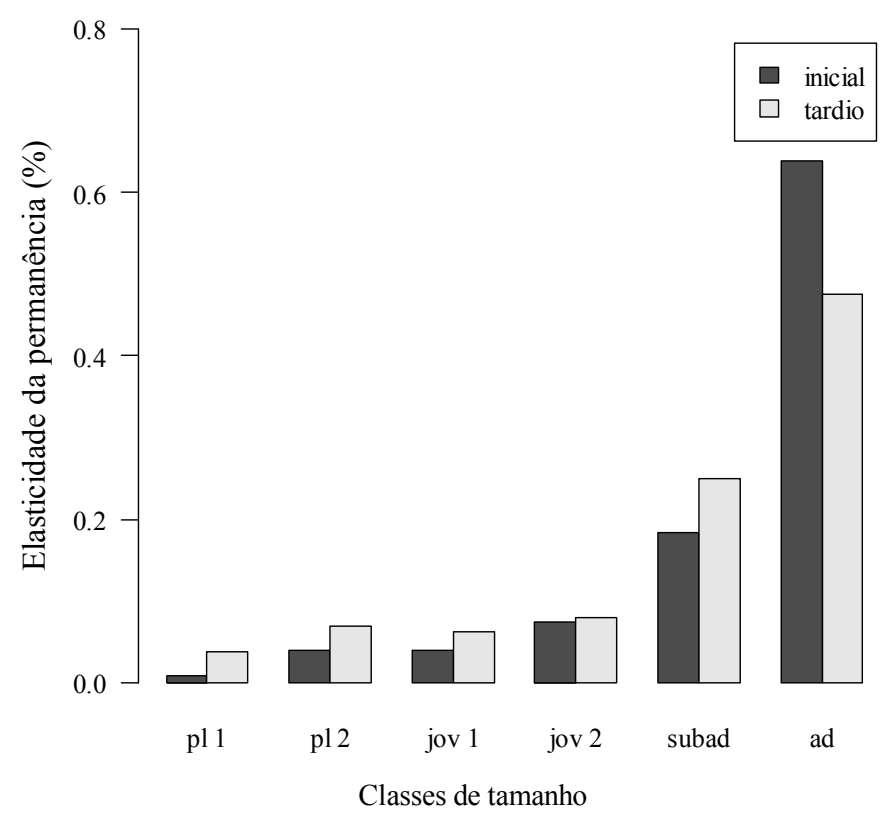

Figura 2. Elasticidades referentes à permanência por classe de tamanho para as populações de Guapira estudadas nos fragmentos de floresta secundária de dois estádios sucessionais (inicial e tardio) no Planalto Atlântico Paulista.

\section{Discussão}

Com uma abordagem inédita, demonstramos a complexidade e a importância da demografia das espécies arbóreas para o entendimento dos processos envolvendo a fragmentação e a sucessão secundária na Floresta Atlântica. Ao estudarmos duas espécies arbóreas comuns e de ampla distribuição, as implicações dos nossos resultados tornam-se ainda mais relevantes em termos da conservação das florestas na área de abrangência dessa formação. Os resultados de 
dinâmica populacional obtidos, analisados à luz das conclusões acerca da estrutura e densidade populacionais que possuíamos previamente (Capítulo 1), nos fornecem um interessante painel da ecologia das populações estudadas. Por um lado, para Guapira opposita, a espécie de dossel, a plasticidade demonstrada em termos de estrutura populacional em fragmentos de diferentes estádios sucessionais se confirmou em termos da sua dinâmica, o que reforça a conclusão de que a espécie está bem adaptada a paisagens fragmentadas. Já as populações de Rudgea jasminoides, a espécie de sub-bosque, quando analisadas do ponto de vista da sua estrutura e densidade, nos forneciam indícios de que a espécie corria risco de extinção local nos fragmentos médios em comparação aos grandes, o que no entanto não se confirmou na análise da sua dinâmica populacional, pois as populações apresentaram uma maior taxa de crescimento nos fragmentos médios em relação aos grandes, nos quais a população está estável. Diante desta situação, podemos supor que a taxa de crescimento populacional positivo poderá impedir ou mesmo retardar a extinção local prevista a partir da análise dos padrões de densidade e estrutura. Além das implicações diretas, este resultado ilustra a importância destas duas abordagens complementares para que tenhamos um pleno entendimento da ecologia das espécies.

Para Guapira, o fato de não termos encontrado diferenças entre a taxa assintótica de crescimento populacional em fragmentos de estádio inicial e tardio pode gerar uma interpretação equivocada de que os mecanismos demográficos que ocorrem em ambos os estádios de floresta são os mesmos, o que não é verdade quando observamos os resultados para as taxas vitais. Nesse sentido, a fertilidade nos fragmentos tardios foi o dobro da registrada para os fragmentos iniciais, enquanto esperávamos um padrão contrário, por se tratar de uma espécie com tolerância intermediária à sombra. Além disso, nossas expectativas acerca das diferenças na sobrevivência e no crescimento se confirmaram, embora apenas para os indivíduos mais jovens (classes de plântulas e jovem 1). Dessa forma, conforme previsto pela teoria de demanda conflitante entre a sobrevivência e o crescimento, cogitada como uma das explicações para a coexistência de espécies (Condit et al. 2006), nas florestas iniciais foi registrada uma menor sobrevivência e uma maior taxa de crescimento nestas classes de tamanho, enquanto nas florestas tardias ocorreu o padrão contrário. As mesmas taxas assintóticas de crescimento populacional foram atribuídas a mecanismos demográficos distintos no estudo do efeito da fragmentação sobre a dinâmica populacional da herbácea de sub-bosque Heliconia acuminata, de modo que os valores de lambda indicando populações estáveis $(\lambda \approx 1)$ eram devido a reduções na fertilidade nos fragmentos de 10 ha, enquanto reduções nas taxas reprodutivas e de crescimento contribuíram mais para o lambda calculado nos fragmentos de 1 ha (Bruna \& Oli 2005). Estes resultados 
ilustram como a interpretação dos padrões demográficos das espécies tropicais é complexa, não se reduzindo a comparações entre as taxas assintóticas de crescimento populacional.

A maior taxa assintótica de crescimento populacional encontrada para Rudgea nos fragmentos médios é surpreendente, uma vez que a estrutura populacional desta espécie é afetada pelo tamanho do fragmento, assim como a sua densidade é afetada tanto pelo tamanho quanto pelo estádio sucessional, de modo que hipotetizamos a extinção local da espécie nestes fragmentos (Capítulo 1). Encontrarmos um resultado contrário em termos da dinâmica deve ser interpretado com otimismo tendo em vista a persistência da espécie nos fragmentos médios. As implicações desta constatação são enormes, pois indicam que quando a população é analisada a partir de informações estáticas de densidade e estrutura, o efeito da fragmentação é negativo (Capítulo 1), enquanto que quando é analisada do ponto de vista da dinâmica o efeito da fragmentação é positivo. Se considerarmos a escassez de estudos de dinâmica populacional de espécies arbóreas tropicais (Condit et al. 2006), podemos supor que, a despeito de os efeitos da fragmentação serem objeto de estudos de décadas, sendo uma das questões mais bem estudadas da ecologia na atualidade (revisões em Laurance et al. 2002, Fahrig 2003 e, especificamente para populações de plantas, em Hobbs \& Yates 2003 e Bruna et al. 2009), ainda estamos longe de elucidar de fato seus mecanismos de atuação, conforme destaca Bruna et al. (2009).

Embora esperássemos, no caso de Rudgea, um efeito negativo do tamanho do fragmento sobre a fertilidade, uma explicação plausível para a fertilidade ter sido quase cinco vezes maior nos fragmentos médios em relação aos grandes pode estar relacionada ao aumento da luminosidade no sub-bosque nestes fragmentos, esta por sua vez em decorrência das alterações causadas pelo efeito de borda (revisão em Laurance et al. 2002). Outros estudos que relacionaram a taxa vital fertilidade de espécies de sub-bosque a ambientes com graus constrastantes de luminosidade encontraram resultados semelhantes (Martinez-Ramos et al. 1988, Pascarella \& Horvitz 1998, Valverde \& Silvertown 1998). Da mesma forma que a fertilidade, a taxa vital crescimento de espécies de sub-bosque, sejam herbáceas ou arbóreas, apresenta uma resposta positiva ao aumento da luminosidade (Martinez-Ramos et al. 1988, Pascarella \& Horvitz 1998, Valverde \& Silvertown 1998, McDonald \& Urban 2004, Tanaka et al. 2008). Nesse sentido, assumindo-se a premissa de maior luminosidade nos fragmentos menores, os resultados encontrados para Rudgea, de maior taxa de crescimento nos fragmentos médios em relação aos grandes, estão de acordo com o esperado. As análises de elasticidade das transições também confirmaram nossas expectativas quanto à contribuição proporcional das elasticidades relativas a crescimento e fertilidade serem maiores nos fragmentos menores, embora a magnitude dessa variação tenha sido pequena. Batista et al. (1998), que investigaram a 
dinâmica da espécie arbórea de sub-bosque Fagus grandifolia em um período pré e pós-furacão, encontraram diferenças mais acentuadas nesta mesma direção, assim como Valverde \& Silvertown (1998) para a espécie herbácea de sub-bosque Primula vulgaris. Cabe destacar, no entanto, que não encontramos efeito do tamanho na sobrevivência de adultos, justamente taxa vital com maior potencial para alterar a taxa assintótica de crescimento populacional de espécies de ciclo de vida longo (revisão em Franco \& Silvertown 2004). A análise dos padrões de elasticidade, no entanto, apenas nos fornece indícios das transições ou taxas vitais as quais, se perturbadas, teriam maior potencial para alterar lambda, por esse motivo são chamadas de análises prospectivas (Horvitz et al. 1996, Caswell 2001). Um outro tipo de abordagem analítica, no entanto, denominado Experimento de Resposta de Tabela de Vida ("Life Table Response Experiment" - LTRE), um tipo de análise retrospectiva, é necessário para que as diferenças observadas entre os lambdas sejam de fato decompostas em termos da real contribuição de cada taxa vital (Horvitz et al. 1996, Caswell 2001).

As taxas de crescimento estáveis encontradas para ambas as espécies, demonstram um interessante aspecto sobre o valor de conservação destes fragmentos de floresta secundária. Isso mostra que mesmo fragmentos relativamente pequenos e sob contínua pressão humana são capazes de manter populações estáveis destas espécies arbóreas. O valor em termos de conservação, mesmo de pequenos fragmentos de Floresta Atlântica, é reconhecido em outros estudos (Souza \& Martins 2004, Santos et al. 2007, Ribeiro et al. 2009), diante da alarmante situação deste ecossistema, em que atualmente mais de $80 \%$ dos fragmentos florestais são menores do que 50 ha (Ribeiro et al. 2009). A necessidade urgente de ações de restauração na Floresta Atlântica (Ribeiro et al. 2009), nos permite destacar a importância de qualquer fragmento, tal qual os estudados, como fontes de sementes para tais projetos. Além disso, por se tratarem de espécies zoocóricas, as populações estudadas são um recurso potencial para a avifauna da região. Dessa forma, corroboramos também as idéias que vem sendo apontadas sobre a importância das florestas secundárias para a manutenção e recuperação da biodiversidade (Barlow et al. 2007, Norden et al. 2009).

Por outro lado, esforços futuros para se monitorar as taxas de crescimento e mortalidade dos indivíduos adultos são importantes para que os padrões de estabilidade das populações encontrados possam ser confirmados e a compreensão dos efeitos do tamanho e do estádio sucessional do fragmento sobre a demografia destas espécies seja consolidada. A longevidade das espécies arbóreas é um desafio para este tipo de abordagem, pois em função desta característica as taxas de crescimento são lentas e a sobrevivência é muito elevada, de modo que os eventos de morte são naturalmente raros (Zuidema \& Zagt 2000). Como as taxas assintóticas 
de crescimento populacional, para ambas espécies e fatores, foram muito próximas de um, a capacidade de recuperação das populações à estocasticidade ambiental pode ser limitada (Morris \& Doak 2002). Por se tratarem de espécies extremamente comuns, a ampliação do conhecimento a seu respeito é crucial, pois quaisquer alterações que possam ocorrer nas populações terão uma grande relevância em termos da manutenção estrutural e da conservação dos fragmentos florestais da região.

\section{Referências bibliográficas}

Aguilar, R., Ashworth, L., Galetto, L., Aizen, M.A. 2006. Plant reproductive susceptibility to habitat fragmentation: review and synthesis through a meta-analysis. Ecology Letters 9: 968980.

Arroyo-Rodrigues, V., Aguirre, A., Benitez-Malvido, J., Mandujano, S. 2007. Impact of rain forest fragmentation on the population size of a structurally important palm species: Astrocaryum mexicanum at Los Tuxtlas, Mexico. Biological Conservation 138: 198-206.

Barlow, J., et al. 2007. Quantifying the biodiversity value of tropical primary, secondary, and plantation forests. Proceedings of the National Academy of Sciences of the United States of America 104: 18555-18560.

Batista, W.B., Platt, W.J., Macchiavelli, R.E. 1998. Demography of a shade-tolerant tree (Fagus grandifolia) in a hurricane-disturbed forest. Ecology 79: 38-53.

Brum, H.D., Nascimento, H.E.M., Laurance, W.F., Andrade, A.C.S., Laurance, S.G., Luiza, R.C.C. 2008. Rainforest fragmentation and the demography of the economically important palm Oenocarpus bacaba in central Amazonia. Plant Ecology 199: 209-215.

Bruna, E.M. 2003. Are plant populations in fragmented habitats recruitment limited? Tests with an amazonian herb. Ecology 84: 932-947.

Bruna, E.M. \& Oli, M.K. 2005. Demographic effects of habitat fragmentation on a tropical herb: life-table response experiments. Ecology 86: 1816-1824.

Bruna, E.M., Fiske, I.J., Trager, M.D. 2009. Habitat fragmentation and plant populations: is what we know demographically irrelevant? Journal of Vegetation Science 20: 569-576.

Bruna, E.M., Nardy, O., Sharon, Y.S., Harrison, S. 2002. Experimental assessment of Heliconia acuminata growth in a fragmented amazonian landscape. Journal of Ecology 90: 639-649.

Caswell, H. 2001. Matrix population models. Massachusetts: Sinauer Associates.

Caswell, H., Nisbet, R.M., Roos, A.M., Tuljapurkar, S. 1996. Structured-population models: many methods a few concepts. In: Tuljapurkar, S. \& Caswell, H. (eds). Structured-population models in marine, terrestrial and freshwater systems. New York: Chapman \& Hall, p. 3-18. 
Catharino, E.L.M., Bernacci, L.C., Franco, G.A.D.C., Durigan, G., Metzger, J.P. 2006. Aspectos da composição e diversidade do componente arbóreo das florestas da Reserva Florestal do Morro Grande, Cotia, SP. Biota Neotropica 6: 28p. URL: http://www.biotaneotropica.org.br/v6n2/pt/abstract?article+bn00306022006

Chien, P.D., Zuidema, P.A., Nguyen Hoang, N. 2008. Conservation prospects for threatened Vietnamese tree species: results from a demographic study. Population Ecology 50: 227-237.

Condit, R., et al. 2006. The importance of demographic niches to tree diversity. Science 313: 98101.

Crone, E.E. 2001. Is survivorship a better fitness surrogate than fecundity? Evolution 55: 26112614.

Cruz-Rodriguez, J.A., Lopez-Mata, L., Valverde, T. 2009. A comparison of traditional elasticity and variance-standardized perturbation analyses: a case study with the tropical tree species Manilkara zapota (Sapotaceae). Journal of Tropical Ecology 25: 135-146.

Fahrig, L. 2003. Effect of habitat fragmentation on biodiversity. Annual Review of Ecology, Evolution, and Systematics 34: 487-515.

Farrington, S.J., Muzika, R.M., Drees, D., Knight, T.M. 2009. Interactive effects of harvest and deer herbivory on the population dynamics of american ginseng. Conservation Biology 23: 719-728.

Ferreira, L.V., Laurance, W.F. 1997. Effects of forest fragmentation on mortality and damage of selected trees in central Amazonia. Conservation Biology 11: 797-801.

Franco, M. \& Silvertown, J. 2004. Comparative demography of plants based upon elasticities of vital rates. Ecology 85: 531-538.

Gandolfi, S. 2000. História natural de uma floresta estacional semidecidual no município de Campinas (São Paulo, Brasil). Tese (Doutorado em Biologia Vegetal). Universidade Estadual de Campinas, Campinas.

Girao, L.C., Lopes, A.V., Tabarelli, M., Bruna, E.M. 2007. Changes in tree reproductive traits reduce functional diversity in a fragmented Atlantic Forest landscape. PLoS one 2: e908. doi:10.1371/journal.pone.0000908

Henle, K., Davies, K.F., Kleyer, M., Margules, C., Settele, J. 2004. Predictors of species sensitivity to fragmentation. Biodiversity and Conservation 13: 207-251.

Hobbs, R.J., Yates, C.J. 2003. Impacts of ecosystem fragmentation on plant populations: generalising the idiosyncratic. Australian Journal of Botany 51: 471-488.

Horvitz, C.C. \& Schemske, D.W. 1995. Spatiotemporal variation in demographic transitions of a tropical understory herb: projection matrix analysis. Ecological Monographs 65: 155-192. 
Horvitz, C.C., Schemske, D.W., Caswell, H. 1996. The relative "importance" of life-history stages to population growth: prospective and retrospective analyses. In: Tuljapurkar, S. \& Caswell, H. (eds). Structured-population models in marine, terrestrial and freshwater systems. New York: Chapman \& Hall, p. 247-272.

Kroon, Hd., Groenendael, Jv., Ehrlen, J. 2000. Elasticities: a review of methods and model limitations. Ecology 81: 607-618.

Laurance, W.F., Ferreira, L.V., Rankin-de-Merona, J.M., Laurance, S.G. 1998. Rain forest fragmentation and the dynamics of Amazonian tree communities. Ecology 79: 2032-2040.

Laurance, W.F., Lovejoy, T.E., Vasconcelos, H.L., Bruna, E.M., Didham, R.K., Stouffer, P.C., Gascon, C., Bierregaard, R.O., Laurance, S.G., Sampaio, E. 2002. Ecosystem decay of Amazonian forest fragments: a 22-year investigation. Conservation Biology 16: 605-618.

Lopes, A.V., Girao, L.C., Santos, B.A., Peres, C.A., Tabarelli, M. 2009. Long-term erosion of tree reproductive trait diversity in edge-dominated Atlantic forest fragments. Biological Conservation 142: 1154-1165.

Martinez-Ramos, M., Sarukhan, J., Pinero, D. 1998. The demography of tropical trees in the context of forest gap dynamics: the case of Astrocaryum mexicanum at Los Tuxtlas tropical rain forest. In: Davy, D.J., Hutchings, R.W., Watkinson, A.R. (eds). Plant population ecology. Oxford: Blackwell, p. 293-313.

McDonald, R.I. \& Urban, D.L. 2004. Forest edges and tree growth rates in the North Carolina Piedmont. Ecology 85: 2258-2266.

Metzger, J.P., Martensen, A.C., Dixo, M., Bernacci, L.C., Ribeiro, M.C., Teixeira, A.M.G., Pardini, R. 2009. Time-lag in biological responses to landscape changes in a highly dynamic Atlantic forest region. Biological Conservation 142: 1166-1177.

Morris, W.F. \& Doak, D.F. 2002. Quantitative conservation biology: theory and practice of population viability analysis. Massachusetts: Sinauer Associates.

Norden, N., Chazdon, R.L., Chao, A., Jiang, Y.-H., Vilchez-Alvarado, B. 2009. Resilience of tropical rain forests: tree community reassembly in secondary forests. Ecology Letters 12: 385-394.

Oliveira, M.A., Santos, A.M.M., Tabarelli, M. 2008. Profound impoverishment of the large-tree stand in a hyper-fragmented landscape of the Atlantic forest. Forest Ecology and Management 256: 1910-1917.

Pascarella, J.B. \& Horvitz, C.C. 1998. Hurricane disturbance and the population dynamics of a tropical understory shrub: megamatrix elasticity analysis. Ecology 79: 547-563. 
Ponçano, W.L., Carneiro, C.D.R., Bistrichi, C.A., Almeida, F.F.A., Prandini, F.L. 1981. Mapa geomorfológico do Estado de São Paulo. ITP Monografias 1.

Poorter, L., Zuidema, P.A., Pena-Claros, M., Boot, R.G.A. 2005. A monocarpic tree species in a polycarpic world: how can Tachigali vasquezii maintain itself so successfully in a tropical rain forest community? Journal of Ecology 93: 268-278.

R Development Core Team. 2009. R: a language and environment for statistical computing. Vienna, Austria: R Foundation for Statistical Computing.

Ribeiro, M.C., Metzger, J.P., Martensen, A.C., Ponzoni, F.J., Hirota, M.M. 2009. The Brazilian Atlantic Forest: How much is left, and how is the remaining forest distributed? Implications for conservation. Biological Conservation 142: 1141-1153.

SABESP. 1997. Programa de conservação do Sistema Cotia. Relatório Conclusivo (tomo 3): Avaliação Ambiental. São Paulo: SABESP/Fundação Brasileira para o Desenvolvimento Sustentável.

Santos, K., Kinoshita, L.S., Santos, F.A.M. 2007. Tree species composition and similarity in semideciduous forest fragments of southeastern Brazil. Biological Conservation 135: 268277.

Scudeller, V.V., Martins, F.R., Shepherd, G.J. 2001. Distribution and abundance of arboreal species in the atlantic ombrophilous dense forest in Southeastern Brazil. Plant Ecology 152: 185-199.

Souza, A.F. \& Martins, F.R. 2004. Population structure and dynamics of a neotropical palm in fire-impacted fragments of the brazilian Atlantic Forest. Biodiversity and Conservation 13: 1611-1632.

Tabarelli, M., Mantovani, W., Peres, C.A. 1999. Effects of habitat fragmentation on plant guild structure in the montane Atlantic forest of southeastern Brazil. Biological Conservation 91: 119-127.

Tanaka, H., Shibata, M., Masaki, T., Iida, S., Niiyama, K., Abe, S., Kominami, Y., Nakashizuka, T. 2008. Comparative demography of three coexisting Acer species in gaps and under closed canopy. Journal of Vegetation Science 19: 127-138.

Tomimatsu, H. \& Ohara, M. 2010. Demographic response of plant populations to habitat fragmentation and temporal variability. Oecologia 162: 903-911.

Valverde, T. \& Silvertown, J. 1998. Variation in the demography of a woodland understorey herb (Primula vulgaris) along the forest regeneration cycle: projection matrix analysis. The Journal of Ecology 86: 545-562. 
Veloso, H.P., Rangel-Filho, A.L.R., Lima, J.C.A. 1991. Classificação da vegetação brasileira adaptada a um sistema universal. Rio de Janeiro: IBGE.

Zuidema, P.A. \& Franco, M. 2001. Integrating vital rate variability into perturbation analysis: an evaluation for matrix population models of six plant species. Journal of Ecology 89: 9951005 .

Zuidema, P.A. \& Zagt, R.J.Z. 2000. Using population matrices for long-lived species: a review of published models for 35 woody plants. In: Zuidema, P.A. (ed). Demography of exploited tree species in Bolivian Amazon. Riveralta: PROMAB Scientific series 2, p. 159-181. 
Capítulo 3

Abertura do dossel e profundidade da serapilheira no desempenho de plântulas em fragmentos florestais no Planalto Atlântico Paulista

Canopy openness and litter depth on seedling performance in forest fragments in Southeast Atlantic Plateau 


\section{Resumo}

A heterogeneidade ambiental no sub-bosque de florestas tropicais é fundamental para a criação de diferentes nichos de regeneração. Fragmentos florestais secundários, por sua vez, são ótimos sistemas para se testar hipóteses a esse respeito. Neste trabalho, responderemos à questão de como o desempenho (sobrevivência e taxas de crescimento) de plântulas de espécies arbóreas que diferem no grau de tolerância à sombra é afetado por diferentes combinações de abertura do dossel e profundidade da camada de serapilheira. Esperamos que a interação entre os fatores dossel e serapilheira seja importante para o desempenho das plântulas de ambas as espécies, mas em sentidos opostos, ou seja, a espécie de sub-bosque apresente melhor desempenho em condições de menor abertura de dossel e/ou maior profundidade da serapilheira, enquanto que para a espécie de dossel estas condições diminuam seu desempenho. Para tanto, marcamos e acompanhamos por dois anos plântulas da espécie de sub-bosque Rudgea jasminoides (Cham.) Müll.Arg. e da espécie de dossel Guapira opposita (Vell.) Reitz, e realizamos medidas da abertura do dossel e da camada de serrapilheira, em seis fragmentos de floresta secundária no Planalto Atlântico Paulista. A cada seis meses, registramos a sobrevivência e o crescimento em altura e em número de folhas de cada plântula. $\mathrm{Na}$ análise dos dados, empregamos modelos lineares mistos generalizados (GLMM), para a sobrevivência, e modelos lineares mistos (LMM) para as taxas de crescimento (altura e número de folhas), subdividindo o conjunto de dados conforme a presença de cotilédones, e conduzimos um procedimento de seleção de modelos, comparando os modelos dois a dois, a partir do mais completo. Para ambas as espécies, os efeitos encontrados foram na direção oposta da esperada. Para Guapira, houve efeito negativo da interação entre a abertura do dossel e a profundidade da serapilheira somente sobre a sobrevivência das plântulas maiores (entre 10 e $50 \mathrm{~cm}$ ) e sem cotilédones. Os resultados para Rudgea foram mais complexos, sendo na direção oposta dos encontrados para Guapira. Dessa forma, quando consideradas as plântulas maiores (entre 10 e $50 \mathrm{~cm}$ ) houve efeito positivo da interação entre o dossel e a serapilheira sobre a sobrevivência, e um efeito positivo apenas da abertura do dossel sobre as taxas de crescimento. Já para as plântulas menores de Rudgea (até 15 cm e no mínimo um cotilédone), somente a abertura do dossel teve efeito positivo na sobrevivência. Demonstramos, a partir deste trabalho, a importância da interação entre os fatores abertura do dossel e profundidade da camada de serapilheira para o desempenho de plântulas de espécies arbóreas tolerantes à sombra. Além disso, destacamos a relevância de se considerar as diferentes fases ontogenéticas das plântulas, pois o efeito dos fatores sobre o desempenho dos indivíduos pode mudar. 


\section{Introdução}

Em plantas, a segregação de nichos ao longo de diversos eixos representando as condições ambientais é considerada um dos principais mecanismos que contribuem para a coexistência de espécies (Grubb 1977, Silvertown 2004). De fato, em florestas tropicais, muitas teorias que explicam a elevada diversidade de espécies estão baseadas na existência de diferentes nichos de regeneração (Grubb 1977, Ricklefs 1977, Denslow 1987). Dessa forma, através do surgimento de diferentes nichos de regeneração, a heterogeneidade ambiental no sub-bosque influencia a distribuição, a abundância e a composição da comunidade de plântulas (GarciaGuzman \& Benitez-Malvido 2003). Gradientes de luminosidade, temperatura e umidade do solo e de profundidade da camada de serapilheira estão entre estes principais fatores, considerados como determinantes da regeneração de diferentes espécies vegetais (Grubb 1977). Combinados à heterogeneidade ambiental, uma série de fatores bióticos, tais como a dispersão e o ataque diferencial de herbívoros e patógenos, tem um efeito decisivo no recrutamento das populações (Janzen 1970, Connell 1978, Fine et al. 2004, Clark et al. 2007).

A luz é um dos principais fatores responsáveis pela criação da heterogeneidade no subbosque de florestas tropicais. Muitos trabalhos já demonstraram experimentalmente que a luz limita a emergência, a sobrevivência e o crescimento das plântulas (Kobe 1999, Nicotra et al. 1999, Lewis \& Tanner 2000, são alguns exemplos). De uma forma geral, pode-se afirmar que as classificações das espécies quanto a tolerância à sombra são bons preditores da sua resposta a gradientes de luz (Kitajima 1994, Condit et al. 1996). No entanto, sabe-se que mesmo espécies arbóreas de sub-bosque respondem positivamente ao aumento na disponibilidade luz, porém a diferença está no fato dessas espécies também conseguirem bom desempenho em condições de luminosidade extremamente limitadas (Kobe 1999, Poorter 1999).

A presença de serapilheira em profundidades variáveis também gera diferentes microsítios para a regeneração das espécies arbóreas (Facelli \& Pickett 1991), tendo sido realizados diversos estudos experimentais sobre o tema (revisão em Sayer 2006). Os efeitos da serapilheira ocorrem ainda na fase de semente e variam conforme seu tamanho (Sayer 2006). No caso de sementes grandes, a presença de serapilheira, comparativamente ao solo descoberto, é positivamente associada à sobrevivência, provavelmente auxiliando no escape à predação (Sork 1983, Cintra 1997). Para espécies com sementes pequenas, foi comprovado experimentalmente que a serapilheira tem um papel importante na formação de um banco de sementes, uma vez que a sua remoção pode induzir a germinação de algumas destas espécies (Vazquez-Yanes et al. 1990, Metcalfe \& Turner 1998). Plântulas de espécies de sementes pequenas respondem à presença e a variações na profundidade da serapilheira de maneira extremamente diferenciada, 
variando desde fortemente inibidas a fracamente afetadas (Vazquez-Yanes et al. 1990, Molofsky \& Augspurger 1992). Uma vez germinada a semente, a despeito do fato de que a serapilheira representa uma barreira física para a emergência das plântulas, o desempenho e a sobrevivência podem ser afetados positivamente, pelo escape aos herbívoros (Cintra 1997), e pelo aumento na taxa de crescimento devido a maior disponibilidade de nutrientes (Brearley et al. 2003), ou pela proteção contra a dessecação (Molofsky \& Augspurger 1992, Seiwa \& Kikuzawa 1996). Já os efeitos negativos podem ser diretos (Cintra 1997) ou indiretos, tais como através da diminuição da taxa de crescimento relativo (Garcia-Guzman \& Benitez-Malvido 2003), do aumento da herbivoria e da incidência de patógenos (Garcia-Guzman \& Benitez-Malvido 2003), ou por danos físicos provocados pela sua queda (Scariot 2000, Gillmann et al. 2004, entre outros). Depreende-se, portanto, que o efeito exercido pela camada de serapilheira é extremamente específico, independentemente da fase considerada (semente ou plântula) (Sayer 2006).

Diante da especificade das respostas e da alta variabilidade que tanto a luz (abertura do dossel) quanto a serapilheira podem apresentar no sub-bosque de florestas, o efeito da interação entre estes dois fatores é de difícil previsibilidade. É intrigante notar que, conforme já destacado, quando analisada isoladamente, a serapilheira tem efeitos diretos ou indiretos no desempenho das plântulas. No entanto, todos os estudos que avaliaram seu efeito (presença/ausência ou tratamentos de remoção parcial) simultaneamente à disponibilidade de luz encontraram resultados similares, nos quais a luz apresentou efeitos significativos, enquanto para a serapilheira o efeito foi fraco ou inexistente (Cintra \& Terborgh 2000, Benitez-Malvido et al. 2005, Makana \& Thomas 2005, Seiwa 2007).

Em paisagens fragmentadas, a heterogeneidade ambiental é aumentada pela ação antrópica gerando uma demanda a respeito de como as espécies arbóreas respondem a essas alterações nos habitats florestais. Dessa forma, os fragmentos florestais secundários são ótimos sistemas para testes sobre a resposta diferencial de plântulas de espécies arbóreas à heterogeneidade ambiental, pois em contraste ao grande número de estudos experimentais, relativamente pouco se sabe sobre as respostas de plântulas já estabelecidas em condições naturais (Garcia-Guzman \& Benitez-Malvido 2003).

Neste trabalho, responderemos à questão de como o desempenho (medido através da sobrevivência e das taxas de crescimento) de plântulas de espécies arbóreas tolerantes à sombra é afetado por diferentes combinações de abertura do dossel e profundidade da camada de serapilheira, encontradas em fragmentos florestais secundários. Para tanto, selecionamos duas espécies arbóreas abundantes que diferem no grau de tolerância à sombra, uma de sub-bosque (umbrófila ou tolerante) e outra de dossel (tolerância intermediária). Esperamos que a interação 
entre os fatores dossel e serapilheira seja importante para o desempenho das plântulas de ambas as espécies, mas em sentidos opostos, ou seja, a espécie de sub-bosque apresente melhor desempenho em condições de menor abertura de dossel e/ou maior profundidade da serapilheira, enquanto que para a espécie de dossel estas condições diminuam seu desempenho.

\section{Material e métodos}

\section{Área de estudo}

O estudo foi conduzido em seis fragmentos florestais de propriedade particular no

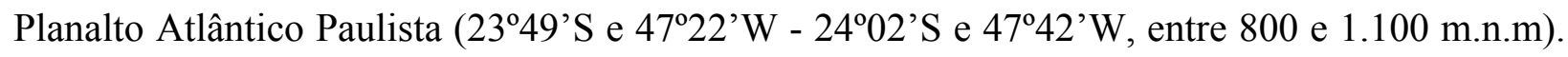
A região apresenta precipitação média anual de $1.300 \mathrm{~mm}$ e clima $\mathrm{Cfa}$, ou $\mathrm{Cfb}$ nas maiores altitudes (SABESP 1997). A Floresta Atlântica que cobria originalmente a região é classificada como Floresta Ombrófila Densa Montana, embora seja uma zona de transição, com a ocorrência de algumas espécies típicas da Floresta Estacional Semidecidual (Veloso et al. 1991). Os fragmentos selecionados para este estudo variam em tamanho (entre 23,3 e 146 ha), histórico de perturbação e estádio sucessional.

\section{Espécies estudadas}

Ambas são espécies arbóreas comuns na Floresta Atlântica no sul e sudeste do Brasil (Scudeller et al. 2001, Oliveira-Filho et al. 2006), sendo extremamente abundantes em fragmentos de floresta secundária (Scudeller et al. 2001, Catharino et al. 2006). As espécies têm ainda em comum a dispersão zoocórica e a tolerância à sombra (Catharino et al. 2006), emboram difiram no grau desta tolerância, além de apresentarem sementes pequenas e cotilédones epígeos fotossintetizantes quando plântulas. Rudgea jasminoides (Cham.) Müll.Arg. (Rubiaceae), é uma árvore de pequeno porte, popularmente conhecida como "jasmim-do-mato" (Zappi 2003), que ocupa o sub-bosque e é classificada como umbrófila ou secundária tardia, ou seja, uma espécie que completa o ciclo de vida à sombra de outras árvores (Catharino et al. 2006). Na área de estudo, esta espécie permanece a maior parte do ano com frutos imaturos, os quais começam a amadurecer a partir do mês de setembro, por aproximadamente quatro meses (C.F. Jurinitz, dados não publicados). Cada fruto geralmente contém duas sementes, que podem ser consideradas pequenas, pesando, em média, 5,3 \pm 0,6 mg (C.F. Jurinitz, dados não publicados). Já Guapira opposita (Vell.) Reitz (Nyctaginaceae) é uma espécie de porte mais variável, conhecida como "maria-mole" (Reitz 1970), uma referência a sua madeira sem valor comercial (Souza \& Lorenzi 2005). Ocupa o dossel em florestas secundárias e apresenta tolerância intermediária à sombra, sendo classificada como secundária inicial (sensu Gandolfi 2000). Na área de estudo, a espécie foi observada em fase reprodutiva entre os meses de outubro e 
dezembro, período que compreende desde a floração até a maturação dos frutos (C.F. Jurinitz, dados não publicados). Cada fruto possui uma semente elíptica, com comprimento aproximado de $1 \mathrm{~cm}$ (Lorenzi 1998). Daqui em diante as espécies serão referidas pelo estrato que ocupam na floresta e/ou pelo nome do gênero.

\section{Desenho amostral}

No interior de cada fragmento florestal, em uma área de 0,5 ha, foram distribuídas sistematicamente 30 parcelas de $4 \mathrm{~m}^{2}$ (120 $\mathrm{m}^{2}$ por fragmento). Em cada parcela foram numerados e mapeados todos os indivíduos de Guapira e Rudgea com altura entre 10 e $50 \mathrm{~cm}$, sendo registrada a altura da gema apical $(\mathrm{em} \mathrm{cm})$, o número de folhas e o número de cotilédones, quando presentes. Empregamos o termo 'plântula' para designar todos os indivíduos amostrados conforme este critério de tamanho, independentemente da presença de cotilédones. O primeiro levantamento foi realizado entre os meses de maio e julho de 2007 (tempo zero - $t_{0}$ ) e as parcelas foram recenseadas aproximadamente a cada seis meses, ou seja, em janeiro de $2008\left(\mathrm{t}_{1}\right)$, entre junho e julho de $2008\left(t_{2}\right)$, em janeiro de $2009\left(t_{3}\right)$ e finalmente em outubro de $2009\left(t_{4}\right)$, totalizando mais de dois anos de acompanhamento $(\approx 2,2$ anos). Durante os recenseamentos foram medidos todos os indivíduos vivos marcados inicialmente e registrados os indivíduos mortos e ingressantes. Uma vez que a morfologia das plântulas destas espécies já era bem conhecida, durante o recenseamento do $t_{2}$, foram incluídos também todos os indivíduos menores do que $10 \mathrm{~cm}$ de altura. Com esta mudança de critério, foram amostradas muitas plântulas somente com cotilédones, das quais não foi registrada a altura.

\section{Variáveis explicativas}

Uma estimativa da abertura do dossel de cada parcela foi obtida através de fotografias hemisféricas, realizadas com uma câmera Nikon D40 e uma lente Sigma $8 \mathrm{~mm}$ em um tripé posicionado no centro da parcela, conforme os procedimentos descritos em Nicotra et al. (1999). A câmera foi mantida a $70 \mathrm{~cm}$ do solo (distância do solo até a lente), sendo seu topo orientado para o Norte magnético e verificada a posição horizontal da lente com o auxílio de um nível de bolha, posicionado em cima desta. As fotografias foram realizadas em novembro de 2008 em dias nublados ou em horários do dia em que o disco solar não estava visível no céu (aproximadamente até às 08:00h e a partir das 16:00h, dependendo da área, já que a topografia pode influenciar). A câmera foi utilizada no programa manual, sendo mantida sensibilidade ISO 400, a menor abertura (22) e variada a velocidade (entre 1/40 a 1/125), conforme as condições de luminosidade do local (quanto maior a luminosidade maior a velocidade). As fotografias foram processadas no programa Gap Light Analyzer (GLA) versão 2.0 (Frazer et al. 1999), sendo mantidos fixos o raio e o limiar requeridos no processo de registro de cada uma das imagens. 
Dentre os parâmetros calculados pelo GLA, utilizamos a porcentagem de abertura do dossel para representar cada parcela.

A profundidade da camada de serapilheira foi estimada para cada parcela durante o segundo recenseamento $\left(t_{2}\right)$. Foram tomadas dez medidas da profundidade (incluindo-se a camada superior de matéria orgânica do solo), distribuídas sistematicamente dentro da parcela, com uma vara de acrílico (de $50 \mathrm{~cm}$ e $1,5 \mathrm{~mm}$ de espessura). Para tal, em cada um dos dez pontos perfurou-se a camada de serapilheira até o momento em que a vara encontrava resistência do solo, sendo marcado esse ponto na vara e registrada essa medida em centímetros. A mediana destas dez medidas por parcela constituiu o descritor de profundidade para a mesma. A correlação entre estas duas variáveis explicativas (profundidade da serapilheira e abertura do dossel) foi verificada tanto para os dados de todos os fragmentos em conjunto $\left(r^{2}=0,07\right.$; $p<0,001$ ), quanto para cada fragmento separadamente (para todos $r^{2}<0,10$ e $p>0,05$ ), e, por ser muito baixa, foi considerada desprezível.

\section{Análise dos dados}

Empregamos um modelo linear misto generalizado ("Generalized Linear Mixed Model” - GLMM) para relacionar a sobrevivência às variáveis explicativas (porcentagem de abertura do dossel e profundidade da camada de serapilheira). O modelo é misto porque o fragmento, fonte uma variação que não controlamos, é considerado como uma variável de efeito randômico, sendo dessa forma reconhecida a estrutura hierárquica da amostragem como uma fonte de pseudoreplicação (Crawley 2007). O modelo generalizado permite que os dados de proporção de sobreviventes sejam analisados sem a necessidade de transformação dos dados ou mesmo a perda da informação do número de "tentativas", bastando especificar a distribuição do erro como Binomial (Crawley 2007). Ao invés de informar apenas uma porcentagem de sobreviventes, nessa análise é utilizado o número de sucessos (sobreviver) e o número de fracassos (morrer) ao final do intervalo de tempo considerado (Crawley 2007), para cada parcela. Dessa forma, esse procedimento constitui uma vantagem, pois leva em consideração o número de tentativas.

Já para as análises envolvendo as taxas de crescimento relativo, empregamos modelos lineares mistos ("Linear Mixed Models"- LMM), pois as distribuições do erros são aproximadamente normais (Crawley 2007). Assim como para a sobrevivência, o fragmento também foi considerado uma variável de efeito randômico, mas, nesse caso, como foi calculada uma taxa por plântula, podia haver mais de um valor por parcela. Como as taxas calculadas para os indivíduos da mesma parcela não podem ser consideradas independentes, a parcela também foi considerada um fator randômico, dentro de cada fragmento. A taxa de crescimento relativo em altura $\left(\mathrm{TCR}_{\mathrm{alt}}\right)$ foi calculada a partir da subtração entre o logaritmo natural da medida final e 
o logaritmo natural da medida inicial, dividida pelo intervalo de tempo em anos, enquanto que a taxa de crescimento relativo em número de folhas $\left(\mathrm{TCR}_{\mathrm{fol}}\right)$ foi calculada subtraindo-se o número final pelo inicial, dividido pelo número inicial multiplicado pelo intervalo de tempo em anos (Benitez-Malvido \& Kossmann-Ferraz 1999, Baraloto et al. 2005). Taxas de crescimento negativas, decorrentes principalmente de danos, foram muito comuns, sendo mantidas nas análises.

Tendo em vista que a presença de cotilédones pode afetar o desempenho das plântulas (Kitajima 1992, 2002), esse critério foi utilizado para subdividir o conjunto total de dados. Dessa forma, três grupos principais de plântulas foram analisados: $i$. todas as plântulas com altura entre 10 e $50 \mathrm{~cm}$; ii. plântulas com altura entre 10 e $50 \mathrm{~cm}$ sem cotilédones; iii. plântulas com altura $\leq$ $15 \mathrm{~cm}$ e no mínimo um cotilédone. Somente para Rudgea foi possível analisar ainda, para a variável resposta $\mathrm{TCR}_{\text {folhas, }}$ as plântulas com altura $<10 \mathrm{~cm}$ apenas com cotilédones, no entanto, estes resultados serão omitidos, pois não diferiram dos obtidos para as plântulas com no mínimo um cotilédone. Como não foi medida a altura das plântulas somente com cotilédones, para a $\mathrm{TCR}_{\text {altura }}$ foi possível apenas considerar o conjunto total de plântulas de $10 \mathrm{a} 50 \mathrm{~cm}$ de altura.

Conduzimos um procedimento de seleção de modelos, partindo-se do modelo mais completo (todos os termos e interações possíveis) até chegarmos ao mais parciomonioso, removendo os termos não significativos e comparando os modelos dois a dois, a cada simplificação, conforme recomendado por Crawley (2007). Ao chegarmos ao modelo mínimo, no qual nenhuma simplificação mais era possível, este era comparado ao modelo nulo, ou seja, um modelo sem os fatores fixos, apenas os randômicos. Dessa forma, a existência do(s) efeito(s) no modelo selecionado só foi confirmada se estes modelos fossem considerados diferentes entre si. Caso contrário, o modelo nulo foi considerado o mais plausível. Além disso, foram verificados os pressupostos dos modelos lineares conforme as recomendações de Crawley (2007) e Bolker et al. (2009). Especificamente para os GLMM's, foram seguidas as recomendações de Bolker et al. (2009) de acordo com as características do conjunto de dados analisado, tais como uso da aproximação de Laplace como método de otimização. As análises foram realizadas no programa $\mathrm{R}$ versão 2.10.1 ( $\mathrm{R}$ Development Core Team 2009), tendo como base os procedimentos descritos em Crawley (2007) e os pacotes lme4 (Bates \& Maechler 2009), para GLMM, e nlme (Pinheiro et al. 2009), para LMM. 


\section{Resultados}

\section{Padrões para as variáveis explicativas}

Considerando-se todos os fragmentos em conjunto, a porcentagem de abertura do dossel registrada ficou entre $0,7 \%$ e $16,7 \%$, sendo a média e o desvio padrão, respectivamente, $5,7 \% \pm$ 3,1\%. Quando analisados os valores por fragmento, no entanto, as diferenças na amplitude de variação ficam evidentes (Figura 1a). Já a profundidade da camada de serapilheira foi de 1,8 cm até $12,7 \mathrm{~cm}$ (média de 5,6 $\mathrm{cm} \pm 2,6$ de desvio padrão). Da mesma forma que para a abertura do dossel, houve grande variação entre os fragmentos (Figura 1b).
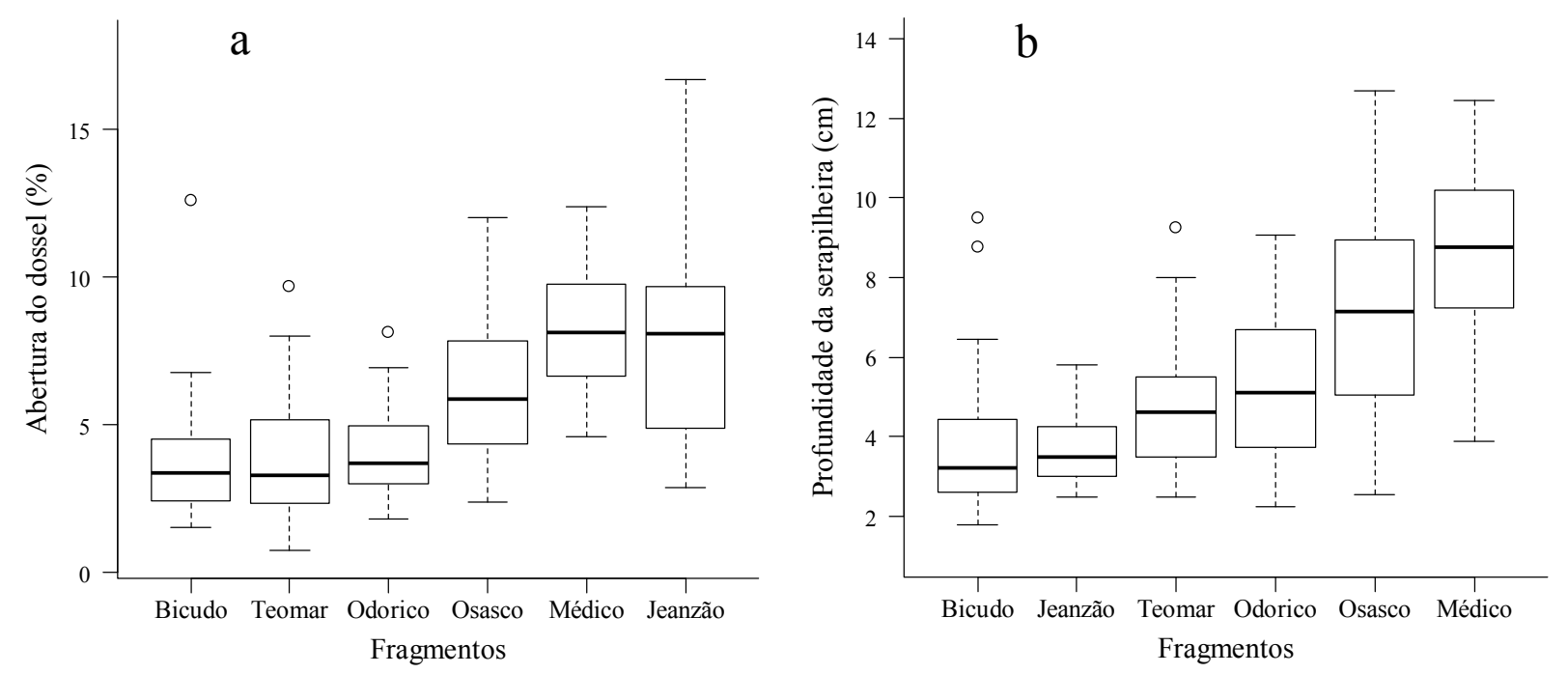

Figura 1. Diagramas de caixa mostrando os padrões de variação da porcentagem de abertura do dossel (a) e da profundidade da camada de serapilheira (b) em cada fragmento florestal estudado no Planalto Atlântico Paulista. As caixas representam os percentis contendo $25 \%$ a $75 \%$ dos dados, a linha horizontal representa a mediana e as barras verticais delimitam a amplitude sem os outliers (representados pelos círculos).

\section{Sobrevivência}

Para ambas as espécies, a sobrevivência das plântulas maiores (altura entre 10 e $50 \mathrm{~cm}$ ) foi alta, mas sofreu uma forte queda quando considerados somente os indivíduos com até $15 \mathrm{~cm}$ de altura e no mínimo um cotilédone (Tabela 1). Ainda para os indivíduos com no mínimo um cotilédone, a taxa de sobrevivência registrada para Guapira, para a qual foram acompanhadas menos plântulas e por menos tempo, foi ainda menor do que a das plântulas de Rudgea (Tabela $1)$.

Para Guapira, embora tenha sido registrada uma menor sobrevivência para as plântulas com até $15 \mathrm{~cm}$ de altura e no mínimo um cotilédone, houve efeito da porcentagem de abertura do dossel e da profundidade da camada de serapilheira somente sobre a sobrevivência das plântulas 
maiores (entre 10 e $50 \mathrm{~cm}$ de altura) e sem cotilédones (Tabela 2). Para estas plântulas, foi selecionado o modelo completo, ou seja, incluindo a interação entre dossel e serapilheira (Tabela 2), de modo que os efeitos destas variáveis não podem ser interpretados isoladamente. Dessa forma, a sobrevivência predita pelo modelo considera também o efeito desta interação, cujo efeito total sobre estas plântulas é negativo (Figura 2a e b).
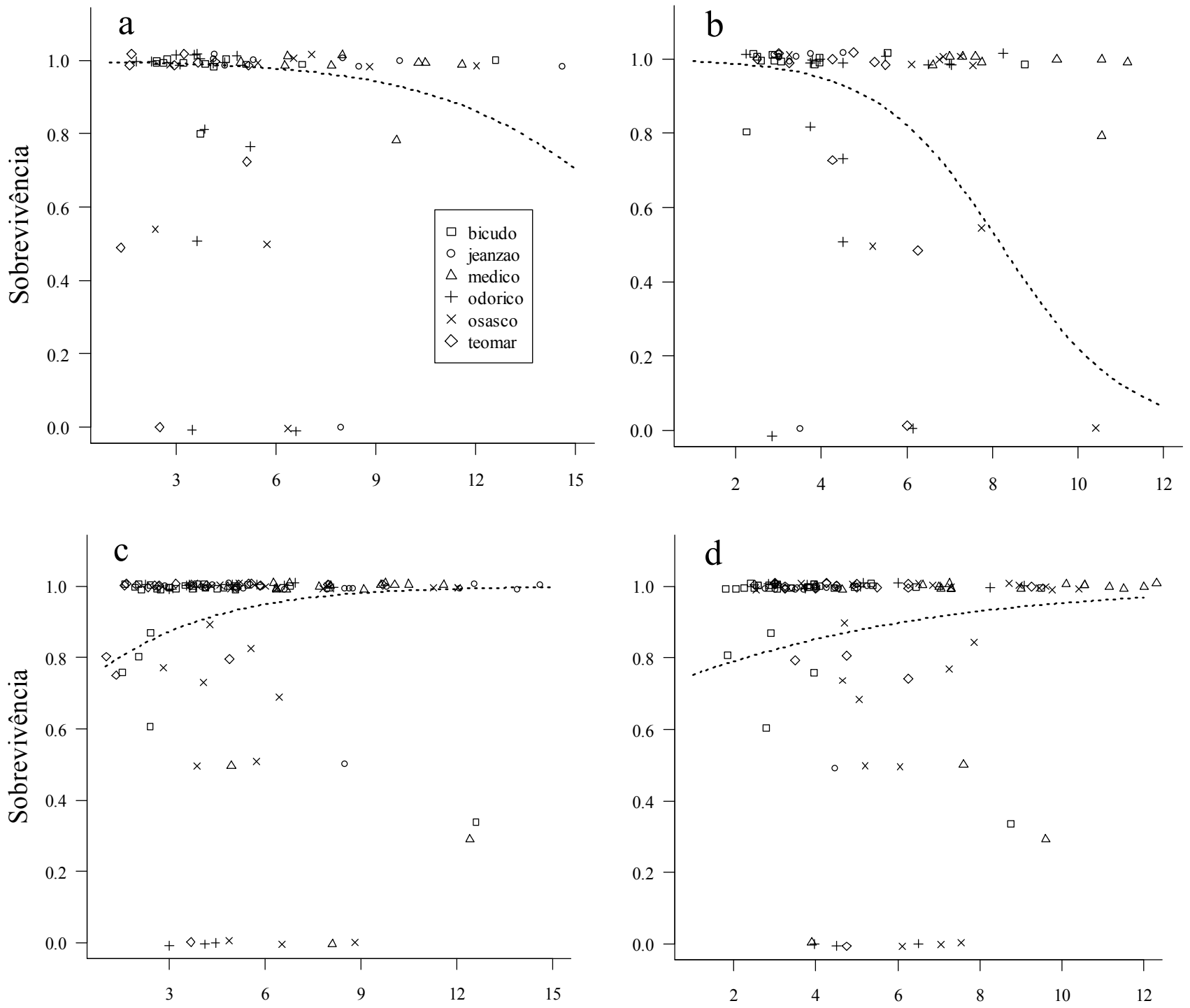

Abertura do dossel (\%)

Profundidade da serapilheira $(\mathrm{cm})$

Figura 2. Sobrevivência registrada para as plântulas com altura entre 10 e $50 \mathrm{~cm}$ em função da porcentagem de abertura do dossel (a) e (c) e da profundidade da serapilheira (b) e (d) nos fragmentos florestais estudados no Planalto Atlântico Paulista. Os gráficos (a) e (b) correspondem às plântulas de Guapira sem cotilédones e os gráficos (c) e (d) às plântulas de Rudgea. Cada símbolo corresponde a um fragmento, sendo a legenda apresentada em (a). A linha pontilhada correspondente aos valores de sobrevivência previstos pelo modelo selecionado para cada espécie, que inclui o termo de interação entre as duas variáveis (ver Tabela 2). Os símbolos na porção superior do gráfico (sobrevivência $=1$ ) foram agitados com o auxílio da função "jitter", para diminuir a sobreposição e assim melhorar sua visualização. 
Tabela 1. Taxas de sobrevivência (\%) e de crescimento em número de folhas $\left(\mathrm{TCR}_{\mathrm{fol}}\right)$ e em altura $\left(\mathrm{TCR}_{\mathrm{alt}}\right)(\mathrm{média} \pm$ desvio padrão) registradas para as plântulas de Guapira e de Rudgea em fragmentos florestais no Planalto Atlântico Paulista, conforme as classes resultantes de uma combinação do tamanho com a presença de cotilédones. Para as taxas de crescimento são apresentados três valores, correspondentes ao crescimento positivo, zero e negativo, seguidas da porcentagem de indivíduos entre parêntesis. O tamanho amostral $(\mathrm{N})$ e o intervalo de tempo considerado em cada conjunto de dados também são informados entre parêntesis.

\begin{tabular}{|c|c|c|c|}
\hline & $\begin{array}{l}\text { Sobrevivência } \\
(\%)\end{array}$ & $\begin{array}{l}\mathrm{TCR}_{\text {fol }} \\
\left(\text { folhas.ano }^{-1} \text { ) }\right.\end{array}$ & $\begin{array}{l}\mathrm{TCR}_{\text {alt }} \\
\left(\mathrm{cm} . \mathrm{ano}^{-1}\right)\end{array}$ \\
\hline \multicolumn{4}{|l|}{ Guapira } \\
\hline $10-50 \mathrm{~cm}$ alt. & $\begin{array}{c}87,7 \pm 27,1 \\
(\mathrm{~N}=200 ; \approx 2,25 \text { anos })\end{array}$ & $\begin{array}{l}0,31 \pm 0,30(40 \%) \\
\text { zero }(20 \%) \\
-0,28 \pm 0,14(40 \%) \\
\text { amplitude: }-0,59 \text { a } 1,78 \\
(\mathrm{~N}=172 ; \approx 1,7 \text { anos })\end{array}$ & $\begin{array}{l}0,09 \pm 0,10(31 \%) \\
\text { zero }(10 \%) \\
-0,10 \pm 0,08(59 \%) \\
\text { amplitude: }-0,42 \text { a } 0,55 \\
(\mathrm{~N}=172 ; \approx 1,7 \text { anos })\end{array}$ \\
\hline $10-50 \mathrm{~cm}$ alt. (sem cotil.) & $\begin{array}{c}87,4 \pm 28,7 \\
(\mathrm{~N}=158 ; \approx 2,25 \text { anos })\end{array}$ & - & - \\
\hline$\leq 15 \mathrm{~cm}$ alt. (mín. 1 cotil.) & $\begin{array}{c}58,2 \pm 43,6 \\
(\mathrm{~N}=184 ; \approx 0,7 \text { anos })\end{array}$ & $\begin{array}{l}2,24 \pm 2,65(34 \%) \\
\text { zero }(61 \%) \\
-0,83 \pm 0,23(5 \%) \\
\text { amplitude: }-1,1 \text { a } 16,0 \\
(\mathrm{~N}=100 ; \approx 0,7 \text { anos })\end{array}$ & - \\
\hline \multicolumn{4}{|l|}{ Rudgea } \\
\hline $10-50 \mathrm{~cm}$ alt.* & $\begin{array}{c}88,6 \pm 27,1 \\
(\mathrm{~N}=440 ; \approx 2,25 \text { anos })\end{array}$ & $\begin{array}{l}0,24 \pm 0,21(44 \%) \\
\text { zero }(20 \%) \\
-0,20 \pm 0,14(36 \%) \\
\text { amplitude: }-0,59 \text { a } 1,77 \\
(\mathrm{~N}=443 ; \approx 1,7 \text { anos })\end{array}$ & $\begin{array}{l}0,08 \pm 0,07(41 \%) \\
\text { zero }(7 \%) \\
-0,08 \pm 0,07(52 \%) \\
\text { amplitude: }-0,54 \text { a } 0,49 \\
(\mathrm{~N}=445 ; \approx 1,7 \text { anos })\end{array}$ \\
\hline$\leq 15 \mathrm{~cm}$ alt. (mín. 1 cotil.) & $\begin{array}{c}53,2 \pm 37,8 \\
(\mathrm{~N}=698 ; \approx 1,25 \text { anos })\end{array}$ & $\begin{array}{l}1,86 \pm 1,09(78 \%) \\
\text { zero }(20 \%) \\
-0,39 \pm 0,20(2 \%) \\
\text { amplitude: }-0,80 \text { a } 5,64 \\
(\mathrm{~N}=280 ; \approx 1,25 \text { anos })\end{array}$ & - \\
\hline
\end{tabular}

* Como apenas sete destes indivíduos possuíam cotilédones, consideramos desnecessário subdividir esta classe em plântulas com e sem cotilédones, como foi feito para Guapira.

Já para Rudgea, quando considerada a sobrevivência das plântulas com altura entre $10 \mathrm{e}$ $50 \mathrm{~cm}$ também houve efeito do dossel, da serapilheira e da sua interação, sendo selecionado o modelo completo (Tabela 2). No entanto, ao contrário de Guapira, o efeito encontrado é positivo, ou seja, abertura do dossel e a profundidade da serapilheira interagem aumentando a sobrevivência das plântulas desta espécie (Figura $2 \mathrm{c}$ e d). É interessante notar que, quando consideradas as plântulas menores (até $15 \mathrm{~cm}$ de altura e no mínimo um cotilédone), somente a abertura do dossel apresenta um efeito positivo na sobrevivência (Tabela 2, Figura 3). 
Tabela 2. Resultado da seleção de modelos para o desempenho de plântulas de Guapira e Rudgea em função da porcentagem de abertura do dossel (=dossel) e da profundidade da serapilheira (=serap), em fragmentos florestais no Planalto Atlântico Paulista, baseada no método da simplificação. O valor de $p$ apresentado corresponde ao teste de significância para a comparação entre o modelo resultante da simplificação com o modelo nulo (somente fator randômico). Os dois pontos (:) representam a interação entre as variáveis.

\begin{tabular}{|c|c|c|c|c|}
\hline \multirow[b]{2}{*}{ Variável resposta } & \multicolumn{2}{|l|}{ Guapira } & \multicolumn{2}{|l|}{ Rudgea } \\
\hline & Modelo selecionado (termos) & $p$ & Modelo selecionado (termos) & $p$ \\
\hline sobrevivência & & & & \\
\hline $10-50 \mathrm{~cm}$ alt. & nulo & 0,11 & $\begin{array}{l}\text { completo: } \\
\quad \text { (dossel+serap + dossel:serap) }\end{array}$ & 0,0477 \\
\hline $10-50 \mathrm{~cm}$ alt. (sem cotil.) & $\begin{array}{l}\text { completo: } \\
\quad(\text { dossel+serap + dossel:serap })\end{array}$ & 0,006 & - & - \\
\hline$\leq 15 \mathrm{~cm}$ alt. (mín. 1 cotil.) & nulo & 0,41 & dossel & 0,0406 \\
\hline $\begin{array}{l}\mathrm{TCR}_{\text {folhas }} \\
10-50 \mathrm{~cm} \text { alt. } \\
\leq 15 \mathrm{~cm} \text { alt. (mín. } 1 \text { cotil.) }\end{array}$ & $\begin{array}{l}\text { nulo } \\
\text { nulo }\end{array}$ & $\begin{array}{l}0,36 \\
0,15\end{array}$ & $\begin{array}{l}\text { dossel } \\
\text { nulo }\end{array}$ & $\begin{array}{l}0,005 \\
0,57\end{array}$ \\
\hline $\begin{array}{l}\mathrm{TCR}_{\text {altura }} \\
10-50 \mathrm{~cm} \text { alt. }\end{array}$ & nulo & 0,41 & dossel & $<0,0001$ \\
\hline
\end{tabular}

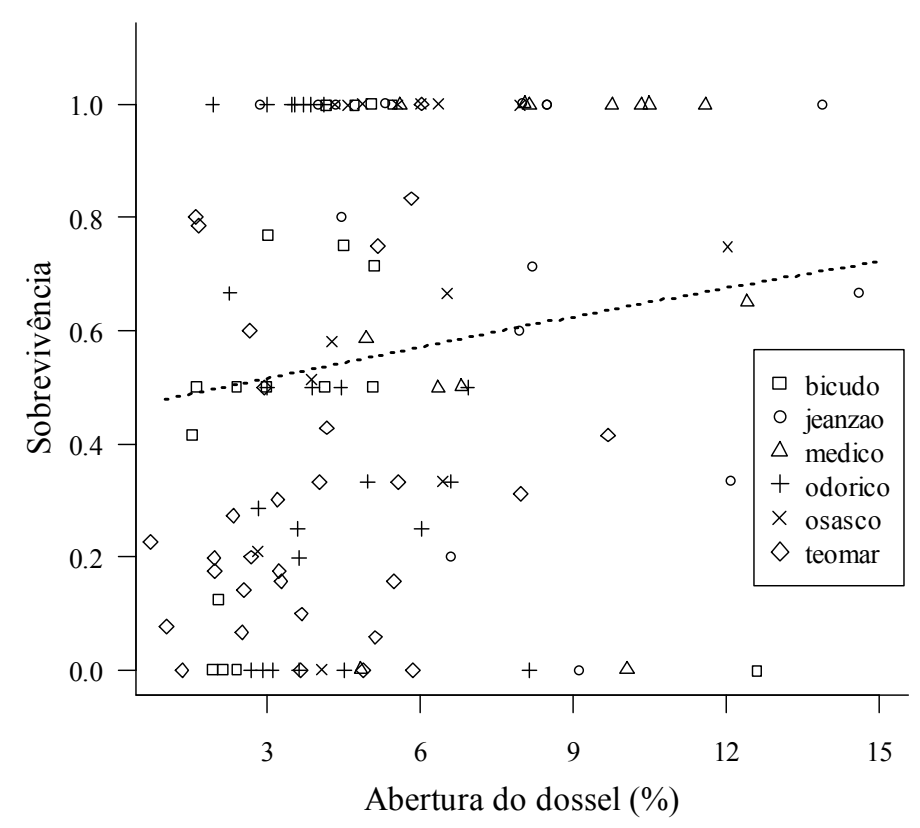

Figura 3. Sobrevivência registrada para as plântulas de Rudgea com até $15 \mathrm{~cm}$ de altura e no mínimo um cotilédone em função da porcentagem de abertura do dossel nos fragmentos florestais estudados no Planalto Atlântico Paulista. A linha pontilhada representa a sobrevivência prevista pelo modelo selecionado, o qual contém apenas a variável dossel (Tabela 2). Os símbolos na porção superior do gráfico (sobrevivência $=1$ ) foram agitados com o auxílio da função “jitter”, para diminuir a sobreposição e assim melhorar sua visualização.

\section{Taxas de crescimento}

Para as plântulas de Guapira com altura entre 10 e $50 \mathrm{~cm}$, as taxas de crescimento em altura e em número de folhas tiveram padrões similares, de modo que ambas podem ser consideradas baixas e o crescimento negativo foi tão ou mais frequente do que o crescimento positivo (Tabela 1). Quando comparadas com as plântulas de até $15 \mathrm{~cm}$ de altura com no mínimo 
um cotilédone, para as quais foi calculada somente a taxa de crescimento em número de folhas, as diferenças são marcantes, pois nestas a taxa de crescimento positivo e de crescimento igual a zero é muito maior, enquanto a frequência de crescimento negativo diminui em comparação às plântulas maiores (Tabela 1). No entanto, independentemente do tamanho da plântula, para nenhuma das taxas de crescimento (altura ou número de folhas) foi encontrado efeito da serapilheira e/ou dossel, de modo que o modelo nulo (somente com o efeito randômico) foi considerado o mais plausível (Tabela 2).

As taxas de crescimento das plântulas de Rudgea apresentaram os mesmos padrões gerais já descritos para Guapira. Dessa forma, as plântulas maiores (com altura entre 10 e $50 \mathrm{~cm}$ ) tiveram menores taxas de crescimento e maior incidência de crescimento negativo em comparação às menores (até $15 \mathrm{~cm}$ de altura e com pelo menos um cotilédone) (Tabela 1). A porcentagem de plântulas menores com crescimento positivo, no entanto, foi muito superior à encontrada para Guapira, devendo-se considerar, porém, que as plântulas de Rudgea foram acompanhadas por quase o dobro do tempo, o que pode ter influenciado este resultado (Tabela 1). O crescimento negativo parece, de fato, pouco frequente na fase em que as plântulas ainda possuem cotilédones, pois foi muito baixo para ambas as espécies (Tabela 1). Para as plântulas maiores (com altura entre 10 e $50 \mathrm{~cm}$ ), os resultados da seleção de modelos para ambas as taxas de crescimento evidenciaram um efeito positivo da abertura do dossel (Tabela 2), embora a magnitude desse efeito tenha sido bem menor do que a detectada para a sobrevivência, de modo que os gráficos serão omitidos.

\section{Discussão}

Neste trabalho, demonstramos que plântulas de espécies arbóreas tolerantes à sombra apresentam desempenho diferencial em resposta às variações em microescala da abertura de dossel e da profundidade da serapilheira no sub-bosque de florestas secundárias. Além disso, demonstramos que a relevância dos fatores que afetam o desempenho das plântulas muda ao longo da sua ontogenia, de modo que características como o tamanho e presença de cotilédones são extremamente importantes de serem consideradas. Nossos resultados foram surpreendentes quanto à resposta das espécies à luz, pois a espécie umbrófila (sub-bosque) apresentou melhor desempenho sob maior abertura do dossel, enquanto a espécie com tolerância intermediária à sombra (dossel) apresentou pior desempenho nestas condições. No entanto, a interação da abertura do dossel com a profundidade da camada de serapilheira teve um papel chave no desempenho das plântulas de ambas as espécies, confirmando nossas expectativas. 
A importância da interação entre a abertura do dossel e a profundidade da serapilheira para o desempenho diferencial de plântulas já foi demonstrada experimentalmente, sendo fortemente dependente da espécie considerada (Molofsky \& Augspurger 1992, Seiwa \& Kikuzawa 1996). Nossos resultados apontam para a mesma direção, indicando que a característica de tolerância à sombra simplesmente não é suficiente para predizer a resposta de determinada espécie a essa interação, assim como demonstrado por Molofsky \& Augspurger (1992).

Uma resposta positiva no desempenho de plântulas à disponibilidade de luz já foi relatada por diversos autores como independente do grau de tolerância à sombra da espécie (Kitajima 1994, Poorter 1999, Montgomery \& Chazdon 2002), o que explicaria o resultado obtido para a espécie de sub-bosque. Quando consideradas as plântulas maiores (altura entre 10 e $50 \mathrm{~cm}$ ), o fato da interação da abertura do dossel com a serapilheira ser relevante e a relação ser também positiva, nos leva a supor que uma serapilheira mais profunda compensaria possíveis efeitos negativos do excesso de luz, notadamente a perda de umidade. Da mesma forma, Molofsky \& Augspurger (1992) encontraram que, sob condições de luz plena, a espécie tolerante à sombra Gustavia superba tinha melhor desempenho, neste caso estabelecimento, na presença de serapilheira. Na sombra, porém, a serapilheira não apresentava efeito no desempenho da espécie, o que levou os autores a sugerir a mesma explicação de retenção da umidade pela serapilheira (Molofsky \& Augspurger 1992). Seiwa \& Kikuzawa (1996), que encontraram resultados semelhantes, também sugerem que o melhor desempenho seja principalmente devido à proteção contra a dessecação, mas apontam que o aumento nos nutrientes minerais resultantes da decomposição da serapilheira pode contribuir para o seu efeito positivo. A nossa constatação de que, para as plântulas menores e com pelo menos um cotilédone, haja apenas o efeito positivo da abertura do dossel, também é compatível com esta explicação, à medida que a baixa estatura destas plântulas faria com que elas estivessem sujeitas proporcionalmente a uma menor variação na camada de serapilheira e, portanto a menores variações de umidade. A dessecação sendo menos importante nessa fase faria com que apenas a abertura do dossel fosse relevante, tendo um efeito positivo na sobrevivência e nas taxas de crescimento destas plântulas. É importante destacar, no entanto, que esta explicação é especulativa e tem como premissa que, para esta espécie, a serapilheira de fato atua apenas positivamente na retenção da umidade.

Para as plântulas da espécie com tolerância intermediária à sombra (subdossel/dossel), também houve efeito da interação entre a abertura do dossel e a profundidade da serapilheira, para as plântulas de mesmo tamanho que para a espécie de sub-bosque (altura entre 10 e $50 \mathrm{~cm}$ ). No entanto, surpreende o fato do resultado ter sido exatamente o oposto do obtido para a outra 
espécie, uma vez que, sendo de tolerância intermediária à sombra, esperávamos que esta espécie respondesse positivamente à abertura do dossel. O desempenho da espécie, no entanto, é afetado negativamente por ambos os fatores. Novamente, o elemento crucial para a interpretação de tal resultado é a interação com a profundidade da serapilheira, a qual supomos que seja tão prejudical à espécie a ponto de suplantar qualquer efeito positivo que o dossel poderia ter. Nesse sentido, nos parece mais plausível que a serapilheira aumente a incidência de danos por herbívoros e patógenos, uma vez que seu efeito foi sentido na sobrevivência e não nas taxas de crescimento. Essa hipótese já foi comprovada experimentalmente para algumas espécies arbóreas tropicais, de modo que em experimentos com tratamentos de adição de serapilheira foi observado um aumento na herbivoria em comparação aos tratamentos de remoção (BenitezMalvido \& Kossmann-Ferraz 1999, Garcia-Guzman \& Benitez-Malvido 2003), assim como a incidência de patógenos teve uma relação positiva com a profundidade da camada de serapilheira (Benitez-Malvido \& Kossmann-Ferraz 1999). Além disso, Facelli (1999) mostraram que a incidência de fungos patogênicos estava condicionada à presença da serapilheira e à retenção de umidade por ela provocada, o que por sua vez, teve um efeito na mortalidade das plântulas da espécie arbórea estudada.

Com relação às taxas de crescimento, o efeito ter sido fraco ou inexistente não surpreende, uma vez que, para plântulas de espécies arbóreas, a sobrevivência e a taxa de crescimento são consideradas demandas conflitantes, ou seja, o investimento em sobrevivência acaba compromentendo o investimento em crescimento e vice-versa (Kitajima 1994, Baraloto et al. 2005, Seiwa 2007). Kitajima (1994) encontrou uma correlação negativa entre a taxa de crescimento relativo e a sobrevivência de plântulas à sombra, relacionadas provavelmente a uma maior alocação dos recursos para as raízes e para defesas contra herbívoros. De fato, é importante ressaltar que as condições de extremo sombreamento às quais a maioria das plântulas está submetida no sub-bosque denso das florestas é um ambiente estressante (Facelli 2008). Em função destas condições de estresse, as taxas de crescimento são lentas e comumente negativas (Kitajima 1994), conforme encontramos.

Embora não tenhamos elementos suficientes para comprovar os mecanismos pelos quais a interação entre a abertura do dossel e profundidade da serapilheira afeta diferencialmente o desempenho das espécies estudadas, demonstramos a importância da interação destes dois fatores para definir como o desempenho de plântulas de espécies arbóreas é afetado pela heterogeneidade das condições abióticas em microescala em florestas secundárias. Consideramos esta uma questão crucial, pois indica que o conhecimento somente acerca do papel de cada fator individualmente pode levar à criação de falsas predições (Xiong et al. 2003). Experimentos são 
necessários para se elucidar de fato esses processos, de modo que estudos observacionais como este têm o papel de fornecer indícios da magnitude real das variações encontradas em campo, além de gerar predições a serem testadas. Do nosso ponto de vista, estes resultados são inéditos e trazem grandes implicações para os estudos com plântulas de espécies tropicais, uma vez que a maioria dos estudos define "plântulas" como todos os indivíduos menores do que determinada altura, ignorando, dessa forma, as diferenças marcantes que podem existir na ecofisiologia desses indivíduos, como encontrado no presente estudo. Além disso, é necessária cautela relação à premissa assumida em muitos estudos de que ao longo da ontogenia as necessidades de luz das espécies arbóreas são as mesmas da fase adulta, na qual baseamos as nossas expectativas em função da falta de informações específicas sobre a fase de plântula, uma vez que outros autores também registraram mudanças marcantes nos requerimentos abióticos conforme a fase do ciclo de vida das espécies arbóreas (Clark \& Clark 1992, Baraloto et al. 2005).

Nossos resultados também deixam clara a importância de se considerar a variação natural em microescala como uma alternativa aos contrastes com serapilheira versus sem serapilheira, ou clareira versus não-clareira, empregados em experimentos em campo (Seiwa \& Kikuzawa 1996, Makana \& Thomas 2005, Seiwa 2007), ou mesmo às condições experimentais controladas em casas de vegetação (revisão em Sayer 2006). Seiwa (2007) destaca que, provavelmente, boa parte das discrepâncias encontradas na literatura com relação às respostas à luz de plantas tolerantes à sombra advem das elevadas intensidades de luz utilizadas nas estufas ou casas de vegetação, em comparação aos níveis encontrados nos habitats naturais das espécies. Da mesma forma, em uma meta-análise sobre os efeitos da serapilheira sobre a vegetação, em média, a vegetação foi mais afetada pela serapilheira nos estudos realizados em campo do que nos realizados em estufa ou casa de vegetação (Xiong \& Nilsson 1999).

Num contexto mais amplo, corroboramos a hipótese da existência de nichos de regeneração para as espécies arbóreas tropicais proposta por Grubb (1977), cujo papel na coexistência de espécies e na estruturação das comunidades tem sido foco de um debate intenso (Chave 2004, Silvertown 2004, entre outros) e que, cada vez mais, parece dizer respeito à escala de observação. Nesse sentido, uma reconciliação entre duas explicações não necessariamente excludentes para a estruturação de comunidades está em curso, de modo que os mecanismos previstos pela teoria de nicho atuariam em uma escala local, enquanto os processos neutros seriam mais relevantes numa escala regional (Adler et al. 2006). De fato, as variações em menor escala na abertura do dossel e na profundidade da camada de serapilheira são importantes fontes de heterogeneidade no sub-bosque das florestas tropicais tendo um efeito no recrutamento das 
plântulas, como demonstrado também por diversos autores (Molofsky \& Augspurger 1992, Seiwa \& Kikuzawa 1996, Norden et al. 2007, entre outros).

\section{Referências bibliográficas}

Adler, P.B., HilleRisLambers, J., Levine, J.M. 2007. A niche for neutrality. Ecology Letters 10: 95-104.

Baraloto, C., Goldberg, D.E., Bonal, D. 2005. Performance trade-offs among tropical tree seedlings in contrasting microhabitats. Ecology 86: 2461-2472.

Bates, D. \& Maechler, M. 2009. Ime4: Linear mixed-effects models using S4 classes. R package version 0.999375-32. URL: http://CRAN.R-project.org/package=lme4

Benitez-Malvido, J. \& Kossmann-Ferraz, I.D. 1999. Litter cover variability affects seedling performance and herbivory. Biotropica 31: 598-606.

Benitez-Malvido, J., Martinez-Ramos, M.M., Camargo, J.L.C., Kossmann-Ferraz, I.D. 2005. Responses of seedling transplants to environmental variations in contrasting habitats of Central Amazonia. Journal of Tropical Ecology 21:397-406.

Bolker, B.M., Brooks, M.E., Clark, C.J., Geange, S.W., Poulsen, J.R., Stevens, M.H.H., White, J.-S.S. 2009. Generalized linear mixed models: a practical guide for ecology and evolution. Trends in Ecology \& Evolution 24: 127-135.

Brearley, F.Q., Press, M.C., Scholes, J.D. 2003. Nutrients obtained from leaf litter can improve the growth of dipterocarp seedlings. New Phytologist 160:101-110.

Catharino, E.L.M., Bernacci, L.C., Franco, G.A.D.C., Durigan, G., Metzger, J.P. 2006. Aspectos da composição e diversidade do componente arbóreo das florestas da Reserva Florestal do Morro Grande, Cotia, SP. Biota Neotropica 6: 28p. URL: http://www.biotaneotropica.org.br/v6n2/pt/abstract?article+bn00306022006

Chave, J. 2004. Neutral theory and community ecology. Ecology Letters 7: 241-253.

Cintra, R. 1997. Leaf litter effects on seed and seedling predation of the palm Astrocaryum murumuru and the legume tree Dipteryx micrantha in amazonian forest. Journal of Tropical Ecology 13: 709-725.

Cintra, R. \& Terborgh, J. 2000. Forest microspatial heterogeneity and seed and seedling survival of the palm Astrocaryum murumuru and the legume Dipteryx micrantha in an amazonian forest. Ecotropica 6: 77-88.

Clark, D.A. \& Clark, D.B. 1992. Life history diversity of a canopy and emergent trees in a neotropical rain forest. Ecological Monographs 62: 315-344. 
Clark, C.J., Poulsen, J.R., Levey, D.J., Osenberg, C.W. 2007. Are plant populations seed limited? A critique and meta-analysis of seed addition experiments. American Naturalist 170: 128-142.

Condit, R., Hubbell, S.P., Foster, R.B. 1996. Assessing the response of plant functional types to climatic change in tropical forests. Journal of Vegetation Science 7: 405-416.

Connell, J.H. 1978. Diversity in tropical rain forests and coral reefs - high diversity of trees and corals is maintained only in a non-equilibrium state. Science 199: 1302-1310.

Crawley, M.J. 2007. The R Book. Chichester: Wiley.

Denslow, J.S. 1987. Tropical rainforest gaps and tree species diversity. Annual Review of Ecology and Systematics 18: 431-451.

Facelli, J.M. 1999. Establishment and growth of seedlings of Eucalyptus obliqua: interactive effects of litter, water, and pathogens. Australian Journal of Ecology 24: 484-494.

Facelli, J.M. 2008. Specialized strategies I: seedlings in stressful environments. In: Leck et al. (eds). Seedling ecology and evolution. Cambridge: Cambridge University Press, p. 56-78.

Facelli, J.M., Pickett, S.T.A. 1991. Plant litter - its dynamics and effects on plant community structure. Botanical Review 57: 1-32.

Fine, P.V.A., Mesones, I., Coley, P.D. 2004. Herbivores promote habitat specialization by trees in Amazonian forests. Science 305: 663-664.

Frazer, G.W., Canham, C.D., Lertzman, K.P. 1999. Gap Light Analyzer (GLA): Imaging software to extract canopy structure and gap light transmission indices from true-colour fisheye photographs, users manual and program documentation. New York: Simon Fraser University, Burnaby, British Columbia, and the Institute of Ecosystem Studies, Millbrook, New York.

Gandolfi, S. 2000. História natural de uma floresta estacional semidecidual no município de Campinas (São Paulo, Brasil). Tese (Doutorado em Biologia Vegetal). Universidade Estadual de Campinas, Campinas.

Garcia-Guzman, G. \& Benitez-Malvido, J. 2003. Effect of litter on the incidence of leaf-fungal pathogens and herbivory in seedlings of the tropical tree Nectandra ambigens. Journal of Tropical Ecology 19:171-177.

Gillmann, L.N., Ogden, J., Wright, S.D., Stewart, K.L., Walsh, D.P. 2004. The influence of macro-literfall and forest structure on litterfall damage to seedlings. Austral Ecology 29: 305312.

Grubb, P.J. 1977. The maintenance of species-richness in plant communities: the importance of the regeneration niche. Biological Reviews 52:107-145. 
Janzen, D.H. 1970. Herbivores and the number of tree species in tropical forest. The American Naturalist 104:501-528.

Kitajima, K. 1992. Relationship between photosynthesis and thickness of cotyledons for tropical tree species. Functional Ecology 6: 582-589.

Kitajima, K. 1994. Relative importance of photosynthetic traits and allocation patterns as correlates of seedling shade tolerance of 13 tropical trees. Oecologia 98: 419-428.

Kitajima, K. 2002. Do shade-tolerant tropical tree seedlings depend longer on seed reserves? Functional growth analysis of three Bignoniaceae species. Functional Ecology 16: 433-444.

Kobe, R.K. 1999. Light gradient partitioning among tropical tree species through differential seedling mortality and growth. Ecology 80: 187-201.

Lewis, S.L. \& Tanner, E.V.J. 2000. Effects of above and belowground competition on growth and survival of rain forest tree seedlings. Ecology 81: 2525-2538.

Lorenzi H. 1998. Árvores brasileiras: manual de identificação e cultivo de plantas arbóreas nativas do Brasil. Volume 2. Nova Odessa: Editora Plantarum.

Makana, J.R. \& Thomas, S.C. 2005. Effects of light gaps and litter removal on the seedling performance of six African timber species. Biotropica 37: 227-237.

Metcalfe, D.J. \& Turner, I.M. 1998. Soil seed bank from lowland rain forest in Singapore: canopy-gap and litter-gap demanders. Journal of Tropical Ecology 14: 103-108.

Molofsky, J. \& Augspurger, C.K. 1992. The effect of leaf litter on early seedling establishment in a tropical forest. Ecology 73: 68-77.

Montgomery, R.A. \& Chazdon, R.L. 2002. Light gradient partitioning by tropical tree seedlings in the absence of canopy gaps. Oecologia 131: 165-174.

Nicotra, A.B., Chazdon, R.L., Iriarte, S.V.B. 1999. Spatial heterogeneity of light and woody seedling regeneration in tropical wet forests. Ecology 80: 1908-1926.

Norden, N., Chave, J., Caubere, A., Chatelet, P., Ferroni, N., Forget, P.M., Thebaud, C. 2007. Is temporal variation of seedling communities determined by environment or by seed arrival? A test in a neotropical forest. Journal of Ecology 95: 507-516.

Oliveira-Filho, A.T., Jarenkow, J.A., Rodal, M.J.N. 2006. Floristic relationships of Seasonally Dry Forests of Eastern South America based on tree species distribution patterns. In: Pennington, R.T., Lewis, G.P., Ratter, J.A., (eds). Neotropical savannas and dry forests: plant diversity, biogeography and conservation. Boca Raton: CRC Press, p. 159-192.

Pinheiro, J.C., Bates, D.M., DebRoy, S., Sarkar, D., R Development Core Team. 2009. nmle: linear and nonlinear mixed effects models. R package version 3.1-96. URL: http://CRAN.Rproject.org/package $=$ nmle 
Poorter, L. 1999. Growth responses of 15 rain-forest tree species to a light gradient: the relative importance of morphological and physiological traits. Functional Ecology 13: 396-410.

R Development Core Team. 2009. R: A language and environment for statistical computing. $\mathrm{R}$ Foundation for Statistical Computing, Vienna, Austria.

Reitz, R. 1970. Nictagináceas. In: Reitz, R. (ed). Flora Ilustrada Catarinense. Itajaí: Herbário Barbosa Rodrigues.

Ricklefs, R.E. 1977. Environmental heterogeneity and plant species diversity: a hypothesis. The American Naturalist 111:376-381.

SABESP. 1997. Programa de conservação do Sistema Cotia. Relatório Conclusivo (tomo 3): Avaliação Ambiental. São Paulo: SABESP/Fundação Brasileira para o Desenvolvimento Sustentável.

Sayer, E.J. 2006. Using experimental manipulation to assess the roles of leaf litter in the functioning of forest ecosystems. Biological Reviews 81: 1-31.

Scariot, A. 2000. Seedling mortality by litterfall in amazonian forest fragments. Biotropica 32: 662-669.

Scudeller, V.V., Martins, F.R., Shepherd, G.J. 2001. Distribution and abundance of arboreal species in the atlantic ombrophilous dense forest in Southeastern Brazil. Plant Ecology 152: 185-199.

Seiwa, K. 2007. Trade-offs between seedling growth and survival in deciduous broadleaved trees in a temperate forest. Annals of Botany 99: 537-544.

Seiwa, K. \& Kikuzawa, K. 1996. Importance of seed size for the establishment of seedlings of five deciduous broad-leaved tree species. Vegetatio 123: 51-64.

Silvertown, J. 2004. Plant coexistence and the niche. Trends in Ecology \& Evolution 19: 605611.

Sork, V.L. 1983. Distribution of pignut hickory (Carya glabra) along a forest to edge transect, and factors affecting seedling recruitment. Bulletin of the Torrey Botanical Club 110:494506.

Souza, V.C., Lorenzi, H. 2005. Botânica sistemática: guia ilustrado para identificação das famílias de Angiospermas da flora brasileira, baseada em APG II. Nova Odessa: Plantarum.

Vazquez-Yanes, C., Orozcosegovia, A., Rincon, E., Sanchez-Coronado, M.E., Huante, P., Toledo, J.R., Barradas, V.L. 1990. Light beneath the litter in a tropical forest - effect on seedgermination. Ecology 71: 1952-1958.

Veloso, H.P., Rangel-Filho, A.L.R., Lima, J.C.A. 1991. Classificação da vegetação brasileira adaptada a um sistema universal. Rio de Janeiro: IBGE. 
Xiong, S., Johansson M.E., Hughes, F.M.R., Hayes, A., Richards, K.S., Nilsson, C. 2003. Interactive effects of soil moisture, vegetation canopy, plant litter and seed addition on plant diversity in a wetland community. Journal of Ecology 91: 976-986.

Xiong, S. \& Nilsson, C. 1999. The effects of plant litter on vegetation: a meta-analysis. Journal of Ecology 87: 984-994.

Zappi, D. 2003. Revision of Rudgea (Rubiaceae) in Southeastern and Southern Brazil. Kew Bulletin 58: 513-596. 


\section{Conclusões gerais}

Neste trabalho, demonstramos como diferentes níveis de abordagem são necessários para se entender a complexa demografia das espécies arbóreas tropicais. Para uma mesma espécie, conforme o aspecto populacional abordado (densidade, estrutura ou taxa assintótica de crescimento), a presença ou a direção do efeito detectado pode mudar, como encontramos para as duas espécies tolerantes à sombra estudadas. Quando consideradas as variações em microescala de fatores reconhecidamente importantes, como a abertura do dossel e a profundidade da serapilheira, diferentes fases ontogenéticas das plântulas podem apresentar respostas contrastantes. Aliada à complexidade da própria demografia das espécies arbóreas, nos deparamos com uma realidade bastante desafiadora em termos da heterogeneidade ambiental dos fragmentos florestais, o que resultou em uma abordagem inovadora.

Para a espécie de sub-bosque, Rudgea jasminoides, o fragmento grande em estádio sucessional tardio destacou-se em densidade em relação aos demais, enquanto que as variações na estrutura populacional foram melhor explicadas pelo tamanho do fragmento. Assim, fragmentos médios apresentaram uma estrutura populacional que desvia da esperada, para espécies tolerantes à sombra em equilíbrio demográfico, o que, somado à diminuição da densidade nestes mesmos fragmentos, nos leva a especular sobre a iminência de extinção local da espécie nestes fragmentos de tamanho médio. Nesse sentido, se as populações estão de fato em declínio nos fragmentos médios, seria de se esperar uma menor taxa assintótica de crescimento populacional, quando analisada a demografia dessa espécie em outro nível, em termos da sua dinâmica. No entanto, encontramos um padrão contrário ao esperado, de modo que as taxas assintóticas de crescimento populacional foram maiores nos fragmentos médios em relação aos grandes, o que pode ser encarado com otimismo em termos da persistência da espécie nestes fragmentos, pois pode impedir ou mesmo retardar a extinção local prevista a partir da análise dos padrões de densidade e estrutura. Problemas na fertilidade e no recrutamento de plântulas, normalmente apontados como um dos efeitos negativos da fragmentação, não são as causas das menores densidades populacionais nos fragmentos médios, os quais apresentaram maior fertilidade do que os grandes. Se os fragmentos médios estão proporcionalmente mais sujeitos aos efeitos de borda do que os grandes, uma das consequências dessas alterações estruturais seria o aumento na abertura do dossel, a qual tem um efeito positivo, quando interage com a profundidade da serapilheira, no desempenho de plântulas desta espécie. Todas estas constatações indicam que não há problemas de regeneração da espécie nos fragmentos médios 
em relação aos grandes. Assim, nossos resultados indicam que, embora tenhamos hipotetizado um risco risco de extinção local para a espécie Rudgea jasminoides nos fragmentos de tamanho médio, os resultados da dinâmica populacional mostram um crescimento potencial da população que pode evitar que isso ocorra, havendo necessidade de se monitorar estas populações em longo prazo para confirmar essa conclusão.

Para a espécie de dossel, Guapira opposita, fragmentos grandes apresentaram maior densidade do que os médios quando consideradas as plantas com DAP, enquanto que para as plantas com DAS o destaque em densidade foi para o fragmento grande em estádio tardio. Em termos de estrutura populacional, no entanto, o tamanho do fragmento sequer representou uma melhora na explicação da variação encontrada nos dados, de modo que o modelo considerando o estádio sucessional do fragmento, analisado de forma contínua, foi selecionado. Assim, a estrutura das populações apresentou uma resposta gradual ao estádio sucessional dos fragmentos, sendo mais próxima da esperada para uma espécie tolerante à sombra nos fragmentos mais tardios. Dessa forma, esperávamos que a taxa assintótica de crescimento populacional fosse maior nos fragmentos de floresta secundária tardia do que nos fragmentos de floresta inicial, o que não ocorreu. Diferentemente de Rudgea, que apresentou um padrão inverso ao esperado, para Guapira não foram encontradas diferenças na taxa assintótica de crescimento populacional ou mesmo nos padrões de elasticidade, embora tenha havido diferenças em algumas taxas vitais. Com relação às plântulas, somente os indivíduos maiores e sem cotilédones foram afetados negativamente pela interação entre a abertura do dossel e a profundidade da serapilheira. A partir do exposto, concluímos que Guapira opposita demonstra uma plasticidade demográfica em florestas secundárias em distintos estádios sucessionais, estando bem adaptada a paisagens fragmentadas, uma vez que outrora ocupava o sub-bosque de florestas primárias e passa a ser uma das principais constituintes do dossel em florestas secundárias em estádio mais avançado.

Para ambas as espécies, o conhecimento gerado neste trabalho deve ser encarado como um ponto de partida para se desvendar os aspectos mais relevantes da sua ecologia populacional. A partir das conclusões relatadas, os indícios para investigações futuras apontam para a necessidade de um monitoramento em longo prazo destas populações, cuja elevada longevidade é um dos principais desafios impostos aos estudos de dinâmica. Mais especificamente, todos os trabalhos com espécies arbóreas tolerantes à sombra destacam a importância da sobrevivência e do crescimento dos adultos para a taxa assintótica de crescimento populacional. Salientamos ainda a importância de empregarmos enfoques complementares, como as avaliações da densidade e da estrutura e os estudos de dinâmica, para que se possa de fato entender o que ocorre em nível populacional. Além disso, deixamos clara a importância dos estudos de 
dinâmica para se elucidar os mecanismos demográficos atuantes em cada população, independentemente de haver diferenças nas taxas de crescimento entre as populações. Esse conhecimento é uma ferramenta fundamental para o planejamento de ações mais direcionadas de manejo e conservação, para as quais os resultados das análises de modelos matriciais são considerados extremamente poderosos. 